Copyright

by

James Ian Tennant

2013 
The Dissertation Committee for James Ian Tennant Certifies that this is the approved version of the following dissertation:

\section{Free Newspapers in the United States:}

\section{Alive and Kicking}

\section{Committee:}

$$
\text { Iris Chyi, Supervisor }
$$

Rosental Alves

Isabella Cunningham

Tom Johnson

Paula Poindexter 


\section{Free Newspapers in the United States:}

Alive and Kicking

by

James Ian Tennant, B.A., M.A.

\section{Dissertation}

Presented to the Faculty of the Graduate School of

The University of Texas at Austin

in Partial Fulfillment

of the Requirements

for the Degree of

Doctor of Philosophy

The University of Texas at Austin

December 2013 


\section{Dedication}

To my parents, Pat and Jack, and my big brother Alan for your unwavering support.

To Dr. Allan W. Hook: my mentor, colleague and fellow hockey fan, a giant of a man who is deeply missed.

To my committee at the University of Texas at Austin: Dr. Iris Chyi, Prof. Rosental Alves, Dr. Isabella Cunningham, Dr. Tom Johnson and Dr. Paula Poindexter. Thank you for your patience and wisdom. 


\title{
Free Newspapers in the United States: Alive and Kicking
}

\author{
James Ian Tennant, Ph.D. \\ The University of Texas at Austin, 2013
}

\section{Supervisor: Iris Chyi}

Free newspapers are a substantial segment of the newspaper industry, as well as an under-studied topic within media research. This dissertation considers the economic health of free newspapers and whether they face a dire future given their heavy reliance on advertising, a source of revenue that has been in decline for newspapers. Some industry observers suggest it is supreme folly for newspapers to give away their content for free, and that advertising is no longer a reliable revenue source for print media in the Internet era. One question guiding this research is whether free newspapers face two options: continue producing free content by relying on advertising (in addition to other revenue sources), or abandon the advertising-based business model. Seven research questions address a number of issues, such as whether free newspapers are profitable, if decision-makers are considering changing their business model, whether they are seeking alternative sources of revenue, whether reader engagement is connected to the price, or a lack of one, of a newspaper, and whether decision-makers are optimistic or pessimistic about the future of their industry. A Web-based survey asked decision-makers at free newspapers in the United States to respond to questions related to the health and future of 
their newspaper or newspapers. Four in-depth interviews with publishers of four different types of free newspapers in Texas were also conducted to complement results generated by the Web-based survey. Results show decision-makers at free newspapers are confident about the future of their particular kind of media. The dissertation concludes by suggesting free newspapers are not only viable but in many markets they are thriving. Sweeping generalizations (often seen in industry discourse) about the future of print newspapers can be misleading. The key for success is engaging readers with content and that means a focus on local issues and events. This study contributes a reality check and calls for further research on the economics of print media in the digital era. 


\section{Table of Contents}

$\begin{array}{ll}\text { LIST OF TABLES } & \mathrm{X}\end{array}$

$\begin{array}{ll}\text { CHAPTER 1: INTRODUCTION } & 1\end{array}$

Chapter 2: Literature Review 5

2.1 Definitions of Free Newspapers .........................................................5

2.2 Why Study Free Newspapers? ...................................................... 10

2.3 History of Free Newspapers ........................................................ 15

2.4 Theoretical Framework: Media Economics ......................................21

2.4.a Business Model ................................................................. 21

2.4.b Advertising ....................................................................23

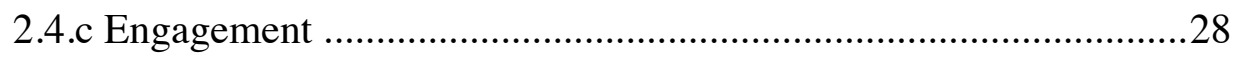

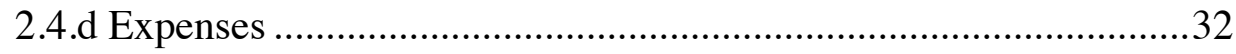

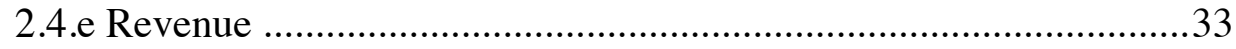

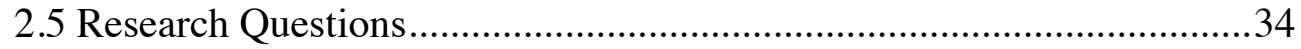

CHAPTER 3: METHODS 36

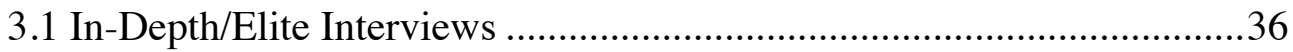

3.1 .a The Austin Chronicle ..............................................................40

3.1.b The Villager ......................................................................42

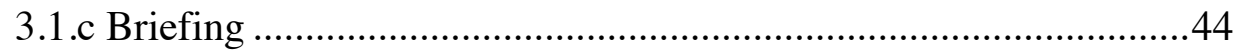

3.1 d The Leader .........................................................................45

3.2 Web-Based Survey …................................................................ 47

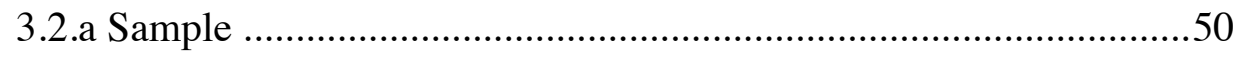

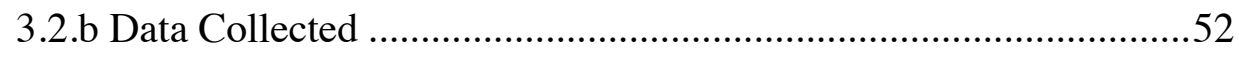

Chapter 4: Results

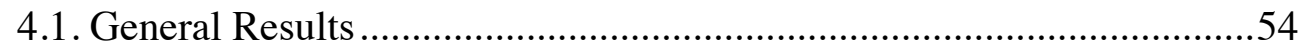


4.1.a General Overview

4.2 Research Question 1: Financial Well-being of Free Newspapers ...........58

4.2.a Research Question 1: Web-based Survey Results ..........................58

4.2.b Research Question 1: Elite Interview Results ................................60

4.2.c Research Question 1: Overview ....................................................64

4.3 Research Question 2: Revamp the Business Model? ..............................65

4.3.a Research Question 2: Web-based Survey Results ..........................65

4.3.b Research Question 2: Web-based Survey Respondents' Text

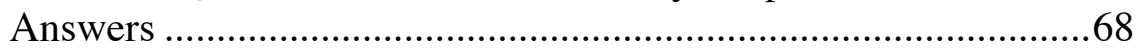

4.3.c Research Question 2: Elite Interview Results..................................71

4.3.d Research Question 2: Overview ....................................................79

4.4 Research Questions 3 and 4: Whither Online Advertising? ....................80

4.4.a Research Question 3: Web-based Survey Results ............................80

4.4.b Research Question 3: Elite Interview Results ................................81

4.4.c Research Question 4: Web-based Survey Results ..........................85

4.4.d Research Question 4: Elite Interview Results ................................87

4.4.e Research Questions 3 and 4: Overview ..........................................90

4.5 Research Questions 5 and 6: Reader Engagement and Free vs. Paid .....92

4.5.a Research Questions 5 and 6: Web-based Survey Results...............92

4.5.b Research Questions 5 and 6: Web-based Survey Respondents'

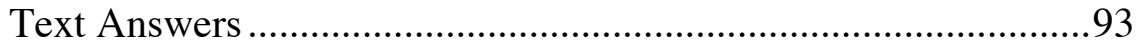

4.5.c Research Questions 5 and 6: Elite Interview Results .....................96

4.5.d Research Questions 5 and 6: Overview ..........................................102

4.6 Research Question 7: Optimistic or Pessimistic About the Future?.....103

4.6.a Research Question 7: Web-based Survey Results .........................103

4.6.b Research Question 7: Web-based Survey Respondents' Text

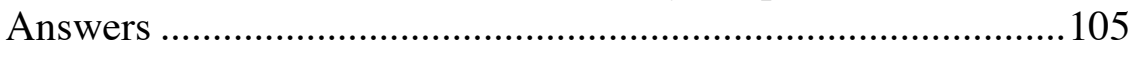

4.6.c Research Question 7: Elite Interview Results................................111 
Chapter 5: Discussion, Conclusion, Limitations, Future Research 117

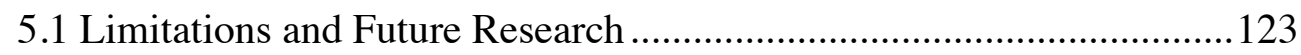

$\begin{array}{ll}\text { APPENDICES } & 126\end{array}$

Appendix 1: Email Script Invitation to Elite Interview Subjects ................126

Appendix 2: Interview Script for Richard S. Alfano, Publisher

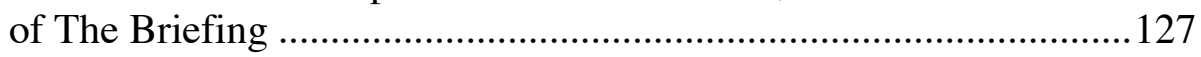

Appendix 3: Interview Script for Nick Barbaro, Publisher of the Austin Chronicle

Appendix 4: Interview Script for Jonathan McElvy, Publisher of The Leader.

Appendix 5: Interview Script for Tommy Wyatt, Publisher of The Villager.

Appendix 6: Front Page of The Austin Chronicle ........................................138

Appendix 7: Front Page of The Villager .....................................................139

Appendix 8: Front Page of Briefing ........................................................140

Appendix 9: Front Page of The Leader .......................................................141

Appendix 10: Web-Based Survey Questions ................................................142

Appendix 11: Email Script Invitation for Web-Based Survey .....................144

Appendix 12: Opening Page of Web-Based Survey ...................................145

Appendix 13: First Prompt Email Script for Web-Based Survey ...............146

Appendix 14: Second Prompt Email Script for Web-Based Survey ...........147

Appendix 15: Third Prompt Email Script for Web-Based Survey ..............148

$\begin{array}{ll}\text { REFERENCES } & 149\end{array}$ 


\section{List of Tables}

T1 Circulation of Free NeWSPAPERS In the United States 2012-2013 14

T2 INFORMATION ON INTERVIEWS WITH ELITES AT FoUR FREE NEWSPAPERS $\quad \mathbf{4 0}$

T3 Profitability of Free NeWSPAPERS in 2012

T4 Free NewsPapers' Anticipated Profitability in 2013

T5 Advertising Revenue at Free NeWSPAPERS in 2012 Compared to 201159

T6 Free NeWSPAPERS' CirCulation In 2012 Compared to 2011

T7 Alternative Sources of Revenue Pursued by Free NeWSPapers $\quad 66$

T8 ATTITUdES OF FREE NEWSPAPER DECISION-MAKERS TOWARDS IMPLEMENTING a Fee to Access Online and Print Content $\quad 67$

T9 Types of Online ANd Print Advertising in Free NeWSPAPERS in $2012 \quad 86$

T10 GEographic SoUrCES For AdVERTISING IN FrEe NEWSPAPERS IN $2012 \quad 86$

T11 DeCision-MAKERS' ATtitudes TOWARD THE Future OF THEIR FREE NEWSPAPER OR PAPER $\quad 104$

T12 DECISION-MAKERS' OPINIONS ON WHETHER FREE NEWSPAPERS' $\begin{array}{ll}\text { FUTURE IS ONLINE-ONLY } & 105\end{array}$ 


\section{Chapter 1: Introduction}

Imagine you own, manage or simply work for a business that gives away its main product. This product is a free newspaper and for decades the operation has been profitable. There have been lean years, but the newspaper never wavered from its publication schedule, whether daily, semi-weekly, weekly or monthly. Sparked by the rise of the Internet in the mid-1990s, criticism arose from industry observers, publishers and owners that newspapers should never give away their content (Buffett, 2012; Ladurantaye, 2012a, 2012b). Nevertheless, free newspapers have existed for two centuries in North America, suggesting the decision to give away content has been somewhat successful.

Free newspapers attract readers with various degrees of high- and low-brow journalism. This audience is then sold to businesses, organizations and individuals seeking to sell their wares or services, or create recognition for a cause, event or a candidate. This, of course, is the classic advertising-based business model employed by paid and free newspapers. The latter, however, may be more vulnerable financially than the former because free newspapers are more reliant on advertising revenue than paid newspapers. Anyone who has been following the plight of newspapers in North America in the twenty-first century knows advertisers are spending less on print products (Mitchell \& Rosenstiel, n.d.). How are the people running free newspapers in the United States reacting to this decline in ad revenue? Do they fear for the future of their business? This study is an attempt to answer those questions and more related to the future of free newspapers. 
Technological change has unleashed a revolutionary disruption of the news media's evolution, perhaps forever dismantling the advertising-based business model for print publications (Doctor, 2010). Advertisers have embraced the Internet and online gathering places like Google, Yahoo!, Facebook, Microsoft and AOL, the top five sellers of online advertising in 2012 (Efrati, 2012). The amount of advertising revenue that newspapers attract has been declining since 2006 (“Advertising expenditures,” 2013), prompting a race to identify new or neglected revenue sources to help keep newspapers alive, thus maintaining an important source of news and information necessary for an informed citizenry. Paid-subscription newspapers continue to wrestle with the pros and cons of installing some form of an online paywall to recoup revenue. Lost in the discussion is the free newspaper, of which there are approximately 1,627 across North America (Fleming, 2012; “About AAN,” 2013). If advertising, the dominant source of revenue for newspapers, continues its migration away from print where does that leave the owner, publisher, manager or journalist at the free newspaper? Shirky (2012) suggests magazines and newspapers that are reliant on advertising for the lion's share of their revenue have three options: shrink their operation, restructure their organization, or "harvest" revenues until the publication collapses (p. 29).

Even though it is common to expect that the end is nigh for newspapers ("Who killed the newspaper?," 2006; Ingram, 2013a), some industry observers are not convinced (Chyi, Lewis \& Zheng, 2011; Garden, 2010). Perhaps free newspapers are the proverbial canary in the coalmine? If they perish or embrace a paid status then the advertising-based business model that has lasted centuries may indeed become obsolete; if they survive, then the advertising-based business model is still relevant and those who scold news 
companies for giving away their content for free are simply wrong. Either way, this dissertation will contribute to the discussion of the viability of the advertising-based business model for free newspapers, and mark one of two possible points in the history of newspapers: the beginning of the end for free newspapers, or the beginning of free newspapers' survival in the digital age.

There is a long tradition of free newspapers in the United States (Brandsberg, 1969). This portion of the newspaper industry is often overshadowed by coverage and analyses of subscription or paid newspapers, particularly dailies located within major metropolitan areas (Bakker, 2008; Picard \& Brody, 1997, p. xiv; Brandsberg, 1969). However, the advent of the digital delivery of news and information has upended the entire newspaper industry as competition for advertising dollars has intensified immensely, creating a disruption that may be more dramatic for free newspapers because of their heavy reliance on print advertising revenue. Free newspapers may find themselves backed into a revenue dead-end while their paid cousins have a side street or two - subscriptions and/or paywalls - that may yet rescue their operations. But perhaps decision-makers who run free newspapers may not see their future in such dark terms? In order to understand the conditions these people find themselves in and the options facing free newspapers, in-depth interviews with were conducted with elite subjects (publishers of four types of free newspapers) to complement a Web-based survey of 158 free newspaper decision-makers in the United States.

This study examines the state of free newspapers (an understudied topic) from the media economics and management perspective. Of particular interest is the impact of declines in advertising revenue for newspapers in general and how the current discussion 
about the future of newspapers (or print media) fails to consider the reality of these papers.

Chapter 2 explores the definition of free papers, classifies free newspapers into several categories, and examines the history of free newspapers, a narrative that necessarily includes paid newspapers because of the dearth of material specifically focused on free publications. Chapter 2 also discusses newspapers' cost structure, the advertising business model and how they relate to free newspapers. Research questions are also presented in this chapter. Chapter 3 outlines the two research methods - indepth/elite interviews and a Web-based survey — employed for this dissertation. Results are presented in Chapter 4 followed by discussion, conclusions, limitations and future research in Chapter 5. 


\section{Chapter 2: Literature Review}

This chapter includes the following sections: a definition of free newspapers, reflections on why the free newspaper industry is a worthy topic, a history of free newspapers, and an outline of the theoretical framework - media economics - guiding this study. The chapter concludes with an introduction of seven research questions.

\subsection{Definitions of Free Newspapers}

The only major difference between a paid and free newspaper is the price of admission and, in many markets, free newspapers generally have a much wider circulation than their paid competitors. Free newspapers are publications a person can receive in the mail, have delivered to the home, pick up at a store or pull from a box on the street without having to pay a cover price or subscription fee. Free newspapers are published monthly, weekly, two or more times a week, and daily. Editor \& Publisher defines a free newspaper as one that does not charge for $95 \%$ or more of its total circulation (Fleming, 2012b). There are free publications called "shoppers" but their emphasis is on advertising with little or no resources devoted to producing public service journalism. Shoppers are not part of this study.

A wide variety of free newspapers can be found in the United States. These include daily newspapers like the geographic-specific Vail Daily in Colorado and Metro, a tabloid-sized daily that targets commuters in three major U.S. cities. More commonly, free newspapers are community or small-town newspapers, so-called alternative newspapers, pro-business publications, and papers that target specific segments of society based on ethnicity, age, cultural, and political interests. 
Free newspapers, like paid newspapers, offer content that their decision-makers believe will interest their particular audience. A multitude of topics are found in free newspapers, reflecting the multitude of styles of free newspapers in the U.S. marketplace, perhaps an array of topics not entirely reflected in paid newspapers. These topics may include a combination of hard news, soft news, local news, opinion articles, editorials, photographs, infographics, illustrations, letters to the editor, listings of upcoming events, advertising, reviews of artistic events, classifieds, obituaries, sports, and even advice on sexual matters. The quality and topical nature of journalism presented by free newspapers in the United States is as diverse as the audience that these free newspapers serve. Indeed, there is such a variety and styles of free newspapers, it could be argued that one of the few things they have in common is that they are free.

For example, the Austin, Texas market is home to three distinct kinds of free newspapers: The Villager, Community Impact and The Austin Chronicle. The Villager represents a weekly newspaper that targets a specific audience: the African-American population of Austin, Texas. Editorially, this broadsheet focuses on events and government policies that affect, directly and indirectly, Austin's African-American community. For example, a front page article from the May 24, 2013, edition is about a report that says African-Americans have suffered a significant decline in economic status (“African Americans in Texas," 2013). The Villager is part of a long tradition of newspapers that give voice to the voiceless, communities of peoples ignored, downplayed and "oppressed" by the "white power structure" (Sloan, 2008, p. 300). Publications established to serve specific groups defined by a common language or cultural heritage tended to have a "high mortality" rate as immigration to the United States ebbed and 
flowed (Sloan, 2008, p. 300). Despite difficulties establishing a strong advertising base, the African-American press has had a steady presence in the United States for more than a century, fighting injustice in many communities where individuals were unable to affect change on their own (Sloan, 2008).

Community Impact is an example of a free monthly newspaper that targets specific socio-economic areas of Austin: the paper is not distributed east of Interstate-35, traditionally considered the dividing line between the more affluent areas to the west and the African-American and Latino neighborhoods east of that major north-south highway (Herrick, 2008). In addition to targeted areas of Austin, this newspaper is mailed free to homes in neighboring communities like Cedar Park, Georgetown, Leander, Hutto, Pflugerville and Round Rock. Based in Pflugerville, Community Impact also has free monthly papers in the Houston and Dallas-Fort Worth metro areas, for a total of 16 titles and a distribution of more than 1 million (“Advertise with us," n.d.).

It is worth noting that Community Impact has so far successfully disproved the assertion that the advertising-based business model is passé and that newspapers should not give away their content. Community Impact apparently "makes money," its operating income was $\$ 1.5$ million in 2012 on $\$ 10$ million in advertising revenue, of which less than $5 \%$ was generated by its website (Helman, 2103). The tabloid-sized newspaper features a clean, stylish design, plenty of infographics and color on nearly every page. However, Community Impact has been accused of being nothing more than a "shopper" that is lacking in opinion writers (Helman, 2013). Some of its editorial content veers close to being pro-business, but its reporters also cover state, county and local 
governments. Publisher John Garrett ${ }^{1}$ freely admits his newspapers do not "do investigative reporting," but they do focus on local news: "I think about online a lot. But our focus is local content, and that's best monetized via print" (Helman, 2013).

Examples of what constitutes "alternative" newspapers can vary widely, although a common thread is these are sources of information and news that are alternative to the mainstream corporate press. Sloan (2008) suggests alternative newspapers in the latenineteenth century included publications that targeted groups of recent immigrants, Native Americans, African Americans, the labor movement, and even anarchists (pp. 247-248). In the twentieth and twenty-first centuries, the term "alternative journalism" covered a multitude of media and audiences, but in general the practitioners "are primarily informed by a critique of existing ways (the dominant practices) of doing journalism" (Atton \& Hamilton, 2008, p. 1). An example in the Austin market is The Austin Chronicle, a publication that has been called a "typical alternative newsweekly" (Barnes, 1995, p. 4).

However, even though a publication like The Austin Chronicle is a member of the Association of Alternative Newsmedia and was modeled after publications born in the 1960s counter-culture movement, it is arguably not radically different from traditional newspapers. It is a profit-oriented business that solicits advertisements from traditional newspaper supporters such as automotive dealerships and retailers. The Chronicle also endorses electoral candidates, its reporters rely on official sources, and they cover basic news beats like the school board, city council, and the state government. What separates

\footnotetext{
${ }^{1}$ John Garrett declined to be interviewed for this study.
} 
weeklies like The Chronicle from more traditional newspapers is that its journalists are unafraid to take a stand or suppress their personal agendas (Barnes, 1995). In that sense then, The Austin Chronicle is similar to other alternative journalistic outlets that are indifferent, if not opposed, to conventional newspaper techniques such as the inverted pyramid, the elite aspect of conventional journalism and "the subordinate role of audience as receiver" (Atton \& Hamilton, 2008, p. 1).

Another form of a free newspaper that has emerged, and subsequently perished in some markets, is one launched by paid daily newspapers to appeal to specific segments of readers. These newspapers, generally aimed at people between the ages of 18 and 29, emphasize entertainment listings, short news stories, oddball features, sports and celebrity news (Zerba, 2013). Zerba studied young readers' critiques of three free weeklies: the RedEye in Chicago (launched by the Chicago Tribune), the 210SA in San Antonio (a product of the San Antonio Express-News), and Quick, a publication distributed by The Dallas Morning News in the Dallas-Fort Worth area. Of those three, only RedEye was still operating in 2013 . One interesting finding generated by focus groups in those three cities was that advertising was received negatively because it overshadowed news content and some advertising content was disagreeable, such as selling sex toys (Zerba, 2013). However, a number of participants "acknowledged that advertisements allow the newspaper to be free" (Zerba, 2013,p. 16).

Free daily newspapers are rare in the United States. Scholar Piet Bakker (n.d.) lists 39 free English-language "daily" U.S. newspapers on his blog Newspaper Innovation. To be clear, not all of those newspapers are actually published seven days a week. For example, express, owned by the Washington Post, is distributed Monday to 
Friday ("Washington Post," 2013). Notwithstanding the debate over what constitutes a “daily" newspaper - can a newspaper published six days a week still be called a “daily"? - the Pew Center's Project for Excellence in Journalism does not define what constitutes a "daily," nor does it distinguish between free and paid newspapers when it reports that there were 1,380 dailies in the United States as of July, 2013 (Edmonds, Guskin, Mitchell, \& Jurkowitz, 2013). The point is if we take Bakker's list and the Pew Center's data at face value, free daily newspapers constitute less than $3 \%$ of all daily papers in the United States.

One chain of free daily newspapers that has attracted attention - Metro - started in Stockholm, Sweden, in 1995 (Bakker, 2002). Metro can be found in three U.S. cities: Boston, Philadelphia and New York. According to Bakker (2008), free commuter newspapers like Metro offer "lighter" editorial fare (p. 427). These newspapers are generally tabloid-size, which means there is limited space to present long-form journalism, they tend to hire younger, less-experienced journalists, and the style of journalism is meant to offer busy readers, or commuters, "quick" access to content (Bakker, 2008, p. 427). Other free dailies in the United States, such as the Vail Daily in Colorado and the Palo Alto Daily Post in California, also use the tabloid format but are more traditional in that their audience is the general public and not just commuters.

\subsection{Why Study Free Newspapers?}

Free newspapers have a long tradition in the United States and North America but it is a medium that has not been studied extensively (Bakker, 2008; Brandsberg, 1969). There is evidence that circulation numbers for free newspapers are not falling as rapidly as those for paid newspapers (Rosenstiel \& Mitchell, n.d.), yet it seems that in 
discussions about the future of newspapers, particularly paywalls, the experiences and future of free newspapers is overshadowed by news about paid newspapers. A study that said daily and weekly newspaper publishers in the United States had stepped up efforts to charge for access to online content fails to mention whether any of the newspapers' print versions are free (Jenner, 2012). Nevertheless, the lead scholar on the project declared: “The days of newspapers 'giving it away' are numbered" (Jenner, 2012).

Published in 1969, Brandsberg's analysis of free newspapers provides observations that are still relevant more than 40 years later. Free publications were unpopular with their paid competitors because they competed aggressively for local advertising dollars, and they were not an appealing topic for communications scholars who "paid little or no attention to free circulation papers. Accordingly, the mass media researchers at the universities seldom investigated these publications" (Brandsberg, 1969, p. 1).

Brandsberg (1969) estimated there were roughly 2,000 free newspapers in the United States in 1968, including shopping guides (publications that emphasize advertising over editorial content). Brandsberg identified approximately 1,000 free circulation newspapers, which he defined as newspapers with at least $50 \%$ of its total circulation being free. However, he acknowledged difficulties in establishing a comprehensive list of all the free publications in the United States. In total, Brandsberg (1969) identified 1,070 free newspapers, although he included shopping guides in his study. Also, 34\% of the free newspapers were located in major metropolitan areas of California and New York. Of the 39 free "dailies" identified by Bakker (n.d.), nearly 31\% were located in Colorado. These two statistics may suggest a geographical affinity for 
free news, or perhaps more likely that once a free newspaper has established itself in a community, would-be competitors must also embrace the free business model.

Regarding the importance of free circulation newspapers, Brandsberg (1969) said the 1,070 free papers he identified, which were overwhelmingly weeklies, had a combined circulation of more than 15.7 million in 1968 . Returning to the overall tally of 2,000 free papers and shopping guides in the United States at that time, Brandsberg estimated the total circulation was around 30 million in 1968 compared to a circulation of more than 27.5 million for paid weeklies in 1967 . He also noted that in the same year, 1,749 daily U.S. newspapers had a paid circulation of more than 61 million (1969). He concludes: "These figures alone were enough to demonstrate that shopping guides and free circulation newspapers constituted an indeed big industry. Ironically, it had become huge with very few people realizing it" (Brandsberg, 1969, p. 13).

Fast forward to the twenty-first century and the free newspaper industry has grown. In 2009, there were 4,160 paid, 982 free and 913 combined (a newspaper that is both sold and given away for free) community weeklies (Tebo, 2009). By February 1, 2012, there were 3,809 paid community weekly newspapers in the United States, 1,072 free community weekly newspapers and 1,020 combined weeklies (Fleming, 2012b). In three years the number of paid community newspapers dropped by 351 titles, free newspapers increased by 90, and combined publications rose by 107 .

In addition, total circulation for paid community papers in the United States dropped by roughly 2 million copies between 2009 and 2011 compared to an increase of approximately 2.1 million for free papers. As of Sept. 30, 2011, free newspapers distributed 22.9 million copies compared to 14.1 million paid publications (Fleming, 
2012b). In 2009 , the total circulation for free weeklies was nearly 20.8 million compared to almost 16.1 million for paid community papers (Tebo, 2009). It is no surprise that free newspapers distribute more copies than paid newspapers. Managers at a paid newspaper will try to avoid higher costs by printing more of their product than what their subscribers demand in addition to what they believe they can sell on the streets or in stores. Free newspapers, on the other hand, endeavor to blanket a market through the mail and/or distribution via public locations (street boxes, stores, and coffee shops) in order to establish a wide audience attractive to advertisers. That free community newspapers reach more people than paid newspapers is also exemplified in the number of titles that fall into certain circulation categories. In 2011 , nearly $80 \%$ of paid community weekly newspapers $(3,031$ of 3,809$)$ had a circulation of 5,000 or less compared to $8 \%$ of free community weeklies $(86$ of 1,072) (Fleming, 2012b). The vast majority of free newspapers, more than 91\%, have a circulation of 5,001 or higher (Fleming, 2012b).

Newspapers that fall in the "alternative" category can be considered an important subset of the newspaper industry because of the number of copies they distribute. The Association of Alternative Newsmedia (AAN) has a membership of 118 newspapers that have a combined weekly circulation of approximately 5.7 million in the United States (“About AAN," 2013). ${ }^{2}$ The largest circulation belongs to The Village Voice at 148,100 in New York City while the $J H$ Weekly has the lowest circulation, distributing 12,000 issues a week in Jackson, Wyoming.

\footnotetext{
2 The American Independent News Network, a collection of eight online news sites with a circulation of 420,557 , was excluded because it is not apparent that print products complement this online presence.
} 
In the United States, three free Metro dailies in Boston, Philadelphia and New York City had a combined daily circulation of nearly 567,000 in 2013 , allowing the group to claim it has the fourth largest newspaper circulation behind the USA Today, The Wall Street Journal and The New York Times ("Advertise [b]," n.d.). Editor \& Publisher does not provide circulation data for free dailies in the United States. As of September 30, 2011, 1,382 paid daily newspapers had a combined circulation of nearly 44.5 million from Monday to Saturday, and another 48.5 million on Sundays (Fleming, 2012b), more than likely dwarfing the circulation of free dailies in 2013 given the 2007 estimation of a combined circulation of 3 million for 40 free dailies (Bakker, n.d.).

Nearly 23 million free community/weekly papers are distributed in the United States, as are approximately 5.7 million alternative newspapers (“About AAN,” 2013), and nearly 567,000 free Metro newspapers for a combined total of a little more than 29 million free papers appearing daily, weekly and monthly. (See Table 1).

Table 1 Circulation of Free Newspapers in the United States 2012-2013

$\begin{array}{lr}\text { Newspaper Type } & \text { Circulation } \\ \text { Weeklies/Community } & 23,000,000 \\ \text { Alternative } & 5,700,000 \\ \text { "Metro" Dailies } & 567,000 \\ \text { Total } & 29,267,000 \\ \begin{array}{l}\text { Sources: Editor \& Publisher International Newspaper Data Book 2012; Association } \\ \text { of Alternative Newsmedia; Metro United States. }\end{array}\end{array}$

The point of all these numbers is to reinforce Brandsberg's (1969) observation from more than four decades ago that there are significant numbers of free newspapers circulating in the United States. Free newspapers are a substantial segment of the newspaper landscape, news operations that have relied on the advertising-based business 
model for decades. Yet, industry veterans like Walter E. Hussman Jr., publisher of the Arkansas Democrat-Gazette, argue that offering news for free, whether online or print, “is a bad business model” (Farhi, 2008). Perhaps both free and paid newspapers will disappear over time as the competition for advertising dollars intensifies and ad revenues continue to fall (“Advertising expenditures," n.d.), and perhaps free newspapers will be the first to perish because they are more reliant on ads to pay the bills. But to call the advertising-based business model "bad" is at best an indication of a bias in favor of paid newspapers, or at worst an ignorance of a rich newspaper history founded in the advertising-based business model and of the financial success enjoyed by many free papers.

\subsection{History of Free Newspapers}

Brandsberg (1969) insists free newspapers and shoppers in the United States are primarily a "product of the twentieth century" (p. 16). They began to appear with regularity in the 1920 s, benefited by the creation of bulk third class postage rates in 1928 that allowed free newspapers to greatly expand their circulation and appeal to advertisers (Brandsberg, 1969). However, a historical analysis of free newspapers and their cousins, the penny press, shows that there has always been an audience for free news.

One of the problems the American press faced in the first few decades of the nineteenth century was that many readers declined to pay for the newspapers they were consuming. Citing data from 1821, Steffen (2003) calculates that "one of seven Americans read a newspaper for free. These nonpaying readers were both agents and beneficiaries of a massive giveaway that helped democratize the culture of print" (p. 382). Citizens were keen to stay informed, or entertained, but were reluctant to pay up. 
People would either borrow newspapers from friends or family that had paid the subscription fee, order a newspaper then refuse to pay the subscription bill, or steal newspapers off of doorsteps (Steffen, 2003). However, it must be noted as well that some Colonial-era newspapers, including the first newspaper in the American colony, Publick Occurrences, Both Foreign and Domestick (1690), encouraged readers to share the print product. These newspapers were typically comprised of four pages and one page would be blank, allowing the subscriber to jot down his own news before passing the newspaper on (Sloan, 2008, p. 39).

Editors railed against the loss of subscription revenue but letters to the editor showed readers who borrowed or refused to pay for newspapers - forecasting contemporary debates about whether online content should be free - felt "they had a right to the news" (Steffen, 2003, p. 393). Editors complained about readers who "begged, borrowed or stole papers on a massive scale," but they did little to stop the phenomenon because newspaper proprietors realized a big audience, a readership larger than their subscription base, was attractive to advertisers and also gave the newspapermen more political clout (Steffen, 2003, p. 419).

It is suggested here that free newspapers are related to the penny press that emerged midway through the nineteenth century, but Steffen (2003) argues that the penny press "did not so much cause the circulation revolution as reinforce trends that were already in place. Decades before the new techniques of marketing and manufacturing newspapers made their appearance, the subscription system had already been considerably undermined from within" (p. 385). Readers' efforts to stay informed showed there was a market for newspapers, ostensibly free ones. 
Just as free newspapers are overshadowed by the fate of subscription or paid newspapers and the merits of paywalls in analyses of today's newspaper industry, so too did the emergence of the penny press overshadow the story of readers' desire to access free news. The penny press is simply a more popular topic among scholars than the earlier decades of free media use analyzed by Steffen. Nevertheless, free papers are directly related to the advent of the penny press in the United States in the mid-nineteenth century because the penny press business model - a heavy reliance on advertising revenue (Picard \& Brody, 1997) - is the same employed by free newspapers and is still in place some 180 years later. In essence, Shirky (2012) suggests, there is little difference between free and penny newspapers: by drastically reducing the price of a newspaper, from six pennies to one or even down to zero, the proprietor almost assuredly increases his audience and could then "recoup in ad revenue what he gave up in subscription fees" (p. 29). The penny press and free newspapers also share an emphasis on establishing a much wider circulation compared to their competitors, such as six-penny papers and paid newspapers, respectively (Schudson, 1978).

Some scholars declare that the course of print journalism in the United States changed forever when the penny press emerged in the 1830s (Spencer, 2007; Stovall, 1991; Schudson, 1978). Other academics say a number of factors were involved in the transformation of American journalism during the Jacksonian Age and that the influence of the penny press is overstated (Mindich, 1998; Nerone, 1987). Scholars vary on when and where the penny press started, but the story is forever linked to New York City.

On July 24, 1830, the Boston Transcript produced a number of innovations that eventually found their way to New York, such as a larger paper size, advertising on the 
front page, writing that was supposedly in good taste, and stories that included coverage of the arts and literature (Spencer, 2007). The penny press reached New York on January 1, 1833, with the launch of the Morning Post by Horace Greeley and his partners Horatio David Shepard and Francis W. Story. Apparently Shepard had the idea of a newspaper that cost a penny, as opposed to the six-penny papers that dominated at the time, after seeing merchants in the Bowery marketplace sell products for a penny. Although the Morning Post had enough funds to last only one month (North, 1884), it can be argued Shepard sensed "the viability of the marketplace" (Spencer, 2007, p. 24). Indeed, in 1833 Benjamin Day established The New York Sun to apparently exploit this market (North, 1884). According to Schudson (1978), The New York Sun should be regarded as the first penny newspaper. It was launched on September 3,1833, by Day, one of a handful of "great men" indelibly linked to the rough and tumble world of New York City journalism in the nineteenth century. By January 1834, The New York Sun claimed a daily circulation of 5,000 and in two years that total jumped to 15,000 . Other great men mentioned in histories of the penny press include: James Gordon Bennett and his New York Herald which hit the streets on May 6, 1835; Horace Greeley, whose fame increased after The New York Tribune started in 1841; and Henry Raymond, who launched The New York Times in 1851 (Stovall, 1991; Schudson, 1978).

Although scholars may be splitting hairs with Schudson, they assert Benjamin Day's Sun was the first penny newspaper to have a big impact on the New York market (Spencer, 2007; Stovall, 1991), but not necessarily the first newspaper to charge a penny for the privilege of consuming a populist, some might say sordid, take on the news (Bettig \& Hall, 2012). "Taking his cue from a British newspaper called the London 
Morning Herald, Day treated his readers to a continual parade of petty thieves, hookers, confidence artists, homeless transients and a host of others who had shadowy connections on the wrong side of the law" (Spencer, 2007, p. 26). The New York Sun was a newspaper pegged "at a price within the means of everyone" (Stovall, 1991, p. 124). By 1836, the Sun had a larger circulation than the 11 six-penny papers in New York City (Nerone, 1987).

Among the reasons penny papers are considered a turning point in American journalism is that they redefined what was news: they covered the courts, the police, local as well as national politics, business, and social affairs (Stovall, 1991; Schudson, 1978). The six-penny press was dominated by either "commercial" newspapers that focused their editorial and advertising efforts on shipping news and mercantile issues, or "political" newspapers whose pages focused on national news while promoting the party or candidate who funded the operation (Schudson, 1978, pp. 14-15). Schudson (1978) argues the advent of the penny press in the 1830s meant newspapers "began to reflect, not the affairs of an elite in a small trading society, but the activities of an increasingly varied, urban, and middle-class society of trade, transportation, and manufacturing" (pp. 22-23). The penny papers also differentiated themselves from the six-penny press by claiming an independent political stance and in the process invented "the modern concept of "news"” (Schudson, 1978, p. 22).

However, according to some scholars, this period of American journalism was more complicated than simply the arrival of great men with great ideas about revolutionizing newspapers. Nerone (1987) says the following story line is a myth: a handful of daring editors, primarily in New York City, "revolutionized the content and 
style of American journalism by creating what was essentially the modern popular commercial newspaper" (p. 376). Many facts that the so-called myth is based on are accurate, but they have been organized "around a heroic narrative with didactic (intended for teaching) effect" (Nerone, 1987, p. 377). Indeed, even the price of the penny paper was not sacred. Costs associated with producing a newspaper increased after the start of the Civil War in 1861, forcing Day to raise the Sun's daily price to two cents (North, 1884). The Times, the Tribune and the World all started as penny papers but eventually raised their price to two cents as circulation increased and their businesses gained in value (North, 1884).

Nevertheless, there is a direct line between the penny press and yellow journalism that dominated New York City beginning in June 1897, specifically the reliance on advertising and street sales (Bettig \& Hall, 2012; Spencer, 2007). The roots of this journalistic transformation started in the nineteenth century when readers gradually became a market, an audience that demanded less-costly news, an audience that publishers could sell to advertisers. It could be argued the penny press solidified the advertising-based newspaper business model. Gone was the reliance on six-penny subscriptions and political largesse. In their place came street sales, larger circulations and the need for advertisers' dollars: "Sources of income that depended on social ties or political fellow feeling were replaced by market-based income from advertising and sales" (Schudson, 1978, p. 18).

Free community newspapers began to increase in numbers after the Second World War (Jose, 2000). In most markets, these community newspapers competed directly against paid newspapers, a development paid papers viewed as being "a very negative 
and unwanted influence" (Jose, 200, p. 3). The reaction among some paid papers was to fight back by improving the quality of their publications, derisively calling the competition "'throwaways,"” pushing for anti-littering laws, starting their own free papers and, more commonly, "extolling the superior value of a paper that was paid for (and therefore better read)" (Jose, 2000, p. 3).

\subsection{Theoretical Framework: Media Economics}

\section{4.a Business Model}

A common definition of "business model" has proved elusive, but one suggestion is that it generally means the terms and conditions by which a firm proposes to attract revenue and produce a product (Ala-Fossi et al., 2008, p. 149). A business model helps explain how a business operates, how it plans to create revenue, and it outlines the operation's foundations (Picard, 2002). The primary goal of a firm is to maximize profits. Media industries are unique, however, because most operate in a "dual product market" (Picard, 1989, p. 17). They produce content, or news, which in turn creates an audience marketed to potential advertisers. Consumers either pay a price to access the content or if the content is free they are paying with their time and attention (Picard, 1989).

The business model for newspapers in the United States has functioned virtually unchanged for nearly 200 years (Shirky, 2012). Shirky (2012) likens the newspaper business model to a three-legged stool: one leg is the publisher giving the audience access to the news; the audience is the second leg, giving "the publisher access to the advertisers"; and the third leg is the advertisers paying the publisher to reach the audience, which in turn allows the publisher to cover the costs of providing more news (p. 29). Even though some observers are not so certain that the advertising-based business 
model is doomed (Picard, 2002; Garden, 2010), Shirky (2102) is not one of them: "Every formerly stable leg of that triangle is buckling" (p. 29).

Shirky is not alone in his assertion that the newspaper business model is in trouble. While the Internet can be seen as simply a new way to deliver familiar information (news and entertainment), the impact of social media and blogs are completely new developments and as a result the old business models are suffering (Küng et al., 2008a). The first Internet era began around 1996, characterized by the dotcom boom and bust and much hype, but traditional media survived and were still profitable. Since the dotcom bubble burst in early 2000, the Internet has continued to become increasingly prominent in society, impacting all media (Küng et al., 2008a). The consensus in the first phase of the Internet revolution was that the newspaper business model was under serious threat (Ala-Fossi et al., 2008).

Kaye and Quinn (2010) are more direct, declaring the traditional newspaper business model has been rendered "virtually obsolete" (p. 18). Despite the reality that advertising revenues are keeping the doors open at many newspapers as they try to transition to the digital world, the two "pillars" of newspapers' revenue - subscriptions and ad revenue - "are now crumbling" (Kaye \& Quinn, 2010, p. 19). Not only have online news sources demolished newspapers' geographic advantage, or “near monopolies," the subscription and advertising business models that "supported traditional media companies in the past appear unable to do so in the digital age" (Kaye \& Quinn, 2010, pp. 5, 23).

Whether the advertising-based business model is dead or dying may depend on what market you are standing in. Newspapers in smaller markets are not suffering as 
mightily as newspapers in large- or mid-sized markets, and the small-market publications may even prosper because they are closer and more attuned to their audience's and advertisers' needs (Salkever, 2012). But, of course, free publications can be found in large markets as well as small markets and the reality is advertising revenue, a cornerstone of the free newspaper business model, has been under siege for several years (“Advertising expenditures,” n.d.).

\section{4.b Advertising}

In the mid-nineteenth century, newspapers relied on high subscription prices and had a low circulation, reaching maybe $15 \%$ to $25 \%$ of the population, depending on other factors such as literacy levels, location, and economic conditions (Picard, 2002). Leading up the twentieth century, literacy had improved, the Industrial Revolution had re-shaped society, and cities grew exponentially as urbanization transformed North America. All these factors helped create larger audiences for newspapers as they weaned themselves off political patronage and become more reliant on advertising revenue. Ad dollars accounted for about half of newspapers' revenue in 1880, up to two-thirds by 1910 and approximately $80 \%$ by 2000 (Picard, 2002).

The influx of new media unleashed by the Internet as the twentieth century rolled into the twenty-first century exacerbated newspapers' already declining readership and limited their ability to raise ad rates. When the recession that started in 2001 ended in 2003 "advertisers did not return to their previous pattern of spending across media" (Picard, 2008, p. 705). The creation of online outlets like Monster.com, eBay and craigslist.org impacted newspapers' bottom line by siphoning off classified ads. These sites and others captured what was relatively easy revenue for newspapers. 
Newspaper industry analyst John Morton (2009) argues that more relevant than the closures of the Seattle Post-Intelligencer, the Tucson Citizen and Denver's Rocky Mountain News was "the collapse of classified advertising at large metropolitan dailies, which is the major cause of the differing fortunes of large and small dailies" (para. 6). Previously, $50 \%$ or more of advertising revenue for large dailies was generated by classified ads. The three major revenue generators in that section of the newspaper were automotive, real estate and help wanted listings and they "started tanking in the final months of 2007" (Morton, 2009, para. 7).

As the number of media outlets multiplied and newspaper readership declined, newspapers' share of the advertising pie shrank, falling by about one-third since 1970 (Picard, 2008). However, total advertising spending climbed from $\$ 2$ billion in 1950 to $\$ 47.4$ billion in 2005, which had the effect of lifting all boats. Economic problems for the newspaper industry started to worsen as the global financial crisis started in 2007 and carried over to 2008 , singularly impacting advertising revenues as marketers cut their budgets. The period was marked by a three-year decline in total advertising expenditures in the United States, the first time this had happened since the Great Depression (Kaye \& Quinn, 2010). Even before then, local online ad revenue fell for newspapers, from $44.1 \%$ in 2004 to $33.4 \%$ in 2007, while "non-newspaper Internet companies" attracted $43.7 \%$ of local online ads (Kaye \& Quinn, 2010, p. 8). Not only are newspapers more deeply impacted by economic downturns - one of the first media to be cut by businesses and ad agencies - but research suggests the newspaper industry is slower to bounce back from a recession compared to others (Van der Wurff et al., 2008). 
In 2008, Picard was cautiously optimistic about the newspaper industry: “The trends in advertising are not as bad as some in the industry have feared, nor are they good enough to ignore or feel great confidence in the future financing that advertising will provide newspapers" (2008, p. 714). Trends at that time suggested display advertising would continue to shore up newspaper revenues but great growth was hard to expect. National advertising would remain but be difficult to predict, and declines in classified revenues were expected to continue to fall (Picard, 2008). And then the economic picture worsened within 12 months.

The year 2009 has been called the "Perfect Storm" for the newspaper industry because a recession negatively impacted advertising spending, massive debt loads limited some major media outlets' economic options, and a "historic restructuring" had been unleashed by online challengers offering free content (Kirchhoff, 2009, p. 1). Financial problems were particularly acute for major newspaper chains like McClatchy Co., Lee Enterprises and the Tribune Co. as they wrestled with massive debt loads, legacy costs such as pension plans, and reduced stock prices, all limiting corporations' ability to raise new capital. In 2009, seven newspaper companies declared bankruptcy, including large operations like the Tribune Co., publisher of the Chicago Tribune and seven other major daily newspapers, and smaller operations like American Community Newspapers (Kirchhoff, 2009, p. 7). American Community Newspapers has been divesting itself of newspaper titles since 2009, including a deal in 2011 to sell 15 community newspapers in the Dallas area to Reno, Nevada-based 1013 Communications (American Community Newspapers, 2011). 
Advertising revenue fell by $6.4 \%$ nationwide from 2009 to 2010 but the good news, if that term is applicable, is that a drop of $6.4 \%$ was not nearly as bad as the $26 \%$ plunge that occurred from 2008 to 2009 (Rosenstiel and Mitchell, n.d.). The trend continued in 2011. Advertising revenue for newspapers in the United States declined $7.3 \%$ in 2011 compared to 2010 , although digital ad revenue grew by $6.8 \%$ (Edmonds et al., 2012). By 2012, advertising revenue had fallen $2 \%$ compared to 2010 but circulation revenue had climbed 5\% and revenue from non-traditional sources (such as digital consulting and e-commerce transactions) jumped by $8 \%$ ("The American newspaper," 2013).

The Pew Research Center's surveys on the news industry do not provide a lot of data specifically about free newspapers. With that in mind, data from The State of the News Media 2011 regarding the newspaper industry will be presented followed by information that focuses on free newspapers. In general, "structural economic problems facing newspapers are more severe than those of other media" (Rosenstiel \& Mitchell, n.d.). It was estimated that from 1,000 to 1,500 newsroom jobs were eliminated, making newsrooms 30\% smaller than in 2000 (Rosenstiel \& Mitchell, n.d.). Print circulation continued to fall in 2010 , weekdays by $5 \%$ and Sundays by $4.5 \%$, but that is an improvement considering circulation had plummeted by $10 \%$ on weekdays and by $9 \%$ on Sundays in 2009 (Rosenstiel \& Mitchell, n.d.). Quoting data from the Newspaper Association of America, the Pew Research Center estimated paid circulation in 2009 was $\$ 10.1$ billion, a $10 \%$ decline from a peak of $\$ 11.2$ billion in 2003 . The Pew's researchers also found that advertising revenue accounted for $73 \%$ of U.S. newspapers' total revenue, down from $80 \%$ in 2003 (Rosenstiel \& Mitchell, n.d.). However, the Newspaper 
Association of America ("The American newspaper," 2013) reported that data it compiled for 2012 from 17 public and private newspaper companies showed print advertising accounted for $46 \%$ of total newspaper media revenue while circulation generated $27 \%$, new revenue sources $8 \%$, digital advertising $11 \%$, and niche publishing and direct marketing $8 \%$.

Despite these numbers, the newspaper industry is profitable (Soloski, 2012). According to The State of the News Media 2011, newspapers were generally operating in the black in 2010, with typical profit margins of 5\%, albeit less than a quarter of what profit margins were in the 1990s (Rosenstiel \& Mitchell, n.d.). Other estimates suggest profit margins in 2008, 2009 and 2011 were around 15\%, and nearly $18 \%$ in 2010 (Wilkinson, 2012), numbers that one academic noted were "more than three times the historical average $4.7 \%$ profit of a Fortune 500 company" (Edge, 2012, p. 8). But once interest, taxes and special charges were applied in 2011 the net margins were reportedly "razor thin" (Edmonds et al., 2012, p. 2), although the industry-wide average profit margin of 5\% was close to the $6 \%$ average for the S\&P 500 (Soloski, 2012).

Many newspaper companies would be doing better financially if they were not saddled with interest payments on debt incurred during a wave of consolidation between 1993 and 2007, when large chains consumed seven other newspaper chains (Soloski, 2012). Indeed, data on profit margins appear to show "that the newspaper business model is hardly broken. In fact, the business model may be more robust than anyone suspected, because in IT language it seems 'scalable"': Newspapers can respond to declining revenue by cutting expenses, which generally means fewer journalists are employed (Edge, 2012, p. 20). There may also be a connection between the size of an audience and 
advertising revenue: "Though difficult to measure, our analysis suggests that about half of the fall-off in ad revenue now is due to declines in the size of the print audience delivered to advertisers" (Rosenstiel \& Mitchell, n.d.). Related to this analysis and the importance of audience size, the combined circulation of the top 25 U.S. weekly newspapers, "all free publications," dropped by only $.59 \%$ in 2010 compared to a fall of 9.92\% in 2009 (Rosenstiel \& Mitchell, n.d.).

\section{4.c Engagement}

Although the concept of engagement has been around the print industry for years and has increased in popularity as technology improves the ability to measure an audience's interaction with a medium, a concise definition of engagement has nonetheless proved elusive (Napoli, 2011; Malthouse \& Peck, 2011). Napoli (2011) quotes an advertising executive as saying: "Engagement is like obscenity. None of us can

define it, but we're all pretty sure when we see it" (p. 96). Part of the confusion may stem from two types of engagement that are related if not forever linked: engagement with an advertisement or a brand, and engagement with the medium or context where the advertisement or brand is located (Napoli, 2011).

Among the 20 definitions of engagement gathered by Napoli (2011), ranging from a consumer's emotional connection to qualitative experiences with content, whether a medium is free or paid is not included as a factor in audience engagement. Engagement has been defined as "the sum of the motivational experiences consumers have with the media product” (Calder \& Malthouse, 2008, p. 5). According to this definition, which guides this study, engagement is strongly related to a medium's content and what it does for a consumer. People have always talked about what they gleaned from the media 
(Duke, 2011), not whether a medium was free or not. If consumers are engaged in a media product, and experiencing "motivational experiences" such as talking about or sharing their interaction with the content, then advertisers have a better chance of becoming part of the experience (Calder \& Malthouse, 2008, p. 6).

Research suggests that a print newspaper is a "normal good" in that when income increases so does the consumption of newspapers (Chyi \& Yang, 2009, p. 602). Chyi and Yang (2009) identified a positive relationship between income and print newspaper use and a negative relationship between income and online news consumption: when income increases the consumption of online news decreases and when income decreases the consumption of online news increases. The assertion is that "online news is an inferior good among users" (Chyi \& Yang, 2009, p. 602). In other words, in terms of income and demand, online news is inferior to the available alternative that is print news. Perhaps free newspapers are considered an inferior good compared to paid or subscription newspapers because they are, well, free? If income drops perhaps people might be more willing to pick up the free product? However, Anderson (2009) asserts people “don't think as much about things they don't pay for, and as a result they don't think as much about how they consume them" (p. 67). This argument suggests a reader will be more deeply engaged with a newspaper she paid for because she has "invested" in that product. Some advertisers apparently believe the act of paying for a product means the consumer will consume it with more relish than if the product is free. "In fact, advertisers will pay as much as five times more to be part of that relationship than they'll pay for a free magazine that may be treated as junk mail” (Anderson, 2009, p. 58, italics in original). 
Despite Anderson's claim, advertisers still buy space in free newspapers, as this study will show.

Perhaps more important in this debate about the engagement of free versus paid is whether a newspaper's distribution method can be trusted. Advocates of paid newspapers tell prospective advertisers that because their circulation numbers are verifiable they can be sure their advertisement has a much better chance of being seen than if it were in a free newspaper whose readership is harder to pin down (Morton, 2001). However, this criticism of free newspapers can be countered by other methods of verification, such as post office receipts if a newspaper reaches consumers through the mail. A free newspaper that drops copies at numerous locations around a city, such as The Austin Chronicle, not only pays companies to verify its circulation (Nick Barbaro, personal communication, June 14, 2013), it will also keep track of how many newspapers from the previous week remained on a stand to show advertisers how many copies had been picked up.

This verification method assumes the newspaper is truthful about how many copies are left on the stand, an experience The Village Voice has encountered. The venerable New York City alternative newspaper dropped its cover price in 1996, an act that has been referred to as "the day The Village Voice stopped mattering" (Anderson, 2009, p. 55). Something that used to cost money and then becomes free seems to lose quality, Anderson argues, while quality is not an issue for something that has always been free. It was suggested of The Village Voice that perhaps it would have been better to put the 58-year-old weekly newspaper out of its supposed misery, like an aging racehorse, instead of succumbing to "the humiliation of going free" (Jacobson, 2005, p. 10). Jacobson scoffed at David Schneiderman, CEO of the Village Voice in 2005, who said 
the weekly had almost doubled its circulation from 130,000 to 250,000 by going free. Schneiderman said the 250,000 circulation number was based on $1 \%$ returns, prompting a snarky response from Jacobson that may be indicative of the overall doubt cast on the free newspaper industry: "'Are you counting those hundreds of papers that are thrown away because some dog pissed on them?"” (2005, p. 6). Schneiderman apparently ignored the taunt and said that going free actually saved The Village Voice because its audience expanded (Jacobson, 2005).

Anderson (2009) argues that even charging a penny makes people stop and think about paying. The consumer is forced to make a decision as to whether the printed product is worth the price and effort of paying. "Free, in contrast, speeds right past that decision, increasing the number of people who will try something. What Free grants, in exchange for forsaking direct revenues, is the potential of mass sampling" (Anderson, 2009 , p. 59). A newspaper that charges a cover price or subscription fee is in effect selling to two markets: potential readers and advertisers (Hoskins et al., 2004), whereas a free newspaper is only formally selling to one, the advertisers, in terms of charging fees. The free newspaper is also "selling" itself to potential readers, offering content that hopefully engages the passer-by enough so that she stops to pick up the paper.

If the news, information and advertising in a newspaper are not engaging it will have a hard time holding a reader's attention, regardless of whether it is free or not. The differences between a free and a paid publication may depend on each distinct market and is therefore not generalizable to an entire industry. Like paid newspapers, there are good, bad and mediocre free newspapers in terms of editorial quality and commitment to covering the news, and that level of quality or commitment is not necessarily related to 
whether the newspaper is free or not (Ingram, 2012). But it could be argued that a total circulation of more than 29 million free newspapers in the United States suggests some readers are engaged.

It must also be acknowledged that reader engagement is more crucial for free newspapers than paid newspapers because the free paper does not receive subscription or street sales revenue. The free paper's content must attract and retain an audience. The free paper lives or dies by its editorial content and its distribution methods, two major costs for any newspaper. This study attempts to determine how decision-makers at free newspapers view engagement, and whether their content and/or free distribution gives their newspaper or papers an advantage over paid competitors.

\section{4.d Expenses}

Producing a newspaper is a labor-intensive process (Picard \& Brody, 1997). One estimate is that 40 cents of every dollar in revenue a newspaper receives goes towards paying labor costs (Picard \& Brody, 1997). A case study suggested the following breakdown of expenses for a daily newspaper in the United States: building, general and administrative $31 \%$ to $34 \%$; newsprint and ink $17 \%$ to $21 \%$; news $14 \%$ to $15 \%$;

production $12 \%$ to $14 \%$; and $10 \%$ to $12 \%$ for the advertising and circulation departments (Fink, 1996, p. 122).

In 2009, a senior analyst for Moody's Investor Service declared there was a "structural disconnect" in the newspaper industry because newspapers were devoting the vast majority of their cash operating costs to funding the corporation, and to producing and distributing their product: $70 \%$ for distribution, production and corporate costs; $14 \%$ to create editorial content; and $16 \%$ to fund advertising sales (Fitzgerald, 2012). The 
analyst noted few resources were earmarked for the dominant revenue generator (advertising), and that the combination of these fixed costs - the $70 \%-$ and high debt put pressure on cash flow as revenue declined (Fitzgerald, 2012). This can't be a recipe for success given the reality that advertising accounted for $73 \%$ of total revenue for U.S. newspapers in 2010 (Rosenstiel \& Mitchell, n.d.). This study seeks to determine, via research questions, if free newspapers are in the same position and whether they are trying to diversify their sources of revenue.

\section{4.e Revenue}

The Organization for Economic Cooperation and Development (2010) has estimated (based on figures from 2008 or "the latest available year") that the reliance on advertising revenue, as opposed to copy sales, is highest among newspapers in the United States (87\%), Luxembourg (77\%) and Canada (77\%) compared to many European countries that range between $50 \%$ to $60 \%$ while Japan was the lowest at $35 \%$ (p. 35). If decision-makers at a free newspaper decide that relying on advertising revenue leaves their business vulnerable to shifts in the advertising industry, what options are available? A common expectation is that a combination of revenue sources will be the norm for news organizations, such as online fees, partnerships, and events like book fairs (Kaye \& Quinn, 2010).

At the other extreme, a newspaper may reduce its publication schedule, like the New Orleans Times-Picayune cutting back from seven days a week to three, while promoting its website as an alternative for those days the print product is not available (Chittum, 2013a). In a hypothetical example, if a mid-market, 38,000-circulation newspaper shifted exclusively to online it would see expenses drop by $\$ 3.65$ million 
because it no longer has printing and distribution costs, while the return on sales would rise from $32.4 \%$ to $61.8 \%$ (Picard, 2002). But as scholars note, this is an unrealistic scenario because it assumes advertising and circulation revenue would not decrease (Chyi $\&$ Tennant, 2013). This example "reveals the extent to which [non-news] business aspects of production and distribution affect the operations of newspapers" (Picard, 2002, p. 64-65; Thurman \& Myllylahti, 2009).

If a free newspaper instituted a cover price and a subscription fee, researchers assert it could expect to lose more in advertising revenue than what it would gain in revenue from readers (Hoskins et al., 2004). The implication is that the imposition of a price will drive many readers away from the formerly free newspaper, thus reducing the size of the audience, making it tougher to attract advertisers in an already depressed market. Nevertheless, advertising is still the cornerstone of the free newspaper business model.

\subsection{Research Questions}

In order to analyze the current status of free newspapers and whether their strategy for the future includes two options - stay free but seek out additional revenues, or abandon the free model altogether - seven research questions have been developed. The first research question establishes the general economic health of free newspapers.

RQ1: How has advertising revenue and circulation changed, or not, at free newspapers from 2011 to 2012 ?

The next research question addresses whether decision-makers at free newspapers are mulling over whether to revamp their advertising-based business model. 
RQ2: Given the fluctuations in advertising revenues, are executives at free newspapers adjusting their business model to seek a variety of sources of revenue?

Free newspapers' efforts to generate online advertising revenue are addressed in the following two research questions.

RQ3: Are sales representatives at free newspapers selling both platforms, online and print, or are they focused on one platform only?

RQ4: How do the sources and types of advertisements differ between the online and print editions at free newspapers?

Given the argument that a reader will supposedly be more engaged in a print product that she pays for as opposed to one she picks up for free, the following two questions address engagement.

RQ5: To what extent do free newspapers invest in editorial content?

RQ6: To what extent do free newspapers believe they have a relative advantage over paid newspapers?

The final research question addresses what the future may hold for free newspapers.

RQ7: To what extent are executives at free newspapers optimistic or pessimistic about the future of free newspapers? 


\section{Chapter 3: Methods}

Two methods were employed in this research project: qualitative in-depth interviews with elite subjects and a quantitative Web-based survey. These methods were chosen because they can help a researcher receive in-depth information from different types of free papers, and reach a large number of decision-makers at free newspapers.

\subsection{In-Depth/Elite Interviews}

The one-on-one, or in-depth, interview is a qualitative method that can "provide texture and context that can't be gleaned from surveys" (Poindexter \& McCombs, 2000, p. 271). Interviewing publishers, who may be considered "elite" subjects, can help a researcher understand on a deeper level how a newspaper is faring in its market, why certain decisions have been made, or not made, and what the considerations were in a decision-making process. Hendricks (1999) set the bar high when he interviewed 74 newspaper executives from the United States (48) and The Netherlands (26) for his study of the industry. A precise definition of who is an "elite" interview subject varies among qualitative researchers (Harvey, 2011). Definitions vary depending on the context (corporate versus political), geography (a person may be an elite in one area but not in another), timing (a person's so-called elite status might evaporate if she is fired), or social status (Harvey, 2011). However, Harvey's (2011) definition of an elite subject guides this study: men and women who "occupy" senior management positions, people who "have significant decision-making influence within" their organization (p. 433).

Regarding an interview script, Morrissey (1970) asserts that it is risky being confined within a pre-ordained protocol "and not relying sufficiently on old-fashioned 
intuition as to which tool to use in which situation" (p. 110). The scripted interview may be too rigid, not allowing for follow-up questions that may include necessary elaborations and clarifications, on which "the richness of an interview is heavily dependent" (Marshall \& Rossman, 1989, p. 144). An alternative is the "dialogic interview" whereby the researcher and the subject "generate new meaning together" (Marshall \& Rossman, 1989, p. 144). The downside of an informal interview is that the researcher and subject share in the "talk time." This is a conversation, after all, but transcripts show there is more "talk" from the subject than the researcher in a scripted interview (Marshall \& Rossman, 1989, p. 144). The goal is to let the subject frame the discussion (Marshall \& Rossman, 1989). For this study, lists of questions were established to reflect the seven research questions, but they ended up becoming useful guides than strict scripts to follow with strict precision. Interviews became conversations, veering from subject to subject as the researcher sought to make his interviewees feel at ease.

Ultimately, the researcher is dealing with subjective data. Researchers must “acknowledge initially that we are getting merely the informant's picture of the world as he sees it" (Dean \& Whyte, 1970, p. 120). In general, as the results section will show, the four newspaper decision-makers interviewed for this study were fairly forthcoming although the occasional "bars to spontaneity" (Dean \& Whyte, 1970, p. 122-123) surfaced when a decision-maker declined to provide specifics on certain subjects. Dean and Whyte suggest the researcher not pursue whether the subject is being truthful, and instead ask, "What do the informant's statements reveal about his feelings and perceptions and what inferences can be made from them about the actual environment?" (1970, p. 131). 
Seven newspaper decision-makers at seven Texas newspaper operations were contacted informally regarding whether they would agree to an in-depth interview. Four responded positively, one declined after first agreeing to an interview, and communications between the researcher and two newspaper decision-makers simply fell by the wayside as the study progressed and time became a factor during the summer of 2013. Phone messages asking the publisher of a Houston chain of community newspapers for an interview were acknowledged but never acted upon. Another publisher of community newspapers west of Austin, including one that was free when it was purchased then transformed into a paid newspaper, seemed agreeable to be interviewed but a date for a meeting could never be established, in large part because the researcher switched his focus to the four elite subjects who had agreed to be interviewed.

The four elite subjects who were interviewed for this study were first asked informally via email if they would be willing to meet for an interview. Once the subject agreed informally to be interviewed, the researcher then sent each person a formal interview request and consent form via email. (Appendix 1). This script contained information about the researcher, the topic, the general parameters of the interview (for example, the possible length of time needed for the interview), and that the interviewee had the right to decline to be recorded (Marshall \& Rossman, 1989; Poindexter \& McCombs 2000; Morrissey, 1970). Consent was considered granted when the publisher agreed to a date, time and place for the interview.

A list of questions was prepared in advance of each interview. The questions obviously reflect the need to answer as best as possible the seven research questions outlined above. The goal was to encourage these decision-makers to talk about the 
financial health of their advertising-reliant newspapers (RQ 1), how they have, or have not, considered altering their advertising-based business model (RQ 2), how successful they have been, or not, in efforts to generate online advertising revenue (RQs 3 and 4), how they feel about the assertion that a free newspaper is inferior to a paid or subscription newspaper, and what role engagement plays in their market (RQs 5 and 6), and finally whether they are positive about the future of free newspapers (RQ 7).

The lists of questions for each decision-maker were divided into categories such as history, current situation, advertising, editorial, distribution/costs and future. The lists, however, were also altered slightly to reflect the different characteristics of the four publications, their markets and divergent histories. For example, one of the publications does not have a website so there was no sense in asking how it was managing with online ad sales. (See Appendices 2 to 5).

The four decision-makers interviewed for this dissertation are all publishers representing four distinct types of free newspapers: 1) the so-called "alternative" weekly (The Austin Chronicle), 2) a weekly targeted at the African-American community in Austin (The Villager), 3) an independently-owned community weekly located in a major city (The Leader in Houston, Texas), and 4) a free suburban paper, which is part of a large media group, that is published four times a week (Briefing in Dallas, Texas). The interviews were conducted in either the subject's office or a boardroom in their building. They were digitally recorded and lasted between 100 to 120 minutes. (See Table 2). Interview responses were analyzed qualitatively for common themes and differences among the subjects. 
Table 2 Information on Interviews with Elites at Four Free Newspapers

$\begin{array}{lccccc}\text { Newspaper } & \text { City } & \text { URL } & \text { Interview Site } & \text { Subject } & \text { Title } \\ \text { Austin Chronicle } & \text { Austin } & \text { austinchronicle.com } & \text { Boardroom } & \begin{array}{c}\text { Nick } \\ \text { Barbaro }\end{array} & \text { Publisher } \\ \text { Austin Villager } & \text { Austin } & \text { theaustinvillager.com } & \begin{array}{c}\text { Publisher's } \\ \text { Office }\end{array} & \begin{array}{c}\text { Tommy } \\ \text { Wyatt }\end{array} & \text { Publisher } \\ \text { Briefing } & \text { Dallas } & \text { n/a } & \begin{array}{c}\text { Boardroom } \\ \text { at Dallas } \\ \text { Morning News }\end{array} & \begin{array}{c}\text { Richard } \\ \text { Alfano }\end{array} & \text { Publisher } \\ \text { The Leader } & \text { Houston } & \text { theleadernews.com } & \begin{array}{c}\text { Publisher's } \\ \text { Office }\end{array} & \begin{array}{c}\text { Jonathan } \\ \text { McElvy }\end{array} & \text { Publisher }\end{array}$

What follows is a brief, qualitative snapshot of each newspaper. More detail about these newspapers will emerge when common themes resulting from the separate interviews are discussed in the results section.

\section{1.a The Austin Chronicle}

Located in Austin, Texas, this weekly newspaper (Appendix 6) was launched in 1981 by six University of Texas at Austin film graduate students who had no formal journalism training. The goal, according to publisher Nick Barbaro, was to produce an Austin version of the "underground" newspaper model like The Village Voice (New York City), the Berkeley Barb (California), and the Chicago Reader (Illinois) (personal communication, June 14, 2013). Barbaro and his business partner Louis Black (now the editor) traveled to Dallas to consult people who had launched the alternative newspaper Observer in 1980. Their advice, Barbaro recalled, was, "Don't do it! Terrible idea. But we did anyway."

The Austin Chronicle is a traditional "alternative" newspaper in that it mixes arts, culture, music, film and entertainment coverage and listings with news stories and 
features that in many instances are unabashedly biased (Barnes, 1999). As Barnes (1999) suggested: "The Chronicle resembles an entertainment guide with some political coverage" (p. 83). The tabloid-sized paper averages roughly 100 pages a week and attracts a variety of advertisements, although cultural events (particularly music) dominate the back pages. The Chronicle publishes nearly 83,000 papers every Thursday (“Newsweeklies directory,” 2013), but claims a readership of 195,000 (“About,” n.d.). The papers are distributed via 2,000 "drops" (or racks) in coffee shops, convenience stores, bars, restaurants, record outlets, bookstores, and grocery stores.

Early on Barbaro and his group tried to attract investors with a five-year business plan, but they “didn't get any nibbles." They struggled for the first two years, relying on $\$ 80,000$ of family funds to stay in business. As it turns out, using family money and failing to recruit investors meant The Chronicle avoided loading up on debt to foster growth. Most alternative weeklies and big newspaper chains, Barbaro observed, have been hurting financially because their model is to buy a newspaper and then return revenue to the "mother ship," or investors or the bank. The Chronicle never had a bank loan until it bought a building in the 1990s.

The Austin Chronicle is also well-known for launching the South by Southwest (SXSW) festival. The first SXSW was a four-day music festival held in 1987 . The event has since grown into a 10-day event focusing on music, film, and interactive communication. SXSW attracts more than 16,000 people to Austin and is said to be worth $\$ 147$ million to the local economy (Jones, 2013). Barbaro and Black own part of SXSW but it is treated as a separate entity. Nevertheless, the success of this internationally recognized cultural event has made Barbaro and Black financially secure, 
allowing the two to withstand revenue peaks and valleys at their newspaper. Beginning around 2004-2005 The Chronicle experienced a "painful period and that was our adjustment," Barbaro said. He and Black eventually decided "it really is time to make it not lose money for a while."

\section{1.b The Villager}

Also a weekly, The Villager has focused on Austin's African-American community for 40 years. (Appendix 7). Tommy Wyatt, the publisher and owner, had no newspaper experience when he launched The Villager in 1973. He worked in the insurance industry, became active in the community and was a regular reader of the Capital City Argus, a newspaper that also targeted Austin's African-American community but closed its doors in 1969 (“About Capital City Argus,” n.d.). When Wyatt arrived in the 1960s he said he didn't know what was going on. "My biggest educational piece was the weekly newspaper," he said, adding he waited every week to pay 25 cents for the Argus (personal interview, May 23, 2013).

In 1971, Wyatt had an insurance office east of Interstate 35 in Austin where $12^{\text {th }}$ Street was paved, the side roads were not. Wyatt and others recognized that the county commissioner could get those roads paved so he ran for public office. He didn't win. "I blamed the fact that I didn't win that I could not communicate with this community" because the Capital City Argus was no longer in business. He said he was unable to help educate African-American voters in the area that the county commissioner could directly impact their lives. "That's when it became crystal clear that we needed a communication vehicle in the community," Wyatt said, "and that's when we set out to start a newspaper." At first, however, Wyatt's support network of friends, colleagues, and political activists 
were not positive he could make the newspaper work without a circulation of 10,000 to 20,000 papers. "How could I put it?” said Wyatt, recalling their reaction: “"That was a dumb idea." Despite being warned off the adventure, like Barbaro at The Austin Chronicle, Wyatt decided to get into the newspaper business.

Forty years later The Villager is still a small, humble operation: Wyatt is the publisher and editor, his son Thomas Wyatt is the assistant editor and Web master, and his granddaughter, Angela Wyatt, is the executive business operations manager. The broadsheet-sized paper averages about eight pages per week. Approximately 6,000 copies are published on Fridays and distributed via 150 “drops” primarily in East Austin, where African-Americans have traditionally resided in the Texas capital (Herrick, 2008), as well as in some southern and northern sections of the city. Advertisements found in The Villager range from church announcements, motor vehicles and public bodies such as the Travis County Housing Authority, the Texas Lottery, and City of Austin. In some respects The Villager is not a traditional newspaper. For example, Wyatt's column appears on the front page instead of on an opinion page.

There was no doubt, Wyatt said, that The Villager would be a free newspaper. He researched other newspapers' operations and decided, like Barbaro and his colleagues at The Chronicle, that it was too costly to set up a distribution system to support subscriptions, street sales and in-store purchases. In addition, Wyatt's research showed African Americans were less likely to subscribe to a local daily. ${ }^{3}$

\footnotetext{
${ }^{3}$ Austin had an afternoon daily, The Statesman, and a morning paper, The American, until November 1973 when the owners, Newspapers Incorporated, combined the two papers into a morning newspaper, The American-Statesman. Bishop, C. \& Schroeter, R. L. (2013, May 24). Austin American-Statesman, Handbook of Texas Online. Retrieved from http://www .tshaonline.org/handbook/online/articles/eea11.
} 
Wyatt has a degree in business administration and cheerfully admits he learned the newspaper business by looking over the shoulders of local professionals and University of Texas Austin journalism students that he had hired. The Villager was an investment, but he also saw the newspaper as "a community need. It wasn't like I got this great vision. Being active in the community, you find out what the missing pieces are."

\section{1.c Briefing}

Briefing was launched in 2008 as an attempt to attract former readers of The Dallas Morning News who no longer wanted to pay for a newspaper, said Richard Alfano, group publisher and general manager of niche publications at DMN Media. "They just were objecting to paying ever-increasing pricing for it," he said, referring to The Morning News (personal interview, July 9, 2013). Every year a percentage of readers wouldn't renew their subscriptions, despite DMN Media's attempts to lure them back. “They aren't going to pay for a newspaper anymore," Alfano said.

Interviews with former readers, however, showed DMN Media that "people wanted the news," but they were very busy, Alfano said. The result was Briefing, an abbreviated and free version of The Dallas Morning News. (Appendix 8). The broadsheet Briefing publishes almost 100\% "re-purposed content" that an editor and five copy editors pull from The Morning News in "an organized fashion," according to Alfano. The newspaper is delivered to homes from Wednesday to Saturday. It is one piece of a multimedia strategy — print and digital, news and marketing — that DMN Media has pursued to lessen its reliance on print advertising revenue. "We have a kind of mixed 
bag," joked Alfano, although he is extremely proud of DMN Media's stable of products. Each of the newspapers and magazines operated by DMN Media file separate "profit and loss" reports, and even though the publications are not $100 \%$ at arm's length from the flagship newspaper, "we look at it as a standalone," said Alfano.

\section{1.d The Leader}

Houston, the fourth largest city in the United States by population - after New York City, Chicago and Los Angeles (“About Houston,” 2013) - has a crowded newspaper market. The Houston Chronicle, the paid daily, claims 950,000 daily readers and 1.5 million on Sundays ("Houston Chronicle," n.d.). The alternative weekly, the Houston Press, reports a monthly readership of nearly 634,500 (“Advertise [a],” n.d.). Houston Community Newspapers publishes 28 papers, including 22 free weeklies, in the area. Numerous other newspapers focus on specific religious and ethnic communities within the Houston metropolis ("Houston newspapers and news media," n.d.).

The north and northwest neighborhoods of Houston are also home to The Leader, an independently-owned newspaper that distributes nearly 34,000 papers every week. (Appendix 9). Jonathan McElvy purchased The Leader in July 2012 with financial assistance from his father and brother (they have minor stakes in the company). McElvy may only be in his early $40 \mathrm{~s}$, but he is a newspaper veteran. He was a general manager at the age of 26 and a publisher by 27. Prior to buying The Leader in an all-cash deal, McElvy was the former editorial vice-president for ASP Westward ("Jonathan McElvy," 
2012), a group that owned the Houston Community Newspapers (HCN) before that chain was purchased in August 2012 by 10/13 Communications (Spring Observer, 2012).

Not unlike Barbaro and Wyatt, McElvy said he was considered a little wacky for taking on the role of owner and publisher of a newspaper. He was asked: “'Why didn't I buy a Subway?"' (personal interview, July 8,2013 ). This question still gets a chuckle out of McElvy, who has an infectious enthusiasm for the future of newspapers. Newspapers have survived the advent of radio and television (or, as McElvy called them, "disruptions one and two"), but as a student of media history, he is fully aware that he is now responsible for an "old technology" in a new media environment.

"Along came our third major disruption, that was the Web, and now we are dead," said McElvy, mocking the fear that newspapers will perish in the digitally dominated twenty-first century. "Not only can you hear it and see it," he said about the Web, "you can read it." But instead of newspaper decision-makers asking, "What we can do?", newspapers tried to become websites. "Literally, our industry has fallen over its heals for five years trying to become this," said McElvy, pointing to his laptop with a look of disbelief. "We took our old business model and shoved it into a new technology." Additionally, newspapers were used to making $30 \%$ to $40 \%$ profit margins and to save those fantastic profits "they cut all the journalists."

This short history lesson from McElvy was his roundabout way of answering the question of why he bought a newspaper: "I just kind of felt like it was time to shit or get off the pot." He said he could have stayed with the HCN's new owners, 10/13 
Communications, but they wanted him to cut half of their journalists. "How long is that going to last?" he asked. "My philosophy was pretty simple: I'm going to give you something to read."

\subsection{Web-Based Survey}

A Web-based survey offers a number of advantages. It can be low-cost, fast, efficient, contingency questions can be effective, data entry is not difficult, and it can be completed fairly quickly compared to a mail version (Sue \& Ritter, 2012; Stephenson \& Crête, 2011; Descombe, 2009). Of importance for this study, a Web-based survey is more efficient in terms of cost, the time it takes to execute, and covering a wide geographic area (Sue \& Ritter, 2012). Decision-makers at free newspapers are spread across the United States, making the Web-based survey a valuable tool. Along with speed, economy, convenience, simplicity and the ability to cover a vast geography, a researcher can also accurately target an audience while guaranteeing confidentiality (Sue \& Ritter, 2012). Disadvantages of a Web-based survey include the possibility that the email invitation to take the survey may be considered unsolicited or spam, or indeed may not be answered at all (Poindexter \& McCombs, 2000). As will be explained below, measures were taken to target as best as possible people with, hopefully, a vested interest in taking part in a Web-based survey about their industry.

Decision-makers at free newspapers - ie., publishers, executives, advertising managers, and editors - in the United States were asked to take a Web-based survey designed to gauge the economic health of, and prospects for, their newspaper or papers 
and the industry overall. The survey, which may be the first to focus solely on decisionmakers at free newspapers, contained 52 questions that were a mix of open-ended and multiple-choice. (Appendix 10). Questions ranged from general queries into how the respondent's newspaper is delivered and how circulation is verified to more specific questions that targeted advertising revenue and whether the newspaper is profitable. Qualtrics hosted the Web-based survey. It was launched April 12, 2013 and closed May $11,2013$.

What follows are the Web-based survey questions designed to help answer the seven Research Questions. To answer RQ1 (How has advertising revenue and circulation changed, or not, at free newspapers from 2011 to 2012?) the following questions were asked: "Within your geographic market, who are your print competitors?"; "Compared to 2011, advertising revenue in 2012 has. .."; "Please estimate by percentage how much advertising revenue increased in 2012 compared to 2011"; "Please estimate by percentage how much advertising revenue decreased in 2012 compared to 2011”; “Compared to 2011, would you say circulation in 2012 has ..."; "Please estimate by percentage how much circulation increased in 2012 compared to 2011"; and, "Please estimate by percentage how much circulation decreased in 2012 compared to 2011."

To answer RQ2 (Given the fluctuations in advertising revenues, are executives at free newspapers adjusting their business model to seek a variety of sources of revenue?), the following questions were asked: "Has your newspaper sought alternative sources of revenue?"; "Does your newspaper have a website?"; “Are there any fees associated with 
accessing content on your website?"; "Would your newspaper consider implementing a fee for online access?”; "Would your newspaper consider implementing a cover price?"; and, "Is your free newspaper affiliated with a paid newspaper?"

To answer RQ3 (Are sales representatives at free newspapers selling both platforms, online and print, or are they focused on one platform only?), the following questions were asked: "Regarding total advertising revenue, estimate by percentage how much is generated by the online edition?"; and, "Regarding your advertising sales staff, are their duties specific to the print and online editions?"

To answer RQ4 (How do the sources and types of advertisements differ between the online and print editions at free newspapers?), the following questions were asked: "What types of advertisements (approximate by percentage) account for online advertising revenue in 2012?"; "What types of advertisements (approximate by percentage) account for print advertising revenue in 2012?"; "Please estimate by percentage how much of your online revenue came from the following sources in 2012?"; and, "What percentage of your total print advertising revenue came from the following geographic sources in 2012?”

To answer RQ5 (To what extent do free newspapers invest in editorial content?), the following questions were asked: "What is the approximate percentage of space in your newspaper devoted to advertising and editorial content?"; "Do you believe readers are more 'engaged' in a paid newspaper because they had to pay for it?"; and, "Do you think free newspapers have an advantage over paid-subscription competitors?" 
To answer RQ6 (To what extent do free newspapers believe they have a relative advantage over paid newspapers?), the following questions were asked: "What is the approximate percentage of space in your newspaper devoted to advertising and editorial content?"; "Do you think free newspapers have an advantage over paid-subscription competitors?"; "Please expand on your answer to the previous question regarding free newspapers versus paid newspapers"; "Do you believe readers are more 'engaged' in a paid newspaper because they had to pay for it?"; and, "Please expand on your answer to the previous question regarding reader engagement."

To answer RQ7 (To what extent are executives at free newspapers optimistic or pessimistic about the future of free newspapers?), the following questions were asked: "Do you think free newspapers have an advantage over paid-subscription competitors?"; "Please expand on your answer to the previous question regarding free newspapers versus paid newspapers"; "Regarding the future for your newspaper, are you ...?"; "Please expand on your view of your newspaper's future"; "Do you disagree or agree with the assertion that it is only a matter of time before newspapers are an online-only news outlet?"; and, "Please expand on your answer to the previous question regarding whether it is only a matter of time before newspapers are online-only."

\section{2.a Sample}

The primary source for the list of potential survey respondents was the 2012 Editor \& Publisher International Newspaper Data Book, Book 2: Weeklies (Fleming, 2012b). Section 1 of the data book was checked for newspapers published in the United 
States that fit Editor \& Publisher's definition of a free newspaper: 5\% or less of a newspaper's circulation is paid and 95\% is free. ${ }^{4}$ This process yielded 1,269 titles. Other sources were then consulted to broaden the sample of free newspapers, groups such as the Association of Alternative Newsmedia, the blog Free-Daily.com, the Independent Free Papers of America, the Association of Free Community Newspapers. Web searches also helped discover a handful of free newspapers like the Coachella Valley Independent. A so-called "master list" was created where information on 1,397 free newspapers was stored, information such as contact persons, circulation, publication schedule, city and state listed for the newspaper. The goal was to create a census, or at least a means of reaching as many free newspapers in the United States as possible.

In compiling this master list it became apparent that editing was necessary to ensure a more accurate sample while also eliminating duplication. For example, $C \& G$ Newspapers operates 19 newspapers in Michigan (“Advertising information,” n.d.). It was deemed counterproductive to send one decision-maker at $\mathrm{C} \& \mathrm{G} 19$ email invitations to participate in the Web-based survey. In addition, websites were consulted to verify, or in some cases correct, respondents' email addresses, resulting in the refinement of contacts for possible participants and the exclusion of others. In the end, the master list of nearly 1,400 free newspapers was reduced to 714 decision-makers representing 1,264 newspapers.

\footnotetext{
${ }^{4}$ See p. ix, note below graph titled, "Circulation of U.S. Community Weekly Newspapers by Circulation Groups", 2012 Editor \& Publisher International Newspaper Data Book, Book 2: Weeklies.
} 


\section{2.b Data Collected}

An invitation to participate in the Web-based survey was emailed to these 714 decision-makers on April 12, 2013. This email (Appendix 11) introduced the author of this dissertation, explained why they, as decision-makers at free newspapers, were being asked to take part in the survey, and offered contact information for the author and Dr. Iris Chyi, who oversaw the project. This email also contained a link to the survey's opening page (Appendix 12) where the University of Texas at Austin's Institutional Review Board's approval number was displayed, and where the participant was informed that by clicking on the "Next Page" button she or he would be giving consent to participate in the research project. Three prompts asking those who had yet to participate in the Web-based survey were emailed on April 22 (Appendix 13), April 29 (Appendix 14) and May 2, 2013 (Appendix 15).

The response rate was $22.13 \%$, or 158 valid responses from 714 initial email invitations. The total of 158 responses was reached after 46 responses were excluded courtesy of filter questions designed to weed out respondents who either represented a paid newspaper or a shopper, or simply failed to take the survey. Although the final sample may be considered small and not close to a census of decision-makers at free newspapers, the response rate is encouraging considering the response rate for surveys "has fallen dramatically" in the past 15 years (Kohut et al., 2012,p. 1). For a typical telephone survey in 1997 the response rate was 36\%. By 2012 it was $9 \%$. Single digit response rates for Web-based surveys are not uncommon (Baker, 2005). 
Data generated by the Web-based survey was analyzed using SPSS software.

Text responses generated by the Web-based survey were analyzed qualitatively for common themes and differences. 


\section{Chapter 4: Results}

An overview of free newspapers based on data provided by decision-makers who completed the Web-based survey will be presented first, followed by results that address the seven research questions. Each section focusing on a research question will start with data from the Web-based survey, followed by text answers by survey respondents when they are applicable to the research question, and then by comments from the four elite interviews. An "overview” concludes each section by recapping the results and, where applicable, comparing and contrasting results generated by the Web-based survey and the elite interviews.

\subsection{General Results}

One-third of respondents to the online survey represent "alternative" newspapers. The "tabloid" page size format is used by $74 \%$ of the free newspapers, $24 \%$ are "broadsheet" papers and 3\% are "other." Regarding the average size of these newspapers in terms of pages per issue, $38 \%$ said they are 24 pages or less, $36 \%$ from 25 to 48 pages, $20 \%$ are between 49 to 72 pages, $4 \%$ publish from 73 to 96 pages, and $1 \%$ have an average page count per issue of between 97 to 120 pages.

Free newspapers face competition from both free and paid publications. The majority of survey respondents (79\%) compete against a paid-subscription daily newspaper, $38 \%$ against a paid-subscription weekly or monthly newspaper, $29 \%$ against a paid magazine. In addition, $62 \%$ of respondents report competing against a free weekly 
or monthly newspaper, 53\% against a free magazine, and $9 \%$ against a free daily newspaper.

The vast majority (84\%) are weeklies, publishing one day a week. Five percent of the free papers are distributed two days a week, $4 \%$ appear twice a month, $3 \%$ once a month and $1 \%$ publish six days a week.

The approximate circulation per issue of the free newspapers under study here ranges from 2,001 to 150,000 and higher. Nearly one-third of Web-based survey respondents (31\%) report a circulation from 5,001 to $20,000,28 \%$ distribute 20,001 to 35,000 , and $16 \%$ have a circulation in the 35,001 to 50,000 range. A circulation of 65,001 to 80,000 papers per issue was reported by $8 \%$, while another $8 \%$ publish 50,001 to 65,000 papers. At the higher end of the circulation scale, $3 \%$ have an approximate circulation per issue of 150,001 or more, while $1 \%$ report a range of 95,001 to 110,000 and another $1 \%$ of a circulation of 125,001 to 150,000 .

More than one-third (34\%) of the free newspapers serve a "metropolitan area," $24 \%$ a "small city," $10 \%$ a "rural area," and $6 \%$ cover a "rural town." The "other" category accounted for $25 \%$ of the responses. A majority of the respondents, in a text explanation of what "other" may mean, said "suburban."5

\footnotetext{
5 This may indicate that "suburban" could have been a category for respondents, or that the category "metropolitan area" should have been defined more clearly.
} 
It appears free newspapers employ a combination of distribution methods. "Store racks" were used by $76 \%$ of respondents, $58 \%$ had "street boxes," $48 \%$ have a home delivery system, and $41 \%$ used the postal service to deliver their newspapers.

In terms of average age of readership, $43 \%$ estimated the ages are between 46 to $55,30 \%$ suggested the average age is 36 to $45,8 \%$ estimated an age range of 56 to 65 , while $7 \%$ said the age range was 26 to 35 . Ten percent said they did not know while no respondents claimed readers under the age of 25 .

Regarding approximations of how many people are employed at these free newspapers, $30 \%$ of respondents said they have one to 10 people on staff, $27 \%$ have 11 to 20 people, $15 \%$ have a staff of 21 to 30 employees, and $11 \%$ said their newspaper employs approximately 31 to 40 people. Five percent of respondents reported a staff of 51 to $60,3 \%$ said they employ 41 to 50 people, another $3 \%$ said 91 to 100 , a further $3 \%$ replied 101 or more, while $2 \%$ said their staff ranges between 71 to 80 people.

The majority of these free newspapers (65\%) are "independent/family-owned" operations, $28 \%$ are part of a "privately-owned group," and 7\% are part of a "publiclytraded group."

Regarding free newspapers' profitability and the Web-based survey question that starts "In 2012, your newspaper ..." 67\% of respondents finished the sentence by saying they were profitable, $22 \%$ said they "more or less broke even," $10 \%$ indicated they lost money in 2012, while 1\% said they did not know. (See Table 3). Regarding 2013, 73\% of respondents to the Web-based survey question that begins "In 2013, your newspaper 
anticipates ..." anticipate making a profit, $21 \%$ say they expect to break even, $4 \%$ said they did not know, and 2\% anticipate losing money. (See Table 4).

Table 3 Profitability of Free Newspapers in 2012

$\begin{array}{lc}\text { Answer } & \text { Percent } \\ \text { Made a profit } & 67 \\ \text { More or less broke even } & 22 \\ \text { Lost money } & 10 \\ \text { Don't know } & 1 \\ \text { Total } & 100 \\ \text { (Valid cases) } & (127)\end{array}$

Table 4 Free Newspapers' Anticipated Profitability in 2013

Answer

Making a profit

Breaking even

Don't know

Losing money

Total

(Valid cases)
Percent

73

21

4

2

100

(126)

\section{1.a General Overview}

The Web-based survey results suggest a general picture of free newspapers in the United States. The majority of respondents, roughly two-thirds, would not call their newspapers "alternative" thereby suggesting they are more traditional in their news 
coverage. Free newspapers can be found mostly in a "metropolitan area" or a "small city," they prefer the tabloid-sized format, they overwhelmingly (85\%) publish once a week, the majority (65\%) are independent or family-owned and have been so for 31 years or more, say $30 \%$ of respondents. The average page size per issue is 48 pages or less while the approximate circulation ranges from 5,001 to 50,000. The majority of these newspapers have a staff that may be one person or up to 30 . The average age of the readership is from 36 to 55 .

\subsection{Research Question 1: Financial Well-being of Free Newspapers \\ 4.2.a Research Question 1: Web-based Survey Results}

Regarding RQ1 - How has advertising revenue and circulation changed, or not, at free newspapers? - Web-based survey results show advertising revenue has more or less stayed the same from 2011 to 2012 for $41 \%$ of the newspapers. Respondents to the question that starts "Compared to 2011, advertising revenue in 2012 has . .." also replied advertising revenue either increased (32\%) or decreased (27\%). (See Table 5). This suggests that while advertising revenue continues to contract for major newspapers (“Advertising expenditures," n.d.), only $27 \%$ of survey respondents at free newspapers reported a decline in advertising revenue. In other words, advertising revenue either grew or remained constant from 2011 to 2012 for more than two-thirds of the newspapers represented in this sample. However, the revenue news was also mixed. For those respondents who reported an increase in advertising revenue from 2011 to 2012, the average increase was $10 \%$. For those who said ad revenue fell, the average decline was 
$14 \%$, indicating that in some markets revenue shortfalls are steeper than revenue increases.

Table 5 Advertising Revenue at Free Newspapers in 2012 Compared to 2011

Answer

Stayed more or less the same

Increased

Decreased

Total

(Valid cases)
Percent

41

32

27

100

(142)

A similar pattern emerges for circulation numbers: it was either the status quo or an improvement in circulation for the majority of respondents, but when circulation decreased the drop was fairly significant. Web-based survey participants were asked to respond to the question that starts "Compared to 2011, would you say circulation in 2012 has ..." Circulation remained constant in 2012 for $66 \%$ of respondents while $23 \%$ said circulation increased, and 11\% said circulation had decreased in 2012 compared to 2011. (See Table 6). For those who said circulation climbed from 2011 to 2012 the average increase was nearly $11 \%$, and for those who said circulation decreased the average decline was $18 \%$. 
Table 6 Free Newspapers' Circulation in 2012 Compared to 2011

Answer

Stayed the same

Increased

Decreased

Total

(Valid cases)
Percent

66

23

11

100

(142)

\section{2.b Research Question 1: Elite Interview Results}

Advertising revenue appears to be steady, if not growing, at four different types of free newspapers in Texas. Two publishers - Nick Barbaro at The Austin Chronicle and Tommy Wyatt at The Villager - were reluctant to offer specifics about advertising revenue changes in the past year at their respective newspapers, but both men said they're doing fine financially.

Wyatt said advertising revenue at The Villager had been "been pretty level" before 2012 when they started receiving full-page automotive advertising courtesy of a national deal negotiated by the National Newspaper Publishers Association, a group that includes approximately 200 Black newspapers across the United States. Ad revenue in 2012 "went up a little bit with the inclusion of the car ads," he said.

When asked if he minded telling his interviewer how much revenue The Villager generated in 2012, Wyatt smiled and responded: "Yeah." He politely left no doubt that he had no intention of offering specific information. "We are profitable," said the publisher, adding with a chuckle: "We are not getting rich." 
Nick Barbaro was also somewhat reticent about sharing specifics on advertising revenue at The Chronicle and, he admitted, he wasn't necessarily aware of precise numbers because he is not as closely involved with sales as other publishers might be. Nevertheless, he allowed that The Chronicle went through "a couple of really tough years" before they streamlined the operation and are now at the break-even point.

"We're more or less breaking even over the last year-and-a-half, two years," said Barbaro, adding The Chronicle started losing money around 2008-2009, around the time when the United States faced an economic recession. "We were making money before that so we had enough put away to afford to lose money for, I don't know what it was, two or three years."

Jonathan McElvy at The Leader in Houston and Richard Alfano at Briefing in Dallas revealed actual, if general, numbers regarding advertising revenue. These two newspaper executives were naturally pleased to report that their respective operations were doing exceptionally well in terms of generating advertising revenue, although they have different business models.

Advertising revenue at The Leader is expected to increase by $28 \%$ from 2012 to 2013. McElvy said revenue was $\$ 840,000$ in 2012 and he was very confident that it would reach $\$ 1.03$ million in 2013. In 2012, The Leader lost $\$ 40,000$ and it stands to make around $\$ 95,000$ in 2013 , a profit that includes paying the publisher a salary of $\$ 50,000$, which McElvy originally hadn't planned on doing in the first year of his ownership. 
"I believe The Leader can do $\$ 2$ million in revenue in two years," said a confident McElvy. He estimates there are roughly 5,000 businesses in the area of northwest Houston that the newspaper covers, but The Leader's sales staff (five people and an advertising director who was hired in July 2013) are maybe hitting only 100 of them.

The Leader receives some national advertising but it mostly features real estate, banking, insurance, hospitals, and service ads (plumbers, arborists, landscapers, painters and small construction firms) advertisements. Service advertising is a growth area for The Leader, McElvy explained, because Houston has been experiencing a mini boom in house remodeling. "If you think about newspapers today, $90 \%$ of the advertising is service, at least in community newspapers," he said. McElvy was referring to the reality that not only is a reader more likely to see a Macy's full page ad in the Houston Chronicle than in The Leader, that reader is also more likely to see the services of a plumber or arborist offered in The Leader than in the Houston Chronicle where the cost to advertise is more prohibitive for small, local businesses.

This differentiation in type of ads that community newspapers attract versus regional or metro dailies is fine with McElvy, who enjoys creating sayings that capture the spirit of The Leader's operation. "We major in the minors," said the publisher, meaning his newspaper will take all the small ads they can sell. "We want to build this with bricks not big slabs of concrete. You punch one slab of concrete right in the middle and it falls apart. You punch one brick out and there's a hundred bricks around to support it. It's a lot easier to lose one small one." 
In Dallas, Briefing "is the biggest revenue producer and profit producer" of all the publications in the DMN Media roster, according to Richard Alfona, group publisher and general manager of Briefing, neighborsgo, and FD Luxe. While he declined to be specific, Alfona said Briefing generates between $\$ 10$ million to $\$ 20$ million revenue a year and a whopping $48 \%$ profit margin for DMN Media. Jim Moroney III, publisher and chief executive officer of The Dallas Morning News, said in 2011 that Briefing was expected to generate approximately $\$ 15$ million in revenue that year (Tennant, 2011).

Alfona is quick to acknowledge that Briefing's cost structure is different from other free newspapers. It does not have a dedicated sales staff and while it has a sixperson editorial team, Briefing does not pay reporters to cover news and events. The DMN Media sales staff works for all eight of its publications, while the Briefing editorial team pulls stories from its sister publications (primarily The Dallas Morning News) that are deemed to be relevant to the Briefing readership.

Briefing must deal with distribution costs and it is treated as a separate business within DMN Media, but Alfano recognized that Briefing "is so profitable" in large part because of its unique infrastructure. Nevertheless, the four-times-a-week publication is "a $100 \%$ advertising-driven business model" that is attracting a substantial amount of ads and inserts, the latter being one of the biggest revenue producers for Briefing. Alfano also said Briefing is purposely a broadsheet, the same page size as The Dallas Morning News, so ads do not have to be re-formatted to run in both papers, a labor-saving tactic. 


\section{2.c Research Question 1: Overview}

A crucial finding from the Web-based survey is that the free newspaper business is still very vibrant and competitive. Advertising revenue from 2011 to 2012 increased for $32 \%$ of the respondents, or stayed the same for $41 \%$, while circulation increased for $23 \%$ and stayed the same for $66 \%$. This could be considered impressive considering free newspapers report facing competition from an assortment of free and paid newspapers and magazines in their geographic market.

These results are borne out, for the most part, by the elite interview subjects. Although two Austin, Texas, publishers, Tommy Wyatt at The Villager and Nick Barbaro at The Austin Chronicle, were reluctant to provide specifics they insist advertising revenue held steady from 2011 to 2012. The other two publishers, Jonathan McElvy at The Leader in Houston and Richard Alfona at Briefing in Dallas, report advertising revenue had definitely increased from 2011 to 2012. As noted above, Briefing is unique compared to other free newspapers because it does not directly bear the costs of maintaining a fleet of reporters and photographers, instead culling its content from its sister publications, primarily The Dallas Morning News, and other news services. However, with revenues between $\$ 10$ million to $\$ 20$ million and a profit margin of $48 \%$, it is possible that Briefing could withstand the costs of hiring its own reporters. In Houston, The Leader is an example of a suburban or community newspaper that does not have a large news staff (one editor, one freelance reporter and a collection of freelance columnists) but may be able to expand coverage of the community given the newspaper 
made a humble profit in 2012 (roughly $\$ 95,000$ ), and the publisher is confident advertising revenues could increase as much as $28 \%$ in 2013 over 2012 .

\subsection{Research Question 2: Revamp the Business Model?}

\section{3.a Research Question 2: Web-based Survey Results}

The second research question - Given the fluctuations in advertising revenues, are executives at free newspapers adjusting their business model to seek a variety of sources of revenue? - was an attempt to determine if survey respondents and the four interview subjects were not only trying to generate revenue from their websites but also from alternative sources than the ads that appeared in their newsprint. In essence, were they hedging their bets against the seemingly severe demise of advertising revenue?

Survey respondents are targeting typical revenue sources for newspapers, such as selling ads for a special section within the newspaper, or producing a separate, one-topic publication, golf or travel for example, that does not compete with the flagship newspaper in terms of content. It also appears atypical revenue sources are being embraced but perhaps not as aggressively as traditional sources of advertising revenue. Web-based survey respondents were asked to check all that apply, or say "No," to the question, "Has your newspaper sought alternative sources of revenue?" Nearly threequarters of respondents (73\%) report pursuing special advertising sections within the flagship paper and $34 \%$ answered they have produced a separate publication. Regarding atypical, or alternative, revenue sources, $36 \%$ report having sponsored or hosted events and $12 \%$ report offering local businesses marketing consultations. "Other" was answered 
by $18 \%, 5 \%$ have sold E-books and another $5 \%$ said they were not seeking alternative sources of revenue, while $2 \%$ report selling property to raise revenue. (See Table 7).

Table 7 Alternative Sources of Revenue Pursued by Free Newspapers

Answer

Special advertising sections

Sponsoring or hosting events

A publication completely unlike your newspaper

Other

Marketing consultations for local businesses

E-books

No, we have not sought alternative sources of revenue

Selling property

\section{Percent}

73

36

34

18

12

5

5

2

The vast majority, $96.4 \%$, of free newspapers responding to the online survey have a website. However, more than two decades after the launch of the first Web page in the United States (Stainburn, 2013), nearly 4\% of respondents said they do not have a website. Two survey respondents offered comments about why they do not have a website: "Too busy running a newspaper to get involved in things that aren't part of running a newspaper"; and, "We choose to devote maximum time and attention to reporting and developing in-depth content."

An obvious major change in terms of revenue, and business strategy, for a free newspaper would be to no longer give away their content for free. They could start charging readers for access to their online or print content. This attempt at lessening 
reliance on advertising, however, is not a popular business tactic with survey respondents. Web-based survey respondents were asked two questions regarding charging readers: Would they consider implementing a fee for online access?, and, Would their newspaper consider implementing a cover price? More than three-quarters of respondents said they would not be implementing a cover price, compared to $11 \%$ who said they would consider a cover charge. (See Table 8). Although more than half of the respondents $(53 \%)$ said they were not considering an online fee, this number is considerably lower than the $76 \%$ who said they would not charge for their newspaper. In addition, $32 \%$ of respondents said they would consider an online fee, indicating a much stronger interest in some kind of paywall compared to $11 \%$ who replied they might implement a cover charge for their newspaper or papers. Those who did not know if an online fee or cover price is in their future were at $15 \%$ and $13 \%$, respectively.

Table $8 \quad$ Attitudes of Free Newspaper Decision-makers Towards Implementing a Fee to Access Online and Print Content

$\begin{array}{lcc}\text { Answer } & \text { Online Fee (Percent) } & \text { Print Cover Price (Percent) } \\ \text { No } & 53 & 76 \\ \text { Yes } & 32 & 11 \\ \text { Don't Know } & 15 & 13 \\ \text { Total } & 100 & 100 \\ \text { (Valid Cases) } & (125) & (132)\end{array}$


These results suggest a possibility that decision-makers at free newspapers may be more amenable to charging for access to their website but not for access to its newspaper. If this were to happen, decision-makers at free newspapers would find themselves in a similar, but reverse, situation that decision-makers at paid newspapers currently wrestle with. Paid newspapers charge readers a fee for their print product so, the reasoning goes (Chittum, 2013b), why would their online content be free? For free newspapers the question would become: Your print product is free so what is the likelihood that charging for the online version will be a successful strategy?

\section{3.b Research Question 2: Web-based Survey Respondents' Text Answers}

One respondent offered a comment that helps illuminate why some decisionmakers at free newspapers are perhaps considering charging for online access to their content in addition to watching what metropolitan newspaper chains are doing online.

"We are actually about to implement a voluntary subscription in order to let people pay something for the paper," said one respondent.

I feel certain almost all dailies are going to paywalls before much longer. One of the advantages of digital and the ease of phone swiping and electronic purchases is that it will make it more and more simple to charge for a newspaper without having to implement a massive apparatus or coin boxes, etc.

Other respondents who said they may consider implementing a cover price for their paper offered comments that help illustrate that some free newspaper operations are in fact hybrids: both free and paid. "We are free to home delivery, but a paid publication in racks and stacks," reported one respondent. Another said: 
We started a volunteer paid edition to qualify for legal advertising and a postal permit, which we accomplished after one year of publishing. We have approximately 1,200 paid (subscriptions) out of our 31,000 circulation. That number has kept steady, generating a nice revenue stream. We do not mail these paid subscriber copies but deliver along with our free newspaper by carrier.

Many of the survey respondents (there were 86 comments in total) who offered opinions on why they would not alter their business model and implement a cover price echoed common themes. They cited "tradition," that their paper has always been free for decades and you "don't fix what is not broken." A number of respondents also said a cover price would unlikely generate enough revenue to offset the cost of setting up a paid circulation system, whether it be home delivery, coin-operated boxes on the street, store sales or a combination of those possibilities.

Respondents also said suddenly charging customers for a product that had been free would not be a wise business decision, especially in a competitive market.

"Readership would decline dramatically by putting a barrier between us and our readers," said one. "Advertisers want more readers, not fewer." This notion of a cover price being “a barrier" between a newspaper and its audience was reflected in another respondent who said his/her newspaper had been paid at one point and they "would never go back to paid. I don't want a quarter to get between me and my advertiser.” Another respondent did not relish the thought of a reader backlash: "What a battle it would be to get people to pay for what was once free. Our circulation would plummet too.” And of course, a negative adjustment in circulation would impact how much a newspaper can charge for advertising (Chyi \& Tennant, 2013). "I can't figure out how to keep our advertising rates 
at their current level if our circulation dropped significantly," said one decision-maker. "I would guess we couldn't get more than $50 \%$. . of our current distribution to pay for our paper."

One respondent said switching from free to paid is "not a fight worth taking on," but then outlined an exception: "We do intend to make paid subscriptions available behind a paywall through an Internet app." This answer reflects the possibility that charging for online access is more tolerable than charging a reader to pick up the newspaper. Another respondent shared her/his experience with a revenue generator that was also tried by Jonathan McElvy at The Leader in Houston. "We think a free paper should be free," the respondent started. "However, we instituted a voluntary payment system this year where we asked our readers to voluntarily send in a support payment to offset the community news and to help us, in that advertising has been down over the last few years. We had an 18-plus percent return on our request."

Finally, one respondent was succinct in his/her response to the survey question of why not charge a cover price: "The future is free." Despite this declaration, a significant number of free newspapers, $23 \%$, report being affiliated with a paid newspaper. It can be inferred from this result that owners and operators of free and paid newspapers see a benefit in working under the same corporate roof. In a sense, these free and paid papers appear to be hedging their bets by employing two variations of the advertising-based business models instead of relying only on one. 


\section{3.c Research Question 2: Elite Interview Results}

The four Texas newspapers targeted for this study have different approaches to creating alternative sources of revenue, but it is a business strategy all pursue. Again, Briefing is a bit of a different animal in that it is but one title within a major media company that has made a concerted effort in the past few years to diversify its revenue sources while lessening its reliance on print advertising (Tennant, 2011). The advertising sales staff for the eight DMN Media publications, Alfano reports, sell "a portfolio of solutions, not only in print but digital as well." Briefing, then, benefits from being one piece of a large pie of media outlets operated by DMN Media.

The irony, and the result of smart planning, is that Briefing was created to recoup former Dallas Morning News subscribers who were no longer willing to pay to read the news, and yet this free publication is generating a significant amount of advertising revenue for a company that has made it a priority to lessen the importance of advertising revenue. A second free newspaper produced by DMN Media, Al Día, which targets Spanish-speaking readers in the Dallas-Fort Worth market, is the second-best revenue and profit generator for DMN Media after Briefing.

It could be argued that The Villager and The Austin Chronicle were seeking alternative sources of revenue long before this business tactic became increasingly important for newspapers in the past decade or so (Metro SiliconValley, 2013). Tommy Wyatt, publisher of The Villager, and his wife at the time in 1970, launched The Black Registry, an advertising-supported annual directory of services offered by African- 
American businesses and churches, three years before The Villager first appeared. The 2013 edition of The Black Registry, a 32-page booklet (roughly the size of an 8x10 glossy photo), is chock-full of 40 display advertisements and 102 short word listings (business name, address and contact information only) that Wyatt sells for $\$ 30$ each. It is difficult to fully gauge how much net revenue the registry generates, although at $\$ 30$ each the 102 word ads amount to at least $\$ 3,000$. The registry is available for free at The Villager's East Austin office and at businesses that advertise in the booklet. It is also sold for $\$ 3$ at select outlets in the city. The Black Registry is a slick, professional-looking product that must be profitable for Wyatt, an astute businessman who would unlikely support a revenue-losing publication for 43 years. One other possible revenue source - charging for access to The Villager website - is not on Wyatt's to-do list. "It ain’t gonna happen," he said flatly.

The Villager also hosts events, none bigger than its fortieth birthday celebration held at a downtown Austin hotel on May 11, 2013, but Wyatt does not see these gatherings as revenue-generators. "Our events are not designed to raise money," he said. “They are designed to raise visibility of our newspaper. We are saying, 'Hey, we are still here. We are still providing the services that we told you would provide."' Although journalism was not his first profession, Wyatt is a natural salesman and like any good publisher of a newspaper he said he managed to generate a few advertising leads at The Villager's fortieth birthday party. 
On the surface it would seem The Austin Chronicle has created the ultimate alternative source of revenue: the vastly successful South by Southwest (SXSW). The annual event has grown from four days of music featuring 200 bands attended by 700 people in 1987 (Pounds, 2001) to a 10-day conflagration devoted to music, film and interactive media attended by more than 16,000 delegates (Jones, 2013). But The Chronicle and SXSW are separate entities, sharing only a couple of important employees and not revenues. Publisher Nick Barbaro and editor Louis Black own The Chronicle and share ownership of SXSW with others.

"It's really very strange personally helping to run two businesses, one of which is hugely growing and the other is trying," Barbaro said, his voice trailing off as he collected his thoughts. "It's like The Chronicle is the aging grandparent compared to SXSW," he joked. "SXSW has now grown into this multinational behemoth," he suggested before imitating a craggy senior's voice, "and the poor old Chronicle is still getting along okay." However, like a financially secure grandparent who has taken care of his money, The Chronicle's profitable years allowed Barbaro and Black to ride out a period when the newspaper was not making money.

According to Barbaro, the 10-day festival does not support The Chronicle directly although the weekly newspaper certainly benefits from the annual event that overtakes downtown Austin every March, a period when The Chronicle publishes a free daily edition. SXSW is "obviously doing very well, which has afforded us the luxury of sort of being able to carry the paper," Barbaro said. For about eight years up until about 2011, 
Barbaro added, the success of SXSW allowed himself and Black to not pull money out of The Chronicle.

A paywall is unlikely to be a revenue option for The Austin Chronicle. Barbaro is not sold on this business tactic, although he acknowledges the same reality that other newspaper executives have struggled with, including Jim Moroney (Tennant, 2011) at

The Dallas Morning News: how to pay for journalism. Said Barbaro:

The trend I think of more that the journalism industry worries about, is the opposite one, how do you pay journalists anymore? Who is going to pay for the next Watergate investigation, to take a really old example? Enterprise journalism has gotta be paid for somehow. Blogs are not quite the substitute for professional journalism, at least in the eyes of professional journalists. The expectation is that everything is free. I don't think the paywall will hold out against the flood that information must be free. It's an inadequate levee.

Nevertheless, Barbaro is "a little more optimistic about our position vis-à-vis the Internet. We have a reasonably good product out there." He believes The Chronicle has reached a point where its online competitors - the Austin Post (www.austinpost.org/) and the Austinist (austinist.com/) — "are in worse shape than we are because we have the paper to fall back on and they still don't have any revenue model. And if they come up with one we can copy it."

Barbaro is not opposed to the possibility of charging for online access, but he's not sure what that business model will look like.

The theory (when The Chronicle started in 1981) was if people wanted to read what we were producing then we would figure out some way that somebody would pay us for this. And then that's where we are again with the website. If we can keep traffic up and people are responding to what we are doing, and we are in no different boat than The New York Times on this, then at some point in the future if people want this product somebody is going to have to figure out what 
the structure is that somebody is going to pay for this product and what is produced. All journalism is in that boat.

He added that many a newspaper is waiting for the successful online business model to surface. "In a certain sense, we are treading water," he said, not sounding as optimistic as he was earlier in the interview. Or perhaps he was just being realistic. "I don't think anybody has a model for making money online," he said, noting exceptions like Google, Yahoo, or The New York Times. "Everybody is still looking for a model."

When asked if charging a cover price could be in The Chronicle's future, Barbaro was certain that option was not on the table. "I can't imagine we would ever do that," he replied. The same issues, such as establishing the infrastructure to sell newspapers, would still exist as they did in 1981 when The Chronicle first appeared every two weeks as a free product. Barbaro said the founders "had a little bit of a debate" about whether charging a cover price was the way to go. "It was an easier decision at that point" because the neophyte journalists didn't have to build the infrastructure to support a paid product. One argument for charging, Barbaro recalled, was to "make people prove that they really want this thing by paying, even if it's a penny for it." He understands that sentiment, but "I think that argument is over." They now have approximately 2,000 drops and would have to negotiate contracts to cover each location. "Then how many papers would we actually sell? I'm not sure."

Barbaro doesn't see any upside to switching to a paid product. Nobody makes money from subscriptions or sales, he said. "We would still have to make all our money from advertising and our advertisers wouldn't be getting as good a deal as they do now." 
The Chronicle can get 80,000 papers in readers' hands, numbers they pay companies to verify and share with advertisers. For Barbaro, analyses by companies like The Media Audit and Verified Audit Circulation (VAC) are a necessary part of the business, but he believes relevance with readers "comes down to gut perception" and feeling.

I think any number of those statistical sheets don't mean as much as the owner of the place just saw someone walking out their place with a Chronicle. We're still doing okay in that test. People still do read the paper.

Jonathan McElvy, publisher of The Leader in Houston, has spent most of his newspaper career at paid newspapers. If The Leader was a subscription/sales paper when he bought it, McElvy said he "would quickly go in and make it free distribution." At its peak, he noted, circulation accounted for about $10 \%$ of total revenue in the newspaper industry, and he's seen that number as low as 7\%. In other words, as Barbaro suggested, switching from free to paid doesn't make economic sense unless, McElvy admits, he could still charge advertisers the same rates even though his circulation might drop from its current level of nearly 34,000 to perhaps 5,000.

McElvy points to his former employer Houston Community News as an example of how some newspaper companies are cutting expenses to stay profitable. He estimates this chain of more than 28 community newspapers in the Houston area lost roughly $\$ 250,000$ in ad revenue in January 2013, but reached its budget targets by cutting costs. "You can't cut your way to business success," McElvy insisted. "And that's what you're seeing across the industry." 
He has experimented with the voluntary payment method, where a newspaper asks readers to contribute as much as they like to the paper. This is an old revenue generator for newspapers (Brandsberg, 1969), although it is more closely associated with the PBS- or community radio-model whereby fundraising drives are held once or twice a year. The Leader sent out a request letter in December 2012 - the best time to try this, McElvy said, because people are in a giving spirit. The publisher adopted a unique angle, telling readers that The Leader has been delivering community news and information for 58 years and if readers contributed, $25 \%$ of their donation would go to the newspaper's carriers as a Christmas holiday tip. McElvy also told readers that depending on the level of donations received, the newspaper would look into hiring another reporter. The Leader received $\$ 25,000$ in donations within a month, including one check for $\$ 1,000$, and a handful more for $\$ 500$ each.

"You talk about the most humbling experience," McElvy recalled. "And somebody tells me that papers don't matter? They matter to somebody." He maintained they received many donations from 30-year-olds, a demographic that is apparently losing interest in newspapers (Edmonds, R., Guskin, E., Mitchell, A., \& Jurkowitz, M., 2013). The positive feedback from readers also caught McElvy off-guard. "I had no idea," he said, citing comments such as, "'You know how to put out a good product,"” and, "'You know how to run a paper.",

In addition to the voluntary payment effort, McElvy is planning to organize a music festival in 2014, expanding on a successful networking event The Leader hosted in 
2013. He is also considering organizing free events that feature speakers on specific topics, such as health care. "It's all content about local businesses," said McElvy. He said the first phase of his "master plan" was to report on small business issues in a special section while also selling six-month contracts for ads. The second phase, starting in 2014, would be holding an event focused on an issue. McElvy said The Leader hosted a free "business leaders network" event that attracted representatives from 40 Houston businesses despite a rainstorm. The publisher said he was shocked by the interest in the first event. "I don't know if it'll work but I'm gonna fail fast and I'm gonna fail cheap if I do it." The keys are to offer a service for free and bring people together. He says he tells local business owners and managers, "If you're successful as a small business, we're going to be successful."

McElvy is less bullish on secondary print products like special sections, or at least as produced by the previous management at The Leader. Shortly after purchasing the operation in 2012, The Leader published a "God Bless America" page where ads were sold for \$50 each. "So what are you telling me? If you're not on that page you're a Commie?" the publisher asked. "It does nothing to promote the business. The advertiser loses totally in that." The only gain, McElvy added, is The Leader receiving an easy $\$ 50$. "You get addicted to special sections," he lamented.

McElvy's solution was to move away from special sections that appeared almost every second week and create a monthly "B section" that, not unlike the free events outlined above, focuses on topics such as small business, health care, real estate, and 
young families. "We are part of a huge media out there," he said, "and we gotta find our niche."

\section{3.d Research Question 2: Overview}

Regarding efforts to lessen the reliance on advertising as the dominant source of revenue, or even abandoning the free business model altogether in order to generate revenue from a cover price or subscriptions, the Web-based survey results show decisionmakers at free newspapers are trying alternative revenue sources but the familiar methods of generating revenue remain popular. "Sponsoring or hosting events" as a revenueproducer was employed by $36 \%$ of respondents, but then other non-advertising revenue options drop off dramatically, with "marketing consultations for local businesses" at $12 \%$ and selling "e-books" at 5\%. The majority or respondents (73\%) report pursuing "special advertising sections" and more than one-third have published a separate title unlike the parent newspaper, two kinds of enterprises that must rely on advertising. The majority of decision-makers at free newspapers do not impose a fee to access content on their websites, but almost one-third said they would consider some form of a fee. Contrast that apparent willingness to charge online readers with the overwhelmingly conviction $(76 \%)$ that the print product will remain free and one is left with the impression that if a change to the free paper business model is to happen, it might happen online.

Text responses from the Web-based survey respondents reflect a willingness to consider alternative sources of revenue, such as a voluntary payment system, or even charging readers who pick up a paper in a store while also offering free home delivery. 
The text responses, which offer the decision-makers a chance to voice their opinions, also show an overwhelming reluctance to abandon the free business model, at least in print. Many said it was unlikely the return on charging 25 cents or even $\$ 1$ per issue would compensate for the costs of setting up a paid infrastructure (for example, modifying street boxes to accept coins, or even replacing all of the boxes), never mind the wrath of the reading public used to their free newspaper or the advertising community used to a wide circulation.

These considerations were also reflected in interviews with the publishers of four distinct free newspapers. Switching from free to paid would be a fundamental shift that is simply not worth the likely loss of readership, the subsequent decline in ad revenue, the prospect of dealing with disappointed readers. Nevertheless, these publishers endeavor to supplement their newspaper's ad revenue with other publications, hosting events, offering marketing consultations to local businesses and, in the case of The Leader, soliciting voluntary payments.

\subsection{Research Questions 3 and 4: Whither Online Advertising?}

\section{4.a Research Question 3: Web-based Survey Results}

In response to RQ3 - Are sales representatives at free newspapers selling both platforms, online and print, or are they focused on one platform only? - the Web-based survey shows free newspapers consider it important that their sales staff be able to sell advertising in both their print and online editions. Nearly all of the respondents, $96 \%$, report that their sales staff sells for both the print and online editions compared to $4 \%$ 
who said their sales personnel are separate entities - some sell for the newspaper and some for the online edition. However, reflecting the newspaper industry's struggle to offset declining print advertising revenue with online ad revenue (Edmonds, R., Guskin, E., Mitchell, A., \& Jurkowitz, M., 2013), decision-makers at free newspapers estimated online ads contribute an average of only $5 \%$ to total advertising revenue. It is, obviously, still difficult for newspapers to generate enough online revenue to offset declining print advertising revenue. This result also shows that print advertising revenue is still the cash cow for newspapers. This reality is not lost on the publishers interviewed for this study.

\section{4.b Research Question 3: Elite Interview Results}

Nick Barbaro at The Austin Chronicle said his advertising representatives concentrate mostly on the print side of the business, where they also earn more on commissions, perhaps subconsciously alluding to an incentive that may drive sales staff to focus on print at the expense of the website. Nevertheless, he said The Chronicle was largely sold out online and if they were able to increase traffic he thinks they may be able to sell more website ads. "There is just so little money online," he lamented. "In a business sense, we spend an inordinate amount of time" on The Chronicle's website, roughly a 50-50 split in time and effort between the website and the newspaper. "But the revenue is still $95-5$ " in favor of the print edition, he said.

Regarding advertising sales for the print edition, Barbaro said, 'I'm sure it's harder than it used to be. We are doing more or less well enough. I guess they (sales people) are getting enough 'Yesses.' It's certainly harder than it used to be." The 
publisher noted that a number of The Chronicle's core advertisers, such as music outlets and bookstores, are not as flush with cash as they used to be.

“Our website wouldn't exist if it we didn't have the print edition, because it wouldn't make no money," Barbaro suggested. But would the print product exist without the online edition?

Now that's a good question and one that I'm sure has occurred to everybody in our industry: 'What if we just didn't do it?' We are batting our heads against the wall. All the effort that is going into the website is hurting the print edition. Could we just not do it? I don't know, I think then we're back to ... that's just where people get a lot of their information.

Despite voicing frustrations with running a newspaper in the digital age, Barbaro acknowledged, perhaps grudgingly, that The Chronicle brand has to be visible to the online public. "Yeah, at least that's the assumption," he replied, not sounding totally convinced.

Selling advertisements, whether for print or online, is "tough," according to Tommy Wyatt at The Villager. "It's out there. You just have to stay on top of it." Although he sells most of the ads, Wyatt said the sales staff at The Villager includes "all of us," referring to his son and granddaughter. He prefers to think of selling ads as more of a "partnership" with local companies "that we can depend on." They buy ads and The Villager helps them promote events, he added. "Our challenge is to keep the ads coming," Wyatt continued. During his interview near the end of May 2013, Wyatt said interest still seemed strong and he was meeting with three prospective advertisers that week. 
The Leader is not obsessed with selling ads for its website. "We are not in a hurry to sell it," said publisher Jonathan McElvy. He wants to pursue that revenue source at his own pace, while also reflecting Barbaro's opinion that a lot of time and effort goes into a website yet the return is not great. He noted that newspapers used to receive around $\$ 12$ per 1,000 impressions and then that fell to $\$ 7$. The metric was three click-throughs for every 100,000-page views, or an ad would potentially get clicked on three times for every 100,000 page views. “That was a good number," McElvy said, shaking his head. "That's not even good in baseball."

"I don't think our industry is honest about the experience on a website," McElvy charged. "When an ad appears what do you? 'Where's that X?,"” he asked, referring to the tiny X readers can click on to kill an ad that pops up on a screen. "You literally tear the ad off the page when you are online." McElvy also believes advertisers, and in a sense users as well, have not been treated fairly when it comes to website traffic. He cringes at the practice of major daily newspapers featuring celebrity gossip and photos on their home Web page simply to drive traffic. "It became a game of page views."

McElvy favors a gimmicks-free website, a daily version of what they do weekly. The Leader's website (theleadernews.com) is very orderly and easy to navigate, much like the newspaper itself. In his mind the website and the newspaper can serve different purposes: "The Web is for 'what' and the paper is for 'why."”

However, despite McElvy’s seemingly cold approach to website ads, his active mind still generates possible ways to improve The Leader's online operation. The 
newspaper has been generating from $\$ 1,000$ to $\$ 2,000$ a month in online ad revenue, he said, without really working that hard at it. They charge a basic fee of $\$ 250 /$ month to advertise on the website. McElvy does not charge for click-throughs but he does monitor the traffic, suggesting this is information he wants to be aware of despite the low prices newspapers receive on a CPM basis.

McElvy is also interested in trying to monetize The Leader's growing presence on social media, where they avoid dumping too much news content but instead give updates when necessary and try to start a conversation. He thinks Twitter and Facebook might be a "big revenue opportunity," and by "big" he means $\$ 15,000$ to $\$ 20,000$ a year in revenue, as an audience that supplements their print circulation. In early July 2013, McElvy said The Leader generated nearly 1,100 friends on Facebook in one year and almost 2,000 followers on Twitter. These are numbers he hopes to improve so one day he can go to an advertiser and say The Leader reaches 4,000 to 5,000 people every day via social media, in addition to the 34,000 newspapers that are distributed every Friday. "I think it's important for us to continue to build that digital audience," McElvy said. "Because every time somebody sees your name that's good for you."

Briefing purposely does not have a website. Group Publisher Richard Alfano said offering Briefing's content, which is basically material pulled from The Dallas Morning News (DMN) and wire services, for free online would not make economic sense. They would be competing against The Morning News' online presence. "Ideally,” Alfano said, “we want to get people to go DMN or to be a paying digital subscriber." He reminds his 
interviewer that for the most part Briefing's readership consists of former DMN subscribers who no longer wanted to pay for the newspaper. "If you don't want to pay for print for DMN we want to sell you a digital package." Alfano reported that as of early July 2013, when he was interviewed in a Morning News boardroom, digital revenue was up by $30 \%$ overall at DMN Media. However, apparently Dallas residents are reluctant to pay for online news as well. The Dallas Morning News abandoned its paywall on October 1, 2013, making it free while also offering "premium" content to readers still willing to pay (Ingram, 2013b).

\section{4.c Research Question 4: Web-based Survey Results}

Regarding RQ4 - How do the sources and types of advertisements differ between the online and print editions at free newspapers? - Web-based survey responses show there is no discernible difference in the types of ads between the print and online editions. Respondents were asked to estimate by percentage what types of advertisements accounted for print advertising revenue and for online advertising revenue in 2012. Retail was the dominant type of online advertising in 2012 at $38 \%$ while Entertainment was the next prominent category at $15 \%$. (See Table 9). The next highest type of online ads was Other at $9 \%$, followed by Classified/Personal at 3\%, Financial at $2 \%$ and Political at $1 \%$ despite a presidential election being held in 2012. The ranking of these categories was the same for types of print advertising, although the percentages differed. Retail accounted for $41 \%$ of print advertising revenue in 2012, Entertainment $16 \%$, Other was $13 \%$, Classifieds/Personal were 9\%, Financial $4 \%$ and Political ads accounted for $2 \%$. 
Table 9 Types of Online and Print Advertising in Free Newspapers in 2012

Type

Retail

Entertainment

Other

Classifieds/Personal

Financial

Political
Online (Mean)

38

15

9

3

2

1
Print (Mean)

41

16

13

9

4

2

Advertising differences between the online and print versions of a free newspaper showed up in estimations of geographic sources of ad revenue for 2012. Web-based survey respondents were asked to estimate the percentage of total print advertising revenue that came from specific geographic sources in 2012 , and the percentage of total online advertising revenue that came from specific geographic sources in 2012. Survey respondents said $57 \%$ of online revenue came from local ads, while national ads accounted for $7 \%$ and regional ads $6 \%$. For print revenue in 2012 , local ads accounted for almost three-quarters (72\%), compared to regional at 9\%, and national at 5\%. (See Table $10)$.

Table 10 Geographic Sources for Advertising in Free Newspapers in 2012

Geographic Source

Local

Regional

National
Online (Mean)

57

6

7

86

\section{Print (Mean)}

72

9

5 


\section{4.d Research Question 4: Elite Interview Results}

The Villager, which typically runs between six to 12 broadsheet-sized pages per week, is dominated by small ads for churches and a handful of ads for public service agencies like IDEA Public Schools, the Travis County Housing Authority, Texas Lottery, and the City of Austin. Tommy Wyatt acknowledged that government organizations, Travis County, Capital Metro, local colleges, and public service organizations are their biggest customers. These are groups "who are having a hard time reaching our community, but that is a service they have to have."

Wyatt employs the voluntary payment method with churches: they can advertise and decide later what to contribute. It's "like a goodwill offering," he said, but also a "partnership agreement." The Villager not only creates a modest source of income, but the churches also distribute the newspaper. These distribution points help The Villager maintain a connection with people who have moved from East Austin but still attend the same church. Wyatt estimates he probably generates about $\$ 100$ to $\$ 200$ a year from one church ad, which is about the size of a business card. "You put them all together and that's a nice supplemental income."

The times, however, have changed for Wyatt. He used to be able to play one grocery store off another, suggesting that if one didn't make an effort to reach AfricanAmerican customers using The Villager another one would. Now he sees that happening with automotive dealerships. As mentioned earlier, national automotive ads have increased at The Villager thanks to the National Newspaper Publishers Association. The 
NNPA has been working on GM, Toyota and Ford to convince the auto companies that African Americans are a market they need to reach and these papers are the way to do it. "They are in temporarily, it's just a matter of how long we can keep them," Wyatt admitted.

The Villager displays a few ads on its website and the source or types are what a reader would find in the newspaper: local colleges and public outlets like Capital Metro, the City of Austin, and Texas Lottery. Wyatt said the website generates "very little" revenue, in part by design. "What it is, it becomes an added value to our newspaper advertisers." For example, Texas Lottery signs a contract to advertise in The Villager and Wyatt throws the website ad in for free. He said it doesn't make business sense to scare away an advertiser by asking for a small fee for a website ad.

Still, he was asked, why not charge even a little a bit when advertising dollars in general are hard to come by as he has acknowledged? Wyatt wouldn't budge. "It's one of the things that solidifies a continuous contract," he said. "Right now, with all the people that are grabbing at those advertising dollars, you gotta find a way to stay in the game."

Wyatt doesn't fear the Internet, asserting "it has affected the small segmented papers the least. Most of the effect has been on the dailies." Indeed, the publisher considers the Internet "helpful because it increased our circulation." The online version of The Villager can reach people moving out of East and South Austin. And what about social media? "We haven't gotten there yet." 
Once again, Briefing is the outlier. Because it does not have a website, a comparison of the types of ads between the print and online versions is impossible. However, Group Publisher Richard Alfano shed a light on the main type of ads a reader will find in Briefing - grocery stores - and how the free paper fits into DMN Media's selling strategy. The grocery store accounts are a big part of Briefing's "media spend," he said, mostly in the form of inserts that are also stuffed into The Morning News and Al Día. DMN Media takes a "consultative sales approach," he added, meaning the sales staff will help a prospective advertiser put together a multimedia portfolio, both digital and print. Other advertisers a Briefing reader might find include those related health care, medical services, and home care, in addition to inserts from retail outlets such as Frys and Best Buy. "It's about reaching an audience," said Alfano. "The strategy is about reaching a targeted audience that advertisers want to reach for their message, for their products."

As mentioned earlier, the publisher of The Leader doesn't go out of his way to encourage ad sales for its website. The few ads that one might see on its website reflect those you would likely see on The Leader's newsprint: medical services, computer repair, a local Catholic school, and a gourmet food caterer. Not unlike Tommy Wyatt at The Villager, Jonathan McElvy is not intimidated by the Internet, which has introduced a multitude of options for advertisers. He understands that a newspaper has to be online and in the game, but he asks, "What is the purpose of it? Number one to me, it's our best marketing tool available. It's branding." When he bought The Leader in June 2012 the 
first thing McElvy did was build a website. A year later he said theleadernews.com averages about 120,000 page views per month.

"I think our biggest threat is not the Web," McElvy continued. "It's people who think they know the Web." To illustrate his point, McElvy relayed a meeting he and one of his advertising representatives had with one of their best customers, a car repair business. The business owner told the publisher that it took about 18 months and roughly $\$ 10,000$ to re-design his website, which was now attracting about 15 page views a day. McElvy thought the business owner wanted help with his website, but the mechanic was proud of how well they were doing. "'I'm on the Google,"” he told McElvy, then concluded, "'What can The Leader do for me?",

When McElvy tells this story his facial expression drifts between incredulity and exasperation. "It was so telling that this guy didn't know what he was doing," he said, smiling and shaking his head, adding that the website is atrocious. Nevertheless, McElvy

turned the meeting into an opportunity, telling the businessman that The Leader's website attracts about 3,000 to 4,000 page views a day. His newspaper, McElvy continued, can help the mechanic increase his page views by linking from their website to his while also using the print version to promote the car repair shop's website. The mechanic bought a series of half-page ads.

\section{4.e Research Questions 3 and 4: Overview}

Web-based survey and elite interview results are combined here because the two research questions focus directly on online advertising for free newspapers: RQ3 asked if 
sales representatives at free newspapers were selling both online and print platforms, or are they focused only on one, and RQ4 asked if the sources and types of advertisements differ between the online and print editions of free newspapers. The vast majority of survey respondents (96\%) said their sales staff sells for both online and print, yet online ads only account for roughly $5 \%$ total advertising revenue. The breakdown of types of ads does not differ too greatly between online and print, with "retail" accounting for $38 \%$ and $41 \%$ respectively. "Entertainment" was the next highest category, amounting to $15 \%$ for online ads and $16 \%$ for the print edition. In terms of geographic sources for advertisements, "local" was the dominant group at $57 \%$ for online ads and $72 \%$ for print. The dominance of local ads for the print edition should not be surprising since free newspapers live or die by how many local advertisements they can sell.

Responses from the four elite interview subjects were varied and somewhat revealing in that a Web presence is embraced but not necessarily wholeheartedly loved. Online ad sales are part of doing business at The Austin Chronicle, although publisher Nick Barbaro lamented how much time, effort and expense goes into maintaining an online presence yet it is not a significant revenue producer, a point echoed in the Webbased survey responses. Tommy Wyatt at The Villager sees his website as more of a value-added proposition, a place to give loyal advertisers a boost rather than a format to be sold aggressively. Briefing, again, is different because it does not have a website but is also part of a larger digital strategy pursued aggressively by DMN Media, although the company pulled back recently when it modified The Dallas Morning News' paywall. 
Jonathan McElvy sees potential in The Leader's website and social media if he can convince advertisers that the combination of print and online readers is a substantial audience to reach, but he is also adopting a "wait-and-see" approach as the newspaper industry experiments with various models of generating revenue from websites.

The four publishers also note that the types of ads their newspapers attract are for the most part local, again reflecting the Web-based survey results, even though some may be local outlets for national brands like automotive dealerships and grocery store chains.

\subsection{Research Questions 5 and 6: Reader Engagement and Free vs. Paid}

The fifth research question - To what extent do free newspapers invest in editorial content? - and RQ6 - To what extent do free newspapers believe they have a relative advantage over paid newspapers? - are addressed together. RQ5 is perhaps too broad of research question and one that was not directly addressed in the Web-based survey by, for example, asking respondents to attach a dollar figure to how much they spend on editorial, and how that budget item has changed or not over the years. However, respondents linked the two questions by repeatedly equating quality or "compelling" editorial content with engagement, an often-cited advantage free newspapers said they have over paid competitors. By inference, these respondents were talking about an aspect of the newspaper business they clearly invest in.

\section{5.a Research Questions 5 and 6: Web-based Survey Results}

On average, survey respondents said roughly $52 \%$ of space in their newspaper is devoted to advertising and $42 \%$ to editorial content. Survey respondents also 
overwhelmingly, nearly $83 \%$, answered "No" to the following question: Do you believe readers are more "engaged" in a paid newspaper because they had to pay for it? Perhaps this large number is not surprising given these decision-makers represent free newspapers. Just over $17 \%$ of the Web-based survey respondents answered "Yes," that readers are more "engaged" with a newspaper because they had to pay for it.

\section{5.b Research Questions 5 and 6: Web-based Survey Respondents' Text}

\section{Answers}

Respondents were asked to expand on their answer to the question regarding engagement and whether paying for a newspaper matters. Of the 102 text answers, 16\% answered "Yes," engagement is related to payment. All of these responses reflected the notion, which may simply be common sense, that if you pay for a newspaper you will read it. For example: "Readers who pay for something have more investment in their reading." Another response was more succinct: "Human nature." Finally, a third response reflected this general observation that a subscriber, or someone who purchases a newspaper in a store, is likely to read what she paid for, yet also echoes the majority who answered "No" by linking editorial quality with engagement: "If a reader is paying for a product they are far more likely to desire and read the content provided. Our readers are engaged by the quality of our editorial product."

"Quality of content," “compelling content" and "quality of journalism" were phrases that dominated nearly $83 \%$ who expanded on their "No" reply to the question of whether readers are more engaged in a newspaper because they had to pay for it. These 
decision-makers repeatedly referred to quality content, both advertising and editorial, as the key to attracting and keeping an audience. As one said, "Content keeps people engaged, not the 50 cents they paid." It has to be acknowledged that what constitutes "quality" editorial may be in the eye of the beholder. It is a little disconcerting that one respondent said, "the community loves our positive coverage," suggesting news that is critical of local authorities may not be prevalent in that newspaper.

Nevertheless, the sheer volume of respondents who refer to quality content whether that be "positive" or "hard-hitting" - suggests there is a strong commitment, or investment, in editorial content. "Content is king and if the paper is lousy, people will not be engaged, paid or free," said one respondent. Another respondent links the importance of "local" with the question of engagement:

If readers were more engaged with a paid paper then paid papers would not be declining in circulation almost universally. Our free paper focuses on local news and features that readers often can't get anywhere else. And we focus on local businesses for advertisers that are close to their homes and where they work.

It may be somewhat surprising that $100 \%$ of decision-makers at free newspapers did not answer "Yes" to the survey question if they believed free newspapers have an advantage over paid-subscription competitors. The total was nearly $92 \%$, with the remainder saying "No," they didn't think free newspapers have an advantage. One "No" respondent captures the realities of running a newspaper, which is more complex than a simple "Yes" or "No" question:

I think it's harder for free newspapers because we have no revenue source but advertising and printing costs are exorbitant. In a poor economy, we suffer first because most businesses will avoid advertising and just submit press releases to 
our community newspapers. We generally don't print them. However, this creates tension with possible readers who are also business owners.

Survey participants who answered "Yes" to free newspapers having an advantage over paid-subscription competitors often stressed quality local coverage and greater penetration of the market, compared to the paid alternative, that advertisers are looking for. As one respondent suggested, free newspapers offer "distribution where advertisers want it, not just where subscribers want to receive it." Some of the comments were illuminating because they create an impression that the people running free newspapers are bullish on the future. Other comments suggest perspectives of the newspaper business are multi-layered.

"Our advantage," said one respondent, "is we can drill down so deep on the local news that the paid subscription can't come close, as they have cut back so far on reporters they have no local content, lots of AP wire, very little local." Another noted that after being a paid newspaper for 20 years "service issues and cost drove us from the post office to free rack distribution."

Some respondents were very critical of paid competitors and their headscratching decisions. One respondent questioned why the local paid daily two years ago started publishing eight pages of New York Stock Exchange stock quotes every Saturday while still getting scooped on local news. "They are their own worst enemy," the respondent suggested, "and they make it possible for us to eat away at their market share." Another was more explicit: "Paid circulation daily papers are the dinosaurs of 
print media. They are dying. It's a short-term liability to the balance sheet and a huge expense on the (profit/loss)."

One respondent said there is "no longer a negative connotation to free (among) most ad agencies and advertisers if you are delivering the market with a legitimate news vehicle." And lastly, one respondent dug deeper into the complexity of the free versus paid debate while also returning to the point that readers desire quality content, and advertisers desire those readers' eyeballs:

Depends on which side of fence you're on. Paid say, 'People want it so much they pay for it.' Free say, 'People want it so much they seek it out.' They're both correct. The difference will come with how relevant the content is. It's less about free vs. paid. Is it good? Is it relevant? Is it available in 20 different places or one?

\section{5.c Research Questions 5 and 6: Elite Interview Results}

Richard Alfano at Briefing has resources available to him as part of the DMN Media group that the three other publishers interviewed for this study perhaps do not have at their fingertips. For example, Briefing hosted focus groups where readers said they don't care too much about international news, and only a little bit about national news. Readers, relayed Alfano, said they "care more about the local news. I care about what's happening in my backyard." Alfano learned that readers want the news, but they also want information on how to enjoy their lifestyle in Dallas and Texas. "'Why does it have to be about hard-hitting news?"” said one Briefing reader. "'Make it more fun." As a result, Briefing added more "lifestyle" content. "They want to know if there is a tornado in Oklahoma," Alfano said, "but we're not going to make the whole paper about that." 
The goal, he added, is to "engage people on a very targeted, vertical, special interest, passionate level."

Engagement is important to Briefing and Alfano as an antidote to the notion that a paid newspaper has an advantage because the consumer paid for the content, even if it is only a small sum. "We do all the right things to continue to improve the quality of the product, create the engagement so that it's a valuable product to the reader," he said. "Which then makes it an engaged product for the advertiser. Because we can tell them we know people are reading this." Alfano also has access to research that shows what sections are popular with readers, and how many issues a week they are reading. "That's how you sell it. You whip out the research and say, 'Let me show you the research.'”

The Austin Chronicle, meanwhile, "pared down" its editorial model in response to the reduction in advertising revenue it experienced a few years ago, said publisher Nick Barbaro. They cut back on certain sections without changing their core product, which includes stories about politics, arts, culture, food, listings and community events. "We haven't yet had to make a fundamental change in what we do," Barbaro said. Nevertheless, he also looks ahead and if advertising revenue takes a major plunge he would consider killing the film listings. Reviews of films would still be published, but the listings would end. "Film times are a bear" and very labor-intensive, he lamented.

Barbaro fears that if The Chronicle lost one-third of its advertising revenue "we would have to pare back our editorial by another third and I think our basic model would not work at that level." Not only would film listings be on the chopping block, every 
section of the weekly newspaper could be at risk. However, Barbaro does not want to repeat the across-the-board cost-cutting measures executed at many U.S. newspapers where they "have just chopped away what they do." There's no sense, he added, in cutting editorial expenses back $10 \%$ across the board because it's better to do five things well than 30 things badly.

One editorial investment that appears to frustrate Barbaro is paying people to work on the website. He has received complaints from editorial staffers that the website requires so much attention that little time is left for substantial reporting. As mentioned previously, the publisher wrestles with the conundrum bedeviling many other newspaper executives: the print edition produces the majority of the revenue, but the time to produce the newspaper is getting eaten up by duties related to the website, such as keeping blogs updated. Barbaro does not have a solution to that problem, and he watches major newspaper chains to see if any ideas can be replicated in Austin. He is also thinking about ways to improve The Chronicle in both print and online to remain relevant to its readership. For example, he said they are looking at improving the website they launched in 1994 by perhaps adding word clouds, more breaking news, photo galleries, and making navigation easier, all tasks he acknowledged would further tax his editorial staff but it's simply the price of doing business in the digital age.

Barbaro said they are also considering a glossy cover, which may help with efforts to sell full-page advertisements on the back page of The Chronicle, replacing the current listings and five or six small ads. Among its many special sections throughout the 
year is a restaurant poll. In 2012 the poll appeared as a glossy magazine inserted into The Chronicle. In 2013, Barbaro and his crew abandoned that idea and instead produced "The Food Issue" on June 14. Most sections of that issue were devoted to food and the result was a 128-page newspaper, one of the largest they have had in a long time, Barbaro said. "We are looking for ways to make print look better," he added. "Most critical in the long run is that people are still reading it, in some form or another." If people are getting their news online then The Chronicle has to be there, Barbaro admits, and "hopefully we are still getting enough money from the print side to pay for that. When we started the paper it was kind of the same deal." The money was tight but they still had to produce a good newspaper that would engage readers and attract advertisers. The more things change, the more things stay the same.

The Villager, much like other newspapers that appear to have a minimal budget for editorial, publishes press releases to complement original material produced by two freelancers. Unlike traditional newspapers, the publisher's column — titled "Rappin' Tommy Wyatt" - appears on the left side of the front page, rather than on an inside page. The Villager also has a section, called "Youth Brigade," that Wyatt admits is a direct attempt at engaging younger readers. "It is building readership," he said. "We gotta catch 'em early." The section features anywhere from 10 to 20 African-American students, ranging from Grade 5 to high school, who update events happening at their school, their neighborhood or their personal life. Wyatt started the program in 1986. A potential "Brigader" is interviewed by Wyatt to reinforce the notion that he or she is 
representing The Villager and is expected to follow deadlines. Youth Brigade is an effort to build readership because Wyatt is concerned that his readership is "aging." The section is also an attempt at encouraging young people to become interested in journalism.

Jonathan McElvy is also willing to try new editorial sections as a way to stay engaged with his audience and give him an edge over the paid competition. Another one of his mottos is, "Fail first and fail cheap." He wants to test new publications to see what sticks in their part of Houston. As a result, The Leader created another free publication called The List, an aggregation of restaurants by themes. The hamburger list was popular, but Mexican food wasn't, McElvy reported.

"The Hipstrict" is one of the most popular columns in The Leader, the publisher said, a place where readers can find a restaurant review every week. Working on this theme, and the popularity of the food culture and restaurants, McElvy also created a smaller section called "Nibbles" which features short items about restaurants. He said Nibbles is the second most popular page after the opinion page. These kinds of sections may be popular with readers, and they reflect an effort by The Leader to be responsive to its readership. These sections will never be confused with hard news, which McElvy acknowledges still has to be part of what a newspaper offers.

Although McElvy didn't offer specifics on how much The Leader spends on editorial, they too have a small staff. He hired a full-time reporter in February 2013 after the paper reached a consistent level of 16 to 20 pages per week. The Leader also has an editor, a freelance reporter and two freelance columnists. This publisher has a unique 
view of covering his community: a mix of traditional, fearless journalism and a willingness to break newspaper conventions. For example, he believes a reporter's time is wasted sitting for hours covering city council or school board meetings. If municipal representatives are talking about a tax increase, McElvy asserts, The Leader will do a better job covering the topic talking to people who may be affected than simply repeating what public officials say. "People want to read about themselves and their neighbors," he said.

Reflecting the more traditional journalistic approach of helping shape events, McElvy cites and example of a Leader staffer noticing patrons of a Houston bar, located adjacent a rail line, parking their vehicles very close to the tracks. The Leader published a "fascinating" story, McElvy called it, that questioned what would happen if these vehicles get stuck on the tracks. As a result, the bar erected barriers to prohibit parking near the rail line. "We gotta cover that," said McElvy, referring to hard news that mixes with community news.

He also believes newspapers have to take a stand, that they have to be involved in their community to enhance their relevance among readers. "Our job is to improve this community," said McElvy. "Our job is not to solve every social injustice in the world. Our job is to improve where we live." If a business moves to the area and creates jobs, then that's a potential story, and it doesn't have to be promotional or soft. In the first month of owning The Leader, McElvy said, he took a stand in his column. He said doesn't have an opinion about the merits of Wal-Mart as a commercial outlet or as a 
corporation, but when a group, calling itself RUDH (Responsible Urban Development for Houston), opposed the opening of a new store in an area called The Heights, McElvy said he "called them out in a column. Y'all are just a bunch of idiots. Hating Wal-Mart was cool in the 90s." He said once a month he tries to rile someone or some group to help generate interest and letters. Many newspapers, he lamented, have gotten soft. "We quit pissing people off."

\section{5.d Research Questions 5 and 6: Overview}

To reiterate, results from the Web-based survey and elite interviews are presented together because they essentially address the topic of engagement. RQ5 asked, "To what extent do free newspapers invest in editorial content?” while RQ6 asked, “To what extent do free newspapers believe they have a relative advantage over paid newspapers?" Survey results show decision-makers at free newspapers devote an average of $42 \%$ of their pages in a given issue to editorial content, ostensibly a sizeable investment. The majority of respondents $(83 \%)$ do not believe that a person is more "engaged" in a newspaper simply because he paid for it. A vast majority (91\%) of decision-makers at free newspapers also believe they have an advantage over paid newspapers, and many respondents, in their text responses, credited "compelling" local editorial content with giving them that advantage.

The four publishers also linked compelling editorial content with engaging their readers, giving them an advantage over paid competitors. They also note an engaged readership is exactly what advertisers want to see, so they are mindful of not cutting 
editorial budgets too severely while also being open to special editorial projects related to certain topics (such as food) or segments of society (such as young people).

\subsection{Research Question 7: Optimistic or Pessimistic About the Future?}

\section{6.a Research Question 7: Web-based Survey Results}

In effect, the final research question - To what extent are executives at free newspapers optimistic or pessimistic about the future of free newspapers? - required decision-makers to look into a crystal ball. The Web-based survey asked participants to finish the following question: Regarding the future for your newspaper, are you . .? The majority of these executives are optimistic about what the future holds for the newspapers they represent. Respondents said they were strongly positive (31\%) or positive $(50 \%)$ about the future of their newspaper. (See Table 11). Another $15 \%$ were neutral about the future while those who were negative $(3 \%)$ or strongly negative $(1 \%)$ barely totaled $4 \%$ of the respondents. This positivity must be linked to the financial state of newspapers and their markets. As noted earlier, $67 \%$ of respondents said their newspaper made a profit in 2012 and $73 \%$ anticipate making a profit in 2013 . Ten percent of respondents said their newspaper, or papers, lost money in 2012, but only 2\% anticipated losing money in 2013. Those who anticipate their paper will break even in $2013(21 \%)$ echo the number of respondents who said their newspaper more or less broke even in $2012(22 \%)$. 
Table 11 Decision-makers' Attitudes Toward the Future of Their Free Newspaper or Papers

Answer

Positive

Strongly positive

Neutral

Negative

Strongly negative

Total

(Valid)

\section{Percent}

50

31

15

3

1

100

(128)

This positive view of the future of free newspapers is echoed in responses to the survey question: "Do you disagree or agree with the assertion that it is only a matter of time before newspapers are an online-only news outlet?" Nineteen percent of respondents strongly disagreed, $35 \%$ disagreed and $23 \%$ somewhat disagreed with the premise that it is only a matter of time before news on paper is dead. (See Table 12). A small number of respondents, $5 \%$, agreed that the print product will make way for the online-only newspaper, while 7\% said they somewhat agreed, and 3\% strongly agreed. 
Table 12 Decision-makers' Opinions on Whether Newspapers' Future is Online-only

Opinion

Percent

Disagree 35

Somewhat Disagree

23

Strongly Disagree

19

Neutral

8

Somewhat Agree

7

Agree

5

Strongly Agree

3

Total

100

(Valid)

\section{6.b Research Question 7: Web-based Survey Respondents' Text Answers}

Text responses to the questions about the future of free newspapers and whether

online-only is a matter of time help flesh out what the Web-based survey respondents are experiencing "on the ground" and, in some cases, what they fear.

For those survey respondents who strongly agreed with the notion that it's only a matter of time before newspapers are online only, it is clearly inevitable that the digital revolution will eliminate the newspaper medium. "There will come a time, ever sooner, when it no longer is cost-effective to print and deliver a traditional newspaper," said one pessimistic respondent:

However, the news that people find so readily on the Internet is mostly provided by newspapers. So the demise if newspapers will ultimately result in the end of journalism as we now know it. Also, there is simply not enough money/inventory in banner ads to make anywhere near enough money to pay for our organization. 
Another respondent who strongly agreed suggested the time frame of this digital takeover is difficult to forecast because no one knows when the generation of people who love to hold books, magazines and newspapers ages and will be overshadowed by the Ebook generation. This respondent reads one to two e-books a week and is certain it is inevitable that newspapers will be an online-only product. And that's "not necessarily a bad thing if business models change in time with the trend in order to be successful."

Two topics - the generational difference between those who prefer holding a print copy and those who prefer a digital version, and the costs of printing and distributing a newspaper - were common among survey respondents who forecast an online-only future. "It's economics and demographics," said one respondent. "Online publications don't bear the cost of printing and delivery, a newspaper's two biggest outside costs. The Baby Boom generation is likely the last one to embrace the printed product." One respondent, who was neutral on the question, doubted an online-only future was a given but ultimately newspaper owners may have to acknowledge that "the money will follow the readership preferences, so once the digital generation makes up the majority, so too will the efforts of newspapers." However, this notion of the digital steamroller eventually flattening newspapers is contrasted sharply by numerous survey respondents who report a different economic reality in their communities.

One free newspaper executive suggested small-town newspapers may have an advantage, for now, over metropolitan papers because of unreliable Internet service in rural areas. Although newspapers still have to think in terms of a blended print and digital 
delivery, the respondent suggested, inserts are still a valuable advertising vehicle.

"Today, most companies using inserts report that their inserts drive their businesses," reported the respondent. "One area grocery inserter told me recently that nearly 98\% of their business comes from their print insert and less than $2 \%$ comes from their online, email and other electronic products. That says it all!"

Another agreed that a combination of online and print delivery of local news and information is more likely than simply the death of newspapers in favor of digital.

Reaching an audience that attracts advertisers is still the bottom line:

We need to provide content to our readers in ways that will also provide results for advertisers. Print continues to do that. Online and mobile don't, at least not in the same way. Certainly new methods of delivery will arise, and we may opt for better options. But for now, print continues to drive results for advertisers.

A second respondent echoed this cautious optimism saying:

Ads need to be laid out next to text in the traditional way for it to work. Banner ads, click-throughs, etc. are dead and worthless. People still want the news and if you produce a high-quality editorial product, you have a chance. Print still has some legs.

A respondent, who somewhat agreed with the question of whether it's only a matter of time before newspapers are online-only, makes the point that a media company will likely provide both print and digital products, but advertisers will be driving the agenda:

Most think it will be the readers who determine the future of our product, but I tend to think advertisers will continue to drive a print product - most of them still see value to delivering their offer or advertisement in printed form to reach new potential customers. 
A second respondent offered a clinic on approaches to selling ads and a newspaper's supposed advantage:

The printed piece delivered to your home is a form of push marketing - you do virtually nothing to gain the opportunity to participate. Subscription papers are pull marketing, requiring an investment into the effort. Online is still more towards the pull marketing side.

A third echoed these sentiments, reporting that their "print product is still the only medium that receives more than $86 \%$ readership per our CVC audit and more than $83 \%$ response to advertising. Nothing online comes even close to those numbers."

Finally, two respondents suggest that it is not an either/or question. "The Internet and free papers work well together," said one. "The Internet is all about free." The second decision-maker at a free newspaper said:

Everyone consumes information in different ways, and print is still a viable option. You need traditional media such as print, broadcast (radio and television), to remind you of an online presence. Otherwise, out-of-sight, out-of-mind.

Perhaps the future of news may involve more than simply the death of one medium - print - at the hands of another - digital or online. Nevertheless, the final research question elicited passionate and informed responses from people working in the industry. This passion is even more evident in the text responses to whether these decision-makers are bullish, or not, about the future of their free newspaper.

"Business has never been harder or more stressful," said one survey respondent who was negative about the future. "I'm not bullish on the fate of newspapers in general." Another respondent, who said she/he was negative, admitted the "current corporate ownership and attitudes do not match the needs of small, local clients well." A 
person who answered neutral lamented the loss of an automotive section "that has

impacted our cash. We are making the necessary downsizing adjustments and it has been difficult."

Finally, a person who works for an alternative weekly, voices an opinion that is characteristic of comments made by survey respondents who held a negative view of the future of their newspaper:

Alt weeklies are viable for the foreseeable five years. Beyond that I cannot predict the newsfeed habits of the population other than to say if it made a 180-degree turn I'd be very surprised. I think there is impending doom for the traditional model daily newspapers in the immediate future and a certain timed demise of other type newspapers in the not so distant future. Newspapers' lifecycle is coming to an end.

This dark view, however, was vastly overshadowed by positive views about the future. Although the following examples of text answers are positive they do not appear to be self-promotional. It has to be assumed these opinions are based on what these decision-makers at free newspapers are experiencing on a daily basis. Common themes echo earlier responses, that print is still a useful vehicle for advertisers, local content is key, and it may no longer be accurate to talk about the print and website versions of a newspaper as separate entities.

"We believe there is a future for print and are creating a second edition of our paper for neighboring communities," wrote one of the $50 \%$ who said he/she was positive about the future. "A weekly paper combined with a website updated many times daily is the perfect combination. Local businesses will need both print and Web ads going forward." Another said, 
Online will be an important component, but we must continue to focus on print, too. The packaging or delivery system isn't as important as the content. We have to continue to provide relevant and interesting content that can't be found elsewhere.

Yet a third connected advertisers, the audience and quality journalism:

“Advertisers are going to need to reach our audience. With good journalism we'll have a bullish business."

Two survey respondents, from among the $31 \%$ who were strongly positive about the future, said 2012 was a terrific year in terms of revenue. Sales were increasing and readers still appreciate quality local news and information. "People still rely on newspapers for accurate news," said one. "Readers are turning back to the professionals for balanced news coverage." The other respondent outlined the successful recipe at his/her newspaper: "We are combining old-media and new-media solutions to deliver smart, edgy, local content in a market that appreciates it."

Other respondents, while they were strongly positive or just positive, were also aware of the financial challenges that still exist for many newspapers. "We're certainly not talking about a slam dunk for the future," said a strong positive respondent, adding:

We need to continually re-evaluate our products and our product mix, expand our digital offerings and stay open to new revenue sources. But we have a good market, good products and a good staff and I believe we will be able to adapt successfully.

The "heyday" newspapers enjoyed up to about a dozen years ago are gone, said a positive respondent, citing the usual suspects like Craigslist "damaging our classified revenues, auto and real estate" and the loss of readers as young people apparently turn 
away from print. This person, however, turned a negative into a positive, saying these difficult times weed out "the weaker products, leaving less print competition in the marketplace. For those of us remaining, it also forces us to produce better products, making the few papers left better read." In order to remain relevant, a number of respondents suggested, community newspapers have to keep doing what they do well (report local news and events like Little League baseball scores), and be ready to adapt to these fluid technological times. They have to become "'multi-platform' businesses," the place where "residents go to get their news" and advertisers will follow.

Finally, a respondent claiming to be strongly positive about the future of her/his newspaper even disagrees with the word "newspaper":

The term "newspaper" is irrelevant. What is relevant is "compelling content" and how easily it can be disseminated to readers. We are no longer "newspapers" because the means of dissemination/delivery are now manifold. You could have a 100 ways to distribute content, but if it's not worth reading in the first place, then why bother?

\section{6.c Research Question 7: Elite Interview Results}

Publishers at the four free newspapers interviewed for this report shared many of the observations outlined above, such as the need to offer news and information relevant to their readership and that newspapers are media outlets, businesses that are now more than just news on paper.

Briefing is a prime example of a corporate strategy to diversify away from relying solely on selling advertising into a paid product. It is one medium among a collection of media, and digital is a big part of DMN Media's plans for the future, even though 
Briefing does not have its own website. Group publisher Richard Alfano, who is bullish about the future of his newspaper, said the combination of free papers like Briefing and Al Día, its sister publication The Dallas Morning News, and an array of digital and social media services a "has really driven our digital revenues, and I think it's one of the smartest things we've done." Alfano was, of course, speaking before The Morning News dropped its paywall on Oct. 1, 2013, but it can be assumed that DMN Media is still pursing a multimedia approach. On July 9, 2013, Alfano said the "magic sauce" is reach, engaging the audience and offering "a portfolio of solutions" that can address advertisers' marketing concerns, whether that is mobile, digital or print.

This is not say Briefing and DMN Media are not cautious about the future.

"Profits are still there," Alfano said, but "the big challenge for the newspaper industry is we can't generate enough digital revenue fast enough to offset the decline of print." It's necessary to cut costs to maintain profitability, he added, but slashing the budget is not the only answer if a media outlet wants to “keep its edge." DMN Media's answer is to invest in new businesses, consider acquisitions and do "anything that can augment and complement what we have now." This may mean offering readers video and possibly getting into the development of applications. "It's not just about one product," said an enthusiastic Alfano. "It's about the totality of the audience that we could reach through a variety of channels, both print and digitally."

Nick Barbaro, publisher of The Austin Chronicle, is positive about the future but he is also wary. "We've reached a sort of plateau. Ad sales have been fairly steady now 
for" the past 18 months, he said in June 2013. How about the longer term? Can Barbaro imagine being positive in 2014 or $2105 ?$

I don't know. I don't yet see the death of print quite happening. When we do what we do best we do okay with it. Sales on this food issue were good. It's harder to keep people's attention, to grab people's attention. Certainly there are more competitors than there used to be.

Jonathan McElvy, publisher of The Leader in Houston, is confident about the future, but also aware, as a keen observer of the newspaper industry, that many challenges exist and likely always will. Although he contends that "content's been free since radio started, when they started reading our headlines on the air," McElvy mulls over the debate about over whether free online news can ever be monetized. He alternates between "you can't put a price on the story" to wondering if that were possible, what would the business model look like.

But what's the right price for a story? You know what the price is for sugar when you need to buy it. Or oil. Or anything on the commodities market. But is 99 cents the right thing for a story like it was for a song? No, you read a story once and you're done with it, you listen to a song over and over.

Not unlike Barbaro and Tommy Wyatt at The Villager, McElvy is curious to see what other revenue ideas media organizations come up with. "Any print product that does well, good for you," he said.

It's good for me if you do well. I am pulling so hard for The New York Times and the (Washington) Post, and the Belos of the world, and the Hearsts of the world to figure something out. Because if it gets accepted, that's good for me.

In the meantime, McElvy focuses on his community and his market, where he considers The Leader a brand that has the potential to expand into areas of Houston not 
currently being served by a community newspaper. He sees opportunity in the belief that metropolitan Houston's population is expected to hit 10 million in seven years from a level of nearly 6 million in 2010 (“About Houston,” 2013). Looking at Warren Buffett, the billionaire investor who has purchased a number of newspapers in the past few years and does not believe newspapers should give away content for free (Buffet, 2012), McElvy wonders, "What's he doing? He's not stupid. It's not just because he has a fondness for newspapers. There's something going on."

Even though McElvy is passionate about newspapers, he says he could leave the business, although he doesn't sound that convincing. "I could probably buy a Subway and run it," he joked. "But I think there is a value here. I employ 12 people here and they made more money this year than they have in the last 10 years, all of them." The publisher concluded: "I'm proud that I'm in the newspaper business."

Another publisher, Tommy Wyatt at The Villager in Austin, is also confident but wary about the future, while also watching the big media players to see if any online revenue-producing ideas emerge that can be applied to his operation. In the meantime, charging for online access to The Villager is "not an option," Wyatt insists. "Web is a friend." Nevertheless, he is tracking progress at national news outlets like The New York Times and the Wall Street Journal. "When they are convinced that they can make the kind of revenue, close to the kind of revenue (they are) making now without printing a newspaper, they'll stop printing," Wyatt suggested. "At this time it is not possible. You 
pay $\$ 5,000$ a page, $\$ 10,000$ a page, you can't get that kind of money on the Web. It ain't there."

Wyatt has heard that "10 years or more" is the timeline for when many newspapers will stop publishing because print will no longer be a viable medium. "I'm not convinced that is our future in 10 years," he said, adding he runs a tight ship at The Villager and it can sustain itself. "We don't have far to go." The "good news" at The Villager, said Wyatt, is that it is a unique product. There is no other media outlet reporting its brand of news and information about the African American community in the Austin area. The goal, he added, is to keep "our community" motivated and challenged. "I think they will stick with us."

The publisher of more than 40 years acknowledged the future holds many challenges. "You gotta keep your eye on the ball and just roll with the punches, that's what I always say." He doesn't expect dramatic changes in the newspaper business, but if the earth shakes, "It'll roll in from the big guys first. So we watch what they do. We try to adjust when they adjust."

\section{6.d Research Question 7: Overview}

The vast majority of respondents to the Web-based survey, a total of $81 \%$, are either "strongly positive" or "positive" about what the future may hold for their newspaper or papers. In contrast, a total of $54 \%$ of respondents replied they either "strongly disagreed" or "disagreed" to the statement that it is only a matter of time before newspaper are an online-only news outlet. On the one hand decision-makers at free 
newspapers are very positive about the future, but they are not necessarily as certain that their future is print only. The text responses show these decision-makers are aware that newspapers, if they are not already, will become a hybrid print and digital operation.

These sentiments - positive about newspapers' future but curious about what may happen next as the digital era unfolds - were also echoed by the elite interview subjects. Perhaps reflecting their knowledge of their local markets, the publishers were confident that they can maintain their relevance for both readers and advertisers, but they will have to work at it because competition for ad dollars and readers has increased. 


\section{Chapter 5: Discussion, Conclusion, Limitations, Future Research}

This dissertation started from the premise that the downward trend in advertising spending on newspapers leaves free newspapers potentially more vulnerable than paid newspapers because of the former's heavy reliance on ads for revenue. It was argued that free newspapers perhaps face two alternatives: stay the course and ride out the digital wave while also diversifying their sources of revenue, or abandon the free business model altogether and start charging for both the print and online versions of the newspaper.

Results from the Web-based survey and the elite interviews reveal free newspapers are not only surviving but many are prospering. Although they face challenges brought on by the emergence of the digital age and slow economic recovery, for the most part decision-makers at free newspapers are positive, if not excited, about their future. Recall that nearly $67 \%$ of the Web-based survey respondents said their free newspaper or papers made a profit in 2012 and $22 \%$ said they "more or less broke even." Nearly three-quarters (73\%) of the respondents anticipated making a profit in 2013 and another $21 \%$ say they expect to break even. Granted, the Web-based survey was not a census, it did not reach $100 \%$ of all free newspapers in the United States, so the results have to be put into perspective. It is not being argued here that all free newspapers across the United States are doing well financially, or that their profits are being spent on producing quality journalism. It is argued here that the Web-based survey results, complemented by elite interviews with publishers of four divergent types of free 
newspapers, show a newspaper can survive, and even prosper, giving readers its news for free. This in turn demonstrates that the print-based advertising business model is not obsolete.

It must also be acknowledged that the newspapers being discussed here are for the most part weeklies with a page-count that peaks at 48 per issue. Roughly $84 \%$ of the Web-based survey respondents reported their newspaper, or newspapers, are weeklies, while $74 \%$ said the average size of the papers per issue ranged from 24 pages or less and from 25 to 48 pages. These results infer that just as it seems unfortunate or flat out wrong to equate the economic misfortune of big city paid dailies as an indicator of the health of the entire U.S. newspaper industry, so would it be inaccurate to suggest that the results reported here stand for the entire free newspaper industry. Indeed, one problem for a Web-based survey is the "quality of a sampling frame or list" which can affect the ability to generalize to a larger population (Poindexter \& McCombs, 2000, p. 279). However, while this study is merely a snapshot taken in 2013 of a historically under-reported segment of the U.S. newspaper industry, it is also has strength because the Web-based survey of 714 decision-makers representing more than 1,260 free newspapers had a fairly reasonable response rate of $22 \%$.

The four elite interviews also complement the Web-based survey results in that the four publishers were optimistic and curious about the future and, perhaps more importantly, they represent four distinct kinds of free newspapers: a so-called “alternative" newspaper, a community weekly, another weekly targeting African- 
American readers, and a four-times-a-week newspaper that is part of a large media group. There is no desire here to overstate the results, something to the effect that free newspapers are immune to the many challenges facing the news industry in the digital age. But neither can it be ignored that these results show many free newspapers appear to be divorced from the common narrative that newspapers are dying because advertising dollars are being consumed by online behemoths like Google (Ingram, 2013a), or that newspapers are doomed if they don't charge for access to their content (Farhi, 2008, Buffett, 2012; Ladurantaye, 2012a, 2012b). It is simply not the case that newspapers are doomed, that they represent a medium that will be eclipsed much like writing on cave walls. And the point is not that being free of charge is the crucial part of the equation. Many decision-makes at free newspapers acknowledged that being free is not necessarily as important as having a compelling product that people go out of their way to pick up. The point that this dissertation drives home is that advertising-based business model is not only relevant, it does not appear to be going away any time soon.

In addition, smaller newspapers may have a better chance of thriving in the digital age compared to metropolitan dailies. According to one analyst, smaller newspapers have better prospects because they, for the most part, are more attuned to local needs than large dailies or even online hyperlocal initiatives (Meyers, 2004). They have built up trust within the community (Meyers, 2004). “The newspaper's influence within its community, a good that can be created and sustained only by high-quality, geographyspecific editorial content, will be very difficult for any new medium to replicate" 
(Meyers, 2004, p. 62). Perhaps there is an opportunity for larger newspapers in the Internet era: despite layoffs, they still have newsrooms of experienced visual and print journalists who can help improve local news coverage if given a chance, an advantage a hyperlocal website is unlikely to have. Given the apparent success of smaller newspapers to weather the digital storm (Salkever, 2012; Zachary, 2013), more intensive local coverage might entice and retain readers, an audience that is always attractive to advertisers.

It would also be prudent to recognize there will be difficult times ahead for free newspapers. The median age of print readers is 54 (“Across platforms," 2013), indicating an aging readership has to be a concern for any newspaper, free or paid. Although the majority (73\%) of respondents to the Web-based survey estimated the average age of their readership ranges from 36 to 55 , suggesting a not-so-aging readership, it would be folly to be complacent in trying to attract young readers. Free newspapers will also have to continue, if not ramp up, their efforts to diversify their sources of revenue. It may be comforting to hear, as the Web-based survey reported, that advertising revenue remained constant from 2011 to 2012 for $41 \%$ of the newspapers, or that ad revenue actually increased for nearly $32 \%$ of respondents, but this main source of dollars also decreased for almost $27 \%$ of the free papers. This indicates a measure of volatility in the free newspaper business, which in turn fosters wariness about the future. Cautious optimism is reflected by three of the four publishers: Tommy Wyatt at The Villager, Jonathan McElvy at The Leader and Nick Barbaro at The Austin Chronicle. They have had varying degrees 
of success creating secondary sources of revenue, and to a man they are watching what other media companies are doing in case a good idea emerges that can be applied to their markets. Again, The Briefing is a different beast given its reliance on The Dallas Morning News, but its success within DMN Media, surpassing The Morning News in circulation on certain days of the week, indicates free newspapers have a place in some markets. As long as a major media player in a state the size of Texas sees value in producing a free newspaper, then free newspapers will always exist.

Free newspapers, at least the ones represented by an array of decision-makers in this study, are overwhelmingly committed to staying the course. They see a future in print. More than three-quarters of the Web-based survey respondents said they would not introduce a fee for their newspaper, a view echoed by the publishers of four types of free newspapers. The majority of decision-makers at free newspapers involved in this study are committed to the advertising-based business model. This is not to suggest that these decision-makers are immune to the possibility of asking readers to pay for the news. Recall that nearly one-third of survey respondents said they would consider implementing a fee for online access. Charging for access to news may be more palatable for the online version, and easier to implement because an infrastructure would not have to be built from scratch to support subscriptions and street sales. However, a free newspaper considering some type of fee for its website runs into the reality that a news consumer is unlikely to pay for something she gets for free in the print format. 
Indeed, the Web-based survey respondents and the four publishers have mixed feelings regarding the value of pursuing an online presence. While $32 \%$ said they might consider an online paywall of some kind, nearly $88 \%$ said they currently do not have any fees associated with their website. In addition, while almost $96 \%$ of Web-based survey respondents said their advertising sales staff sells for both the online and print versions, on average websites generated only $5 \%$ of total revenue for these free papers.

Nick Barbaro, publisher of The Austin Chronicle, is perhaps the best example of the pressures facing decision-makers at print publications, paid and free. The Chronicle has to be online and its website even needs to be improved, Barbaro acknowledged, but the reality is the website doesn't generate enough revenue to justify the costs and staff time needed to keep it fresh and updated. It's only natural that as a businessman he wonders: why am I devoting so many resources to a money loser? It would seem then that decision-makers like Barbaro and others in the free newspaper industry are saying the future of news is not just online. Their future is in print and their future depends on engaging readers with local content. These decision-makers do not appear to have bought into the narrative prevalent among many major U.S. newspapers that the digital disruption was dramatic, wide-ranging and nearly fatal to their so-called aging business model (Chyi, Lewis, and Zheng, 2012). Ultimately, the ability to attract advertising is key. Twenty-four percent of Web-based survey respondents said their newspaper is available as an app for smartphones, $72 \%$ said they were not, while $69 \%$ said their newspaper or papers were available on tablet computers, and $27 \%$ said they were not. 
This shows that many decision-makers at free newspapers are willing to try new digital formats. However, "advertising has not yet materialized" for newspapers on mobile devices (Edmonds, Guskin, Mitchell, \& Jurkowitz, 2013, para. 11), a confirmation that publishers like Nick Barbaro at The Austin Chronicle are wise to devote the majority of their attention to where many advertisers still find value: the newspaper.

It is hoped that this study contributes to the discussion of the future of newspapers in three ways: broaden the conversation about the health of newspapers beyond just what happens at metropolitan dailies, that free newspapers are alive and kicking which means the advertising-based business model is still relevant, and that perhaps free newspapers, and newspapers in general, are representatives of "secondary technologies" (Bolter, 1991, p. 39). Secondary technologies may once have been dominant, as newspapers were for decades, but they have since been overtaken by emergent technologies. Nevertheless, "secondary technologies survive by meeting some need better than the dominant technology" (Bolter, 1991, p. 39). Free newspapers, some better than others, are clearly meeting the needs of readers and advertisers in their markets or else they would cease to exist. No one can predict the future of the newspaper industry, but it can be said with confidence that free is a model that is still relevant in print.

\subsection{Limitations and Future Research}

Like any study, this effort has its shortcomings. In hindsight, it would have been informative to conduct more elite interviews with publishers of free newspapers in states that are not doing as well economically as Texas. If business activity is down in your 
market it might be difficult to be upbeat about the future of your free newspaper. Connected to the health of a local economy, interviews with publishers of free newspapers that are losing money may have added a counterbalance to the four interviews conducted for this study. Then again, these interviews represent four varieties of free newspapers, which is another strength of this study.

It also has to be acknowledged that all surveys rely on self-reporting and therefore the decision-makers' claims may not be entirely accurate. They are also superficial, but answers to open-ended questions and the findings from the four elite interviews complement the results generated by the Web-based survey. In addition, although the $22.13 \%$ response rate is not as high as a researcher would like, response rates have been dropping over the years (Kohut et al., 2012) and the respondents are decision-makers, people in a position to know their market, the well-being of their newspaper and what the future may hold for them.

Regarding future research, the handful of free daily newspapers in the United States could be a topic for study. An analysis of their business models and styles of journalism may not only inform the larger discussion of the fate of free U.S. newspapers in the digital age, but perhaps also add to the dearth of historical research on free papers. On the immediate horizon is a replication of this study with a focus on Canada where free newspapers can be found in every major metropolitan market. A study of this kind could shine a light on the free newspaper segment of the Canadian media industry, and also provide an opportunity to compare and contrast with data regarding free newspapers in 
the United States. In addition, a study of Canadian free newspapers may also further enrich the thin history of free newspapers in general.

Directly connected to broadening the research on free newspapers to free dailies and free papers in Canada would be a comprehensive study of readers and why they consume free newspapers, or why the do not. A study of this kind could potentially illuminate whether price is a factor, or whether content is the key.

Finally, this analysis of free newspapers could lead to a study of free news in general and, more specifically, the future of paywalls and free news online. Does the example of successful free newspapers confirm readers prefer free news and therefore the push to charge customers for online access to newspaper content is shortsighted? A study of this kind could be more complex than a straight up analysis of free newspapers would it amount to comparing apples and oranges? — but it could also provide some empirical evidence to the debate about how much of a newspaper's future is online, a debate that is more often based on emotion than fact. 


\title{
APPENDICES
}

\section{Appendix 1: Email Script Invitation to Elite Interview Subjects}

\author{
Dear (First and Last Name),
}

My name is J. Ian Tennant and I am a doctoral graduate student in the School of Journalism at the University of Texas at Austin. I am contacting you to ask if you would be willing to sit down for an in-depth interview regarding the future of free newspapers.

The interview is part of my dissertation on the current state of free newspapers in the United States and their future as journalistic institutions.

You have been asked to participate because of your important role at your newspaper. The interview should last between 30 to 40 minutes and it can take place at your business or at a venue of your choosing. The interview will be recorded but if you prefer that it not be, your request will be honored and I will take notes instead.

Free newspapers are an important, and often overlooked, sector of the newspaper industry. Your participation is therefore extremely important to understanding the state of free newspapers.

Thank you very much for your help.

Sincerely,

J. Ian Tennant

PhD Candidate

School of Journalism

The University of Texas at Austin

j.iantennant@utexas.edu

512-705-1347 


\section{Appendix 2: Interview Script for Richard S. Alfano, Publisher of The Briefing}

\section{History}

1. When was Briefing launched?

- Why?

- Distribute more than 202,000 each day, from Wednesday to Saturday.

2. Why free?

3. Are Briefing and Al Día the only free publications in the DMN Media roster?

4. What is your response to the assertion that newspapers should never "give away" their content for free?

5. Jim Moroney: He figures "the terrible mistake" that newspapers made in the mid-1990s was giving away their product for free.

- Is there a difference between offering content for free online versus free in print?

- Offering a free publication within an organization that also has paid papers?

6. Are you ever asked to respond to the claim that a free publication is inferior in terms of editorial quality, or less engaging for readers, compared to a paid publication?

- They paid for it therefore they have a vested interest in it. No vested interest in a product that is free.

7. No website for Briefing? But have a Facebook presence.

8. Broadsheet? Why not tabloid? Easier for their press?

9. Does Briefing have its own identity or is it there to serve the Morning News?

- Do a lot of consumer research before launching Briefing?

10. What percentage of Briefing's 202,000 readers can be considered DMN readers?

- In other words, how much overlap between the two? Or is Briefing bringing a new set of readers? How gauge that?

\section{Current Situation}

11. How many employees specific to Briefing and to DMN?

- Editorial.

- Sales.

12. Is the paper profitable?

- How can tell if part of DMN empire?

13. Who are your competitors?

14. What is your competitive advantage?

- How is your newspaper different from your competitors?

- How different than Neighborsgo? 
15. How are you approaching the mobile information evolution?

\section{Advertising}

16. Total sales?

17. How does print advertising revenue in 2012 compare to 2011: declined, remained stable or increased?

- Why?

18. What categories do your major advertisers fall into?

- For example, real estate, health, automotive, retail, electronics or furniture

- National, regional or local?

19. Have you raised ad rates in the past year?

- If not, when was the last time you did so?

- If so, what were the determinants for raising rates?

20. Has your newspaper reduced or increased its advertising sales staff in the past year?

21. Is the sales staff specific to Briefing or everyone works for the common good?

22. How much charge for Front Page Notes?

\section{Editorial}

23. How much of your content can be found in the DMN?

- Percentage ratio on how much is Briefing content versus DMN or others?

24. Has your newspaper reduced or increased its editorial staff in the past year?

\section{Distribution/Costs}

25. Home delivery?

- How decide what Zip code areas to target?

26. People get the paper whether they want it or not?

- No street boxes, drops to stores or other places?

27. DMN charges Briefing for printing? Has the cost to print increased, decreased or remained stable in the past few years?

\section{Future}

28. Have you ever considered switching to the paid model, start charging readers a fee for the print edition?

- Why or why not?

29. How about launching a website?

- Sell ads on it? 10 years?

30. Are you confident the print version of your newspaper will still exist in 5 or

31. Can you see a time when the newspaper will prove too costly to continue printing and distributing, forcing a move to an online-only publication?

32. How positive about the future?

- Briefing sounds like an expensive newspaper: no online revenue, hand delivered to more than 202,000 homes four days a week. 


\section{Appendix 3: Interview Script for Nick Barbaro, Publisher of the Austin Chronicle}

History

1. Your newspaper has been free from the start.

- Why?

2. Website started in 1995 ?

3. What is the e-newsletter?

4. What is the corporate structure? Who owns what? Chronicle and SXSW.

5 . What is your response to the assertion that newspapers should never "give away" their content for free?

6. Are you ever asked to respond to the claim that a free publication is inferior in terms of editorial quality, or less engaging for readers, compared to a paid publication?

- They paid for it therefore they have a vested interest in it. No vested interest in a product that is free.

\section{Current Situation}

7. How many employees?

8. Profitable?

9. Who are your competitors?

10. What is your competitive advantage?

- How is your newspaper different from your competitors?

11. Is your newspaper attempting to lessen the reliance on print advertising by diversifying revenue sources?

- Events like Hot Sauce Festival are money-makers or more about keeping the brand out there?

12. Does SXSW contribute revenue to the Chronicle. Or totally separate?

13. Been taking on debt with the new building? Planning a new building, right?

14. How are you approaching the mobile information evolution?

- How is the Happy Hour app working out?

\section{Advertising}

15. Total sales?

16. Two years ago noted number of ads had been dropping for the previous 3 to 4 years. Trend continues?

17. How much of your total revenue is generated by advertising (online and print)?

- How much of that is print revenue?

- Online?

- Has online increased or stagnated?

18. How does print advertising revenue in 2012 compare to 2011: declined, remained stable or increased? 
- Why?

19. How does online advertising revenue in 2012 compare to 2011: declined, remained stable or increased?

- Why?

20. What categories do your major advertisers fall into?

- For example, entertainment, automotive, retail, electronics or furniture.

- National, regional or local?

21 . Have you raised ad rates in the past year or 2 ?

- If not, when was the last time you did so?

- If so, what were the determinants for raising rates?

year?

22. Has your newspaper reduced or increased its advertising sales staff in the past editions?

23. How does your sales staff approach selling space in the print and online

- Print first, online second?

\section{Editorial}

24. How has the Chronicle evolved journalistically over the years?

25 . Are there areas of coverage that you would like to see improved?

26. Has your newspaper reduced or increased its editorial staff in the past year?

27 . Weekly page numbers leveled off or still dropping?

28. Have you ever killed or altered a story because of objections from an advertiser?

\section{Distribution/Costs}

29. How verify circulation?

30. Has the cost to print your newspaper increased, decreased or remained stable in the past few years?

\section{Future}

- Still printing at the American-Statesman?

31. Have you ever considered switching to the paid model, start charging readers a fee for the print edition?

- Why or why not?

32. How about charging for access to the online edition?

- Why or why not? 10 years?

33. Are you confident the print version of your newspaper will still exist in 5 or

34. Can you see a time when the newspaper will prove too costly to continue printing and distributing, forcing a move to an online-only publication?

35. How positive/negative about the future?

- Cautiously optimistic 2 years ago, but also uncertain about the future?

36. Any talks of selling the operation?

37. Taken on investors and had help from angel investors? 
38. Intimately involved in putting the paper together? 


\section{Appendix 4: Interview Script for Jonathan McElvy, Publisher of The Leader}

\section{History}

1. Has newspaper been free from the start, since 1954 ?

- Why?

- Distributed on Thursday?

- 33,683 per week? 14-page broadsheet?

- Just the one paper?

2. Why buy The Leader in 2012?

- Explain the process that led to leaving ASP Westward and becoming an owner.

- The other McElvys behind McElvy Media LLC.

- Coming up on year anniversary.

- The List is monthly? You guys start that?

- How has The Leader changed under your leadership?

\section{Current Situation}

3. How many employees?

- Editorial.

- Sales.

4. Profitable?

5. Who are your competitors?

- Don't compete directly with HCN papers?

6 . What is your competitive advantage?

- How is your newspaper different from your competitors?

7. Is your newspaper attempting to lessen the reliance on print advertising by diversifying revenue sources?

- If so, how?

8. How important is your website to the entire operation?

9. How are you approaching the mobile information evolution?

\section{Advertising}

10. Total sales?

11. How much of your total revenue is generated by advertising (online and print)?

- How much of that is print revenue?

- The website?

12. How does print advertising revenue in 2012 compare to 2011: declined, remained stable or increased?

- Why? 
13. How does online advertising revenue in 2012 compare to 2011: declined, remained stable or increased?

- Why?

14. What categories do your major advertisers fall into?

- For example, real estate, health, automotive, retail, electronics or furniture - coupons

- National, regional or local?

- 15. Have you raised ad rates in the past year or 2?

- If not, when was the last time you did so?

- If so, what were the determinants for raising rates?

year?

16. Has your newspaper reduced or increased its advertising sales staff in the past

17. How does your sales staff approach selling space in the print and online editions?

- Print first, online second?

\section{Editorial}

18. What is your response to the assertion that newspapers should never "give away" their content for free?

19. Are you ever asked to respond to the claim that a free publication is inferior in terms of editorial quality, or less engaging for readers, compared to a paid publication?

- They paid for it therefore they have a vested interest in it. No vested interest in a product that is free.

20. How do you react to the criticism/observation that Community Impact is not the prototypical "hard-hitting" newspaper?

- Too much good news and pro-business news?

21. Share content between various editions? Not all original content in each one?

22. Has your newspaper reduced or increased its editorial staff in the past year?

23. Have you ever killed or altered a story because of objections from an advertiser?

\section{Distribution/Costs}

24. How many drops in the area?

25. Home delivery?

26. How verify circulation?

27. Has the cost to print your newspaper increased, decreased or remained stable in the past few years?

\section{Future}

- Where get printed?

28. Have you ever considered switching to the paid model, start charging readers a fee for the print edition?

- Why or why not?

29. How about charging for access to the online edition? 
- Why or why not?

30. Are you confident the print version of your newspaper will still exist in 5 or 10 years?

31. Can you see a time when the newspaper will prove too costly to continue printing and distributing, forcing a move to an online-only publication?

- Quote: "Newspaper companies that try to pretend they are digital companies have it all wrong. We are what we are, warts and all."

32. How positive about the future?

33. Any talk about expanding?

34. Any talks of selling the operation? 


\section{Appendix 5: Interview Script for Tommy Wyatt, Publisher of The Villager}

History

1. Has your newspaper been free from the start?

- Why?

- How get started?

3. What is your response to the assertion that newspapers should never "give away" their content for free?

4. Are you ever asked to respond to the claim that a free publication is inferior in terms of editorial quality, or less engaging for readers, compared to a paid publication?

- They paid for it therefore they have a vested interest in it. No vested interest in a product that is free.

5. When was the website launched?

6 . Is the website a nuisance or an important tool for reaching people?

- Interesting to see video on the website, one of the hottest trends in online media.

\section{Current Situation}

7. How many employees?

- Always a small staff?

8. Profitable?

9. Who are your competitors?

- Get along with Nokia?

- Any talks of merging The Villager with Nokia?

10. What is your competitive advantage?

- How is your newspaper different from your competitors?

11. Is your newspaper attempting to lessen the reliance on print advertising by diversifying revenue sources?

- If so, how?

12. Sought outside investors or donors?

13. Does the Black Registry Publishing Company support The Villager?

14. How are you approaching the mobile information evolution?

\section{Advertising}

15. Total sales?

- Fluctuations over the years?

16. How much of your total revenue is generated by advertising (online and print)?

- How much of that is print revenue?

- The website? 
17. How does print advertising revenue in 2012 compare to 2011: declined, remained stable or increased?

- Why?

18. How does online advertising revenue in 2012 compare to 2011: declined, remained stable or increased?

- Why?

19. What categories do your major advertisers fall into?

- For example, government, health, automotive, retail, electronics or furniture.

- National, regional or local?

20. Have you raised ad rates in the past year or 2 ?

- If not, when was the last time you did so?

- If so, what were the determinants for raising rates? year?

21. Has your newspaper reduced or increased its advertising sales staff in the past editions?

22. How does your sales staff approach selling space in the print and online

- Print first, online second?

\section{Editorial}

23. Describe the style of The Villager.

- How come the front-page commentary?

- Do that from the start?

- How has the editorial style evolved over the years?

24. How do you react to the criticism/observation that The Villager is not a "hardhitting" newspaper?

- Too much good news and pro-business news?

- Can there ever be "too much" of good news and pro-business news?

25. Has your newspaper reduced or increased its editorial staff in the past year?

26. Have you ever killed or altered a story because of objections from an advertiser?

\section{Distribution/Costs}

27. Distributed Thursdays?

28. Who drops the paper around town?

- How many drops?

29. How verify circulation?

30. Has the cost to print your newspaper increased, decreased or remained stable in the past few years?

Future

- Does your newspaper own its press?

31. Have you ever considered switching to the paid model, start charging readers a fee for the print edition? 
- Why or why not?

32. How about charging for access to the online edition?

- Why or why not?

33. Are you confident the print version of your newspaper will still exist in 5 or 10 years?

34. Can you see a time when the newspaper will prove too costly to continue printing and distributing, forcing a move to an online-only publication?

35. How positive about the future?

36. Consider selling?

- More so now after 40 years, or the kids are ready to take it over?

37. Intimately involved in putting the papers together? Keep hands in the mix? 


\section{Appendix 6: Front Page of The Austin Chronicle}

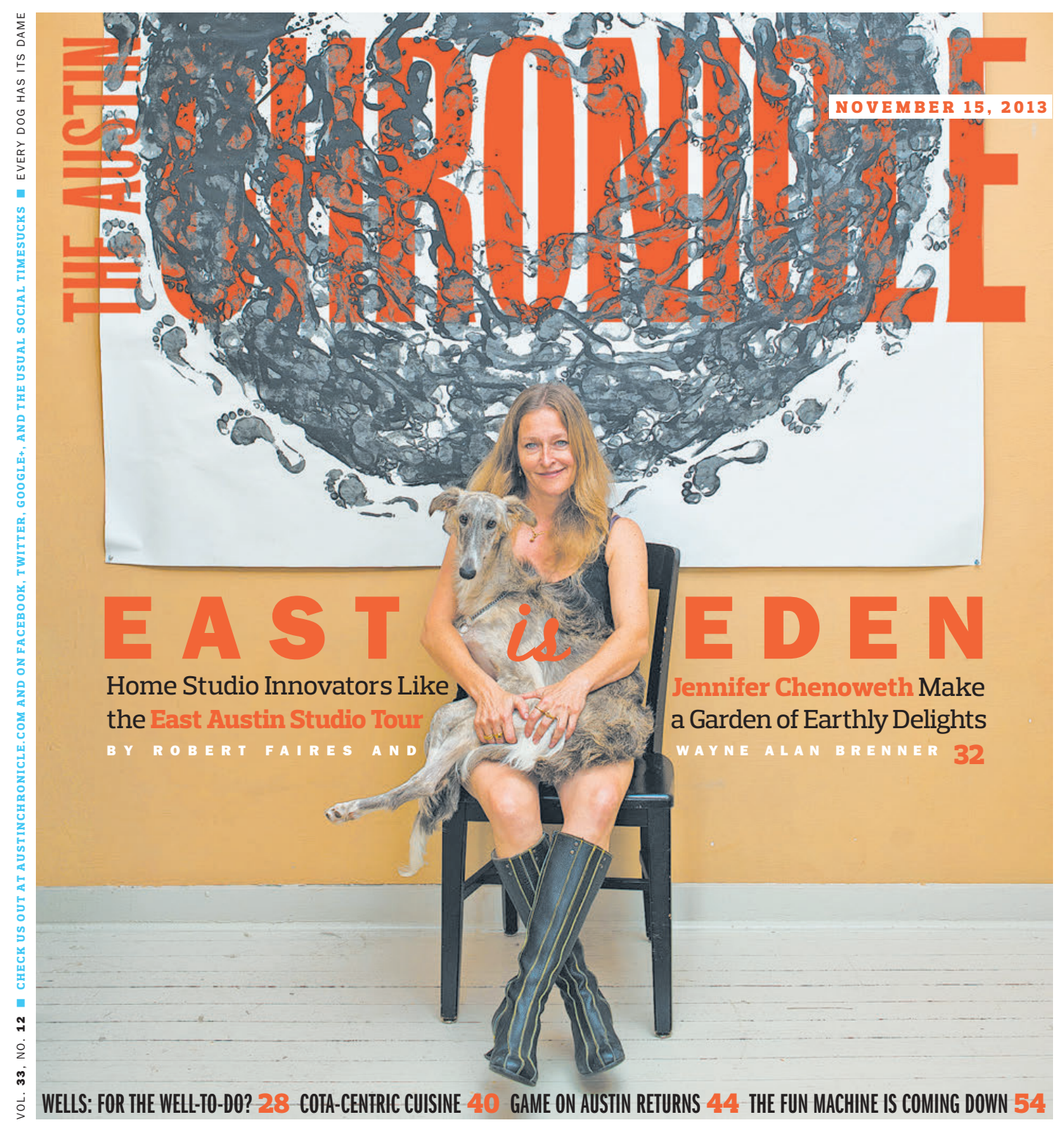




\section{Appendix 7: Front Page of The Villager}

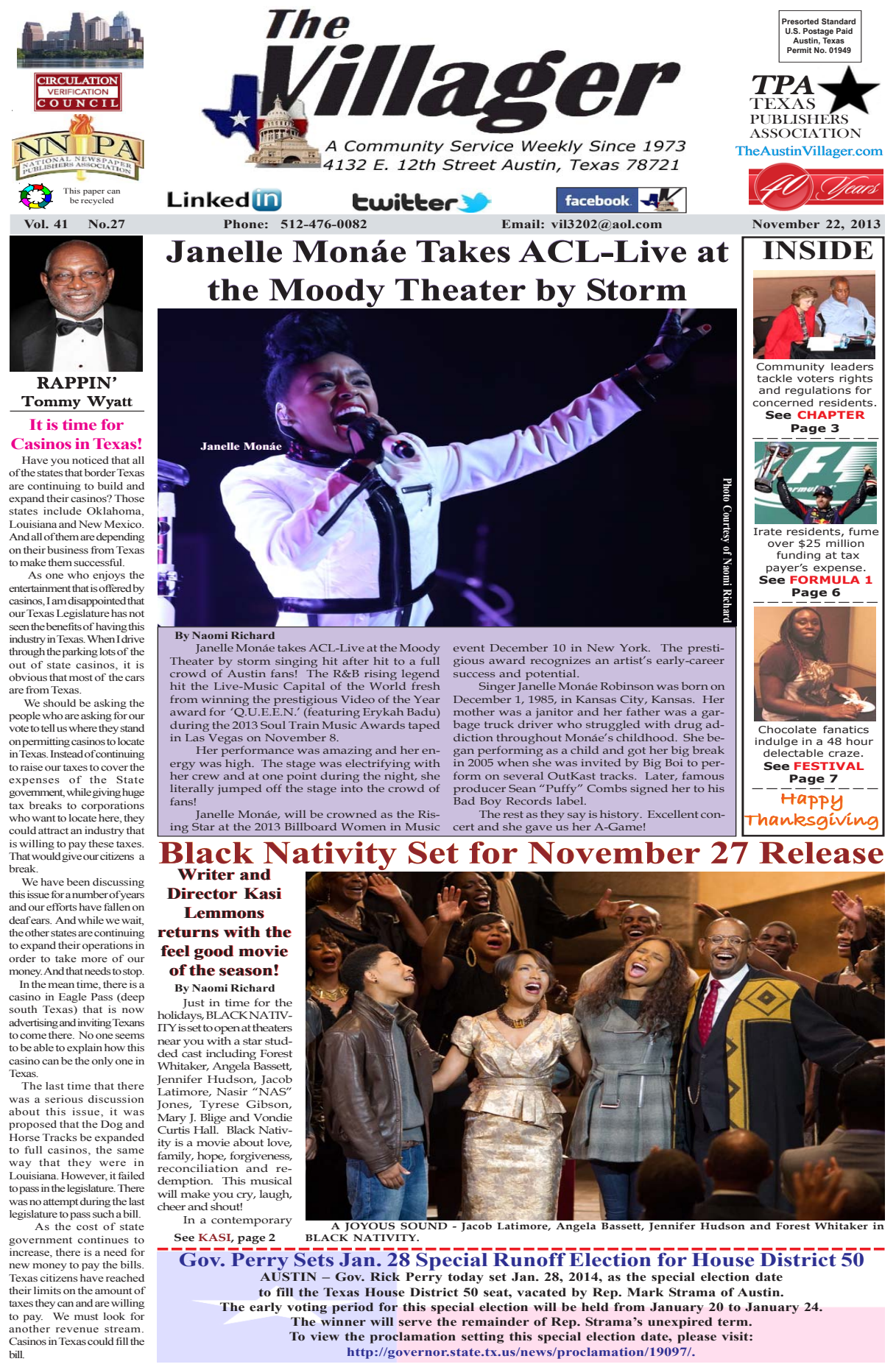




\section{Appendix 8: Front Page of Briefing}
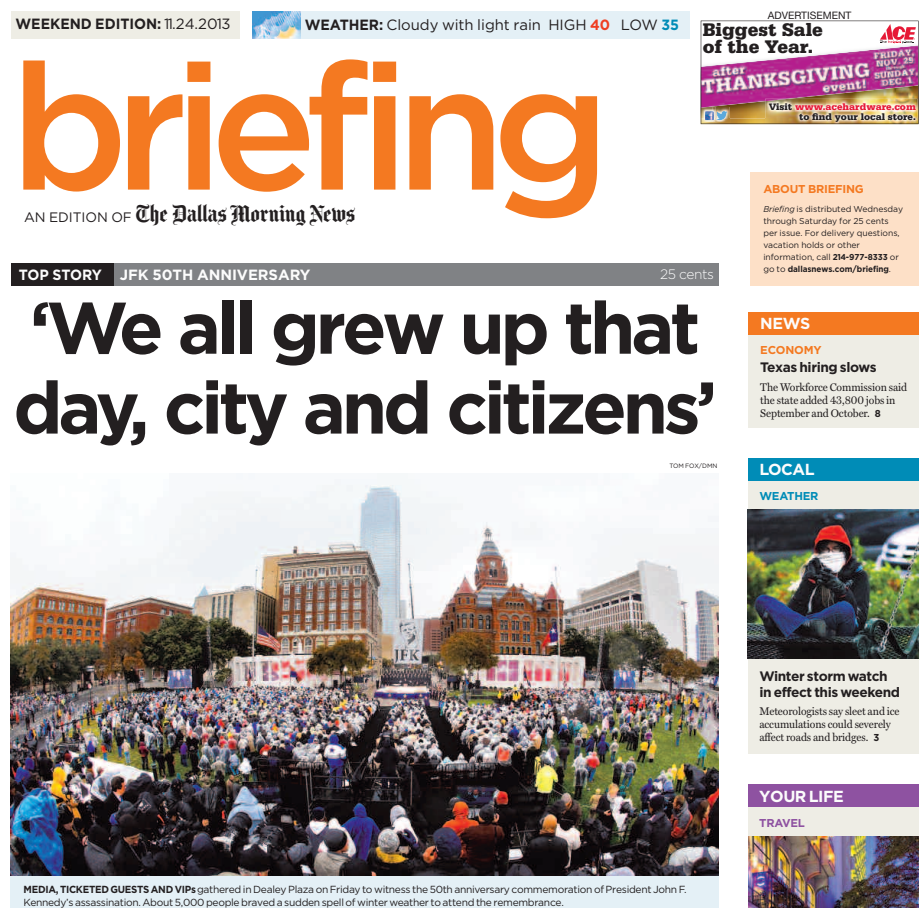

Dallas praises the life and legacy of JFK, whose assassination shaped a city that struggled to come to terms with history
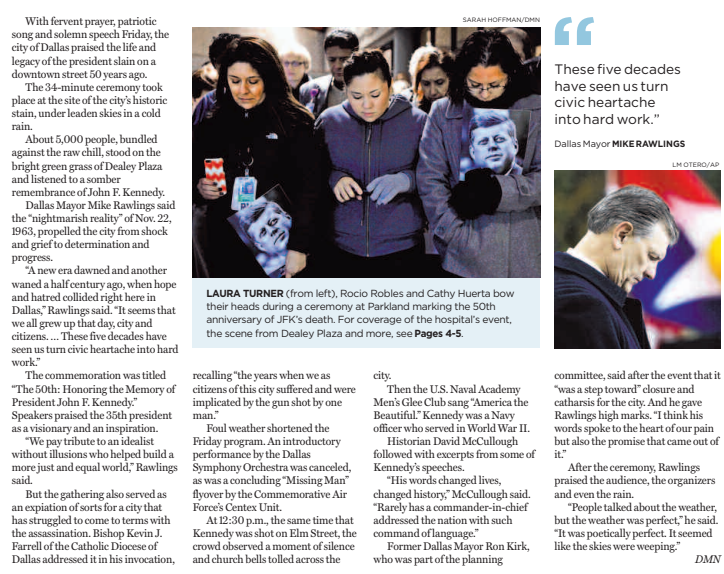

ABOUT BRIEFING
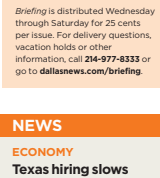

The Workforec Commisision said
the state added 43,800 jobs in
Sepptember and OCtober, 8
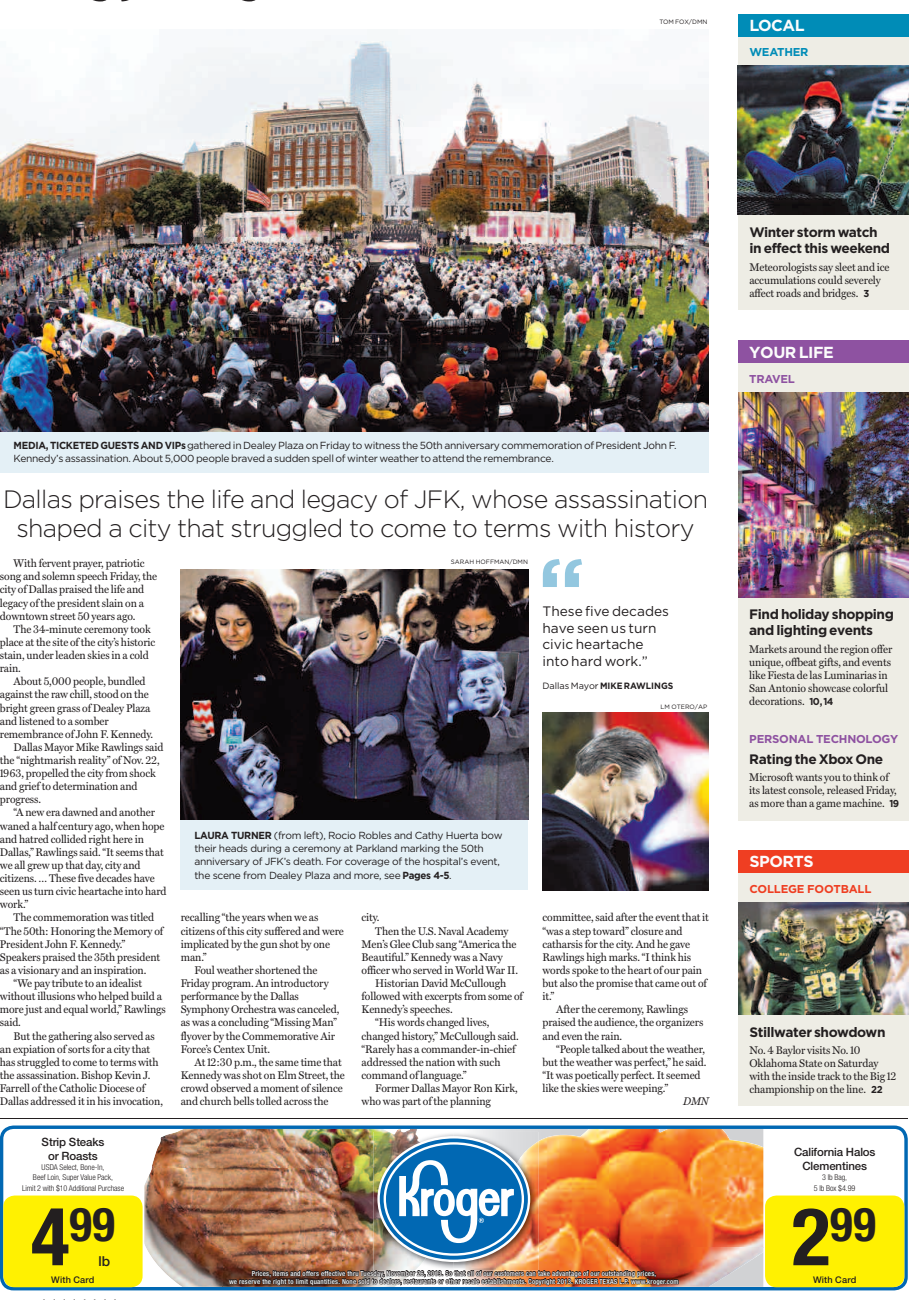

A1 11-23-2013 Set: 19:40:58 


\section{Appendix 9: Front Page of The Leader}

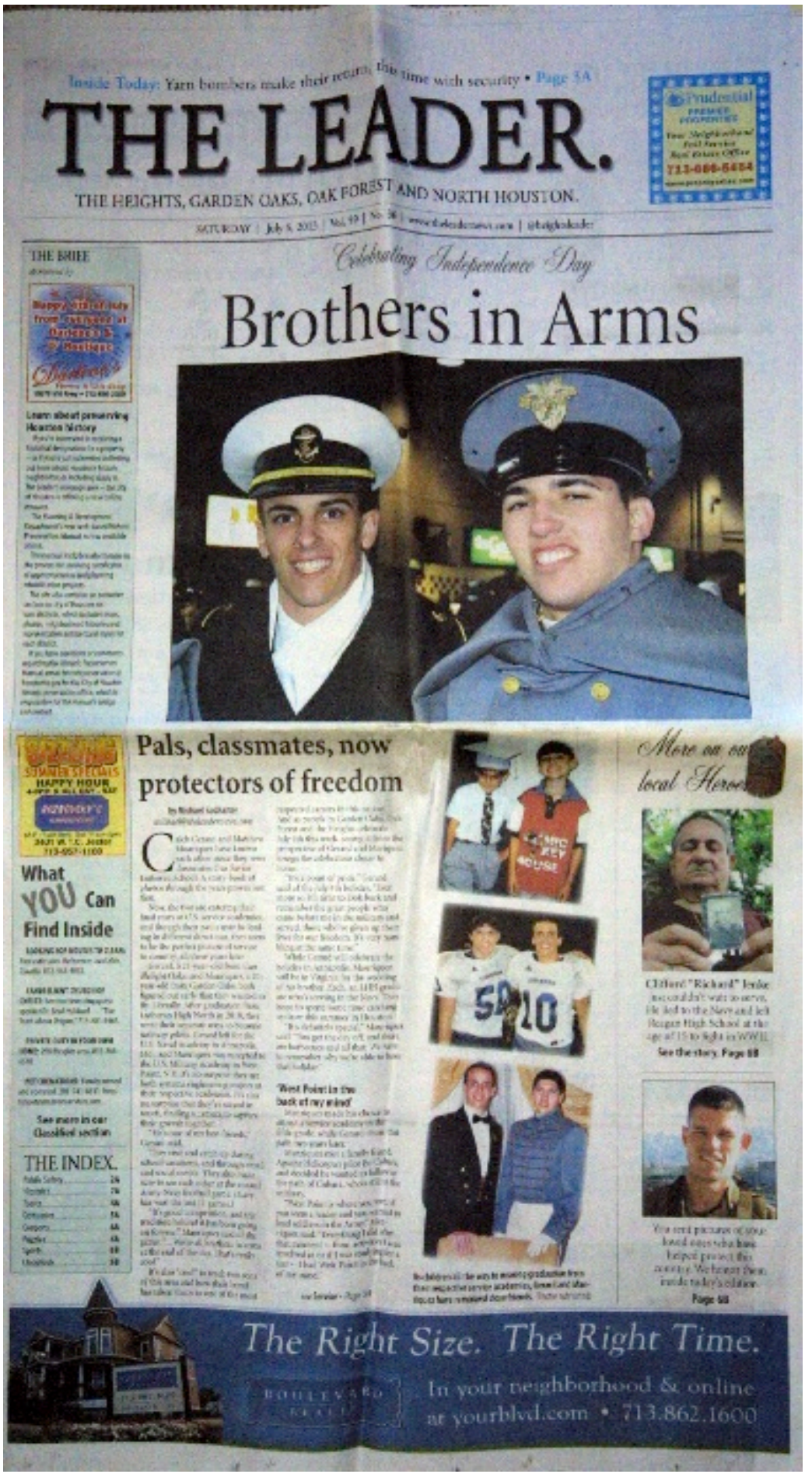




\section{Appendix 10: Web-Based Survey Questions}

Q1. For the purposes of this survey, a free newspaper is defined as one with a circulation that is at least $95 \%$ free. Does that describe your newspaper?

Q2. Would you describe your newspaper to be a shopper?

Q3. Would you say your newspaper is "alternative"?

Q4. What kind of geographic market do you serve?

Q5. What print format does your newspaper use?

Q6. Please describe the ownership structure of your newspaper.

Q7. How long has a company or family owned this newspaper?

Q8. Is your free newspaper affiliated with a paid newspaper?

Q9. Within your geographic market, who are your print competitors? Check all that apply.

Q10. How do you distribute your newspaper? Check all that apply.

Q11. How many issues do you publish per month?

Q12. What is the average size of your newspaper per issue?

Q13. Please estimate the average age of your readership.

Q14. What is the approximate circulation per issue?

Q15. Compared to 2011, would you say circulation in 2012 has ...

Q16. Please estimate by percentage how much circulation increased in 2012 compared to 2011.

Q17. Please estimate by percentage how much circulation decreased in 2012 compared to 2011.

Q18. How does your newspaper verify its circulation? Click all that apply.

Q19. What is the approximate percentage of space in your newspaper devoted to advertising and editorial content?

Q20. Compared to 2011, advertising revenue in 2012 has. . .

Q21. Please estimate by percentage how much advertising revenue increased in 2012 compared to 2011.

Q22. Please estimate by percentage how much advertising revenue decreased in 2012 compared to 2011.

Q23. What types of advertisements (approximate by percentage) account for print advertising revenue in 2012 ?

Q24. What percentage of total advertising revenue for 2012 came from Free

Standing Inserts, Flyers or Circulars?

Q25. What percentage of your total print advertising revenue came from the following geographic sources in 2012?

Q26. Has your newspaper sought alternative sources of revenue? Check all that apply or answer No.

Q27. Does your newspaper have a website?

Q28. Why does your newspaper not have a website? 
Q29. Are there any fees associated with accessing content on your website? Q30. Would your newspaper consider implementing a fee for online access? Q31. Is your newspaper available as an "app" for smartphones?

Q32. Is your newspaper available on tablet computers such as the iPad or the Android?

Q33. What types of advertisements (approximate by percentage) account for online advertising revenue in 2012?

Q34. Please estimate by percentage how much of your online revenue came from the following sources in 2012?

Q35. Regarding total advertising revenue, estimate by percentage how much is generated by the online edition.

Q36. Regarding your advertising sales staff, are their duties specific to the print and online editions?

Q37. Do you think free newspapers have an advantage over paid-subscription competitors?

Q38. Please expand on your answer to the previous question regarding free newspapers versus paid newspapers:

Q39. Do you believe readers are more "engaged" in a paid newspaper because they had to pay for it?

Q40. Please expand on your answer to the previous question regarding reader engagement:

Q41. Would your newspaper consider implementing a cover price?

Q42. Why would your newspaper implement a cover price?

Q43. Why would your newspaper not implement a cover price?

Q44. In 2012, your newspaper ...

Q45. In 2013, your newspaper anticipates ...

Q46. Regarding the future for your newspaper, are you ...?

Q47. Please expand on your view of your newspaper's future.

Q48. Do you disagree or agree with the assertion that it is only a matter of time before newspapers are an online-only news outlet?

Q49. Please expand on your answer to the previous question regarding whether it is only a matter of time before newspapers are online-only.

Q50. Approximately how many people are employed at your newspaper?

Q51. What is the name of your newspaper?

Q52. Please share your job title. 


\section{Appendix 11: Email Script Invitation for Web-Based Survey}

Dear $\$\{\mathrm{e}: / /$ Field/Salutation $\} \$$ m://FirstName $\}$ \$m://LastName $\}$

My name is J. Ian Tennant and I'm a doctoral candidate in the School of Journalism at the University of Texas at Austin. My dissertation will examine the current state of free newspapers in the United States and discuss what the future may hold for these crucial news outlets. Therefore, I humbly ask for your time to participate in this online survey, the results from which will be crucial to my dissertation.

Free newspapers are an important, and often overlooked, sector of the newspaper industry. Your participation is extremely important to understanding the future of free newspapers. If you have any questions, contact myself or Dr. Iris Chyi (chyi@mail.utexas.edu) who is overseeing this project.

I "grew up" working for free newspapers so I know you are super busy, but I hope you can find time to complete this survey, which should take about 10 minutes.

Please click on the link that follows to receive more details about the study and where you will be asked to consent to the process:

$\$\{1: / /$ SurveyLink?d=http://utexascomms.qualtrics.com/SE/?SID=SV_d1gYdDRZGSaRd Qh\}.

Thank you very much for your help.

Sincerely,

J. Ian Tennant

PhD Candidate

School of Journalism

The University of Texas at Austin

j.iantennant@utexas.edu

512-705-1347 


\section{Appendix 12: Opening Page of Web-Based Survey}

Dear Respondent,

You have been asked to participate in research that focuses on free newspapers because you are a decision-maker at your newspaper. Your participation will contribute to the knowledge of a little-researched but important segment of the newspaper business.

The risk for participants is minimal. Your responses will remain confidential and there is no cost to take the survey. You may decline to answer any question and you have the right to withdraw from participation at any time. Your participation is voluntary.

If you have any questions, or would like a copy of the final dissertation this survey will inform, please contact J. Ian Tennant at (512) 705-1347, or j.iantennant@utexas.edu.

This study has been reviewed and approved by the Institutional Review Board (IRB) at the University of Texas at Austin. If you have questions about your rights as a study participant, or are dissatisfied at any time with any aspect of this study, please contact - anonymously if you prefer - the Office of Survey Research at UT (home of the IRB) by phone at 512-471-8871, or email at orsc@uts.cc.utexas.edu.

IRB Approval Number: 2012-11-0082.

By clicking on the "Next Page" button to start the survey, you will be giving consent to participate in this research project. Simply close the window if you decide to not take the survey.

Thank you,

J. Ian Tennant

Doctoral Candidate

School of Journalism

The University of Texas at Austin

j.iantennant@utexas.edu

512-705-1347 


\section{Appendix 13: First Prompt Email Script for Web-Based Survey}

April 22, 2013

Dear Busy People,

This email is a prompt to ask once again if you could please devote 10-15 minutes of your day to take the following online survey about free newspapers. My name is J. Ian Tennant and I'm a Doctoral candidate in journalism at the University of Texas at Austin. My dissertation looks at the fate and the future of free newspapers and your responses to this survey are extremely helpful and important. Please click on the following link to start the process:

\section{GSaRdQh\}}

$\$\{1: / /$ SurveyLink?d=http://utexascomms.qualtrics.com/SE/?SID=SV_d1gYdDRZ

If you have already taken the survey, let me thank you again for your assistance.

Cheers,

J. Ian Tennant

512-705-1347

502B West Live Oak St.

Austin, Texas, USA

78704

j.iantennant@utexas.edu 


\section{Appendix 14: Second Prompt Email Script for Web-Based Survey}

April 29, 2013

Dear Even Busier People,

Big thanks to those who have completed this survey of free newspapers. You folks can ignore this email, but I look forward to sharing my dissertation with many of you who have requested a copy.

For those of you who have yet to contribute, I humbly ask one last time to please devote 10-15 minutes to this online survey about free newspapers. The survey will close at 10 p.m. CST, Friday, May 3.

My name is J. Ian Tennant, I'm a Doctoral candidate in journalism at the University of Texas at Austin and I firmly believe the story of the free newspapers industry has yet to be told in a comprehensive manner. My dissertation looks at the fate and the future of free newspapers and your responses to this survey are extremely helpful and important. Please click on the following link to start the process: GSaRdQh\}

$\$\{1: / /$ SurveyLink?d=http://utexascomms.qualtrics.com/SE/?SID=SV_d1gYdDRZ

Cheers,

J. Ian Tennant

512-705-1347

502B West Live Oak St.

Austin, Texas, USA

78704

j.iantennant@utexas.edu 


\section{Appendix 15: Third Prompt Email Script for Web-Based Survey}

May 2, 2013

Dear Super Busy Folks,

Here it is, the final plea asking you newspaper industry warriors to take my online survey about free newspapers. If I can entice more of you to spare 10-15 minutes of your busy day to take the survey I will surpass a $20 \%$ return rate, which is pretty good for an online survey. The survey closes at 10 p.m. CST, Friday, May 3.

Again, many thanks to those who have taken survey. Please ignore this email if you have already offered your opinions on the free newspaper industry.

To reiterate, my name is J. Ian Tennant, I'm a Doctoral candidate in journalism at the University of Texas at Austin and I firmly believe the story of the free newspapers industry has yet to be told in a comprehensive manner. My dissertation looks at the fate and the future of free newspapers and your responses to this survey are extremely helpful and important. Please click on the following link to start the process: GSaRdQh\}

$\$\{1: / /$ SurveyLink?d=http://utexascomms.qualtrics.com/SE/?SID=SV_d1gYdDRZ

Cheers,

J. Ian Tennant

512-705-1347

502B West Live Oak St.

Austin, Texas, USA

78704

j.iantennant@utexas.edu 


\section{References}

About. (n.d.). The Austin Chronicle. Retrieved August 20, 2013, from http://www .austinchronicle.com/gyrobase/Info/about

About AAN. (2013). Association of Alternative Newsmedia. Retrieved September 25, 2013, from http://www.altweeklies.com/aan/about-aan/Page

About Capital City Argus. (Austin, Tex.) 1962-1969. (n.d.). Library of Congress.

Retrieved May 23, 2013, from http://chroniclingamerica.loc.gov/lccn /sn86088242/

About Houston. (2013). City of Houston. Retrieved July 1, 2013, from http://www .houstontx.gov/abouthouston/houstonfacts.html

Across platforms, 7 in 10 adults access content from newspaper media each week. (2013, March 25). Newspaper Association of America. Retrieved October 16, 2013, from http://www.naa.org/en/Topics-and-Tools/SenseMakerReports/MultiplatformNewspaper-Media-Access.aspx

Advertise (a). (n.d.). Houston Press. Retrieved July 1, 2013, from http://www .houstonpress.com/advertise/

Advertise (b). (n.d.). Metro United States. Retrieved October 1, 2013, from http://www .metro.us/newyork/advertise

Advertising expenditures, annual (all categories). (n.d.). Newspaper Association of America. Retrieved September 21, 2013, from http://www.naa.org/ 
Trends-and-Numbers/ /media/NAACorp/Public\%20Files/TrendsAndNumbers/ Advertising-Expenditures/Annual-Newspaper-Ad-Expenditures.ashx Advertising information. (n.d.). $C \& G$ Newspapers. Retrieved September 18, 2013, from http://www.candgnews.com/AdvertInfo

Advertise with us. (n.d.). Community Impact. Retrieved June 24, 2013, from http://impactnews.com/about-us/advertise-with-us/advertise-with-us

African Americans in Texas see decreased economic mobility, policy report shows. (2013, May 24). The Villager, p. 1.

Ala-Fossi, M., Bakker, P., Ellonen, H-K, Küng, L., Lax, S., Sadaba, C., \& Van der Wuff, R. (2008). The impact of the Internet on business models in the media industries: A sector-by-sector analysis. In L. Küng, R. G. Picard, \& R. Towse (Eds.), The internet and the mass media (pp. 149-169). Thousand Oaks, CA: Sage.

American Community Newspapers sells Star Community Newspapers to 1013 Communications. (2011, February 23). Editor \& Publisher. Retrieved from http://www.editorandpublisher.com/

Anderson, C. (2009). Free: The future of a radical price. New York, NY: Hyperion.

Anderson, M., Guskin, E., \& Rosenstiel, T. (2012). Alternative weeklies: At long last, a move toward digital. The state of the news media. Retrieved July 20, 2013, from http://stateofthemedia.org/2012/native-american-news-media/alternativeweeklies-at-long-last-a-move-toward-digital/ 
Annual daily and Sunday newspaper circulation expenditures. (2012, September 4). Newspaper Association of America. Retrieved from http://www.naa.org/Trendsand-Numbers/Circulation-Volume/Newspaper-Circulation-Volume.aspx

Atton, C., \& Hamilton, J. F. (2008). Alternative journalism. London: Sage Publications Ltd.

Baker, R. (2010). Choosing between telephone and online for survey data collection. Market Strategies International. Retrieved October 12, 2012, from http:// www.marketstrategies.com/library/1970/1/Choosing-Between-Telephone-andOnline-for-Survey-Data-Collection.aspx

Bakker, P. (2002). Free daily newspapers: Business models and strategies. JMM: The International Journal on Media Management, 4(3), 180-187.

Bakker, P. (2008). The simultaneous rise and fall of free and paid newspapers in Europe. Journalism Practice, 2(3), 427-443.

Bakker, P. (n.d.). Newspaper innovation. Retrieved September 23, 2013, from http:// www.newspaperinnovation.com/index.php/north-america/

Barnes, E. C. (1999). What's alternative about alternative newsweeklies?: A case study of the Austin Chronicle (Unpublished master's thesis). University of Texas at Austin, Austin, Texas.

Bettig, R. V. \& Hall, J. L. (2012). Big media, big money: Cultural texts and political economics. Lanham, MD: Rowan and Littlefield.

Brandsberg, G. (1969). The free papers. Ames, IA: Wordsmith. 
Bolton, J. D. (1991). Writing space: The computer, hypertext and the history of writing. Hillsdale, NJ: Lawrence Erlbaum Associates.

Buffett, W. (2012, May 25). Warren Buffett's letter to editors, publishers. The WinstonSalem Journal. Retrieved from http://www2.journalnow.com/

Calder, B. J., \& Malthouse, E. C. (2008). Media engagement and advertising effectiveness. In B. J. Calder (Ed.), Kellogg on advertising \& media (pp. 1-36). Hoboken, NJ: John Wiley \& Sons.

Chittum, R. (2013a, March 1). The battle of New Orleans. Columbia Journalism Review. Retrieved from http://www.cjr.org/

Chittum, R. (2013b, November 19). John Paton, the Gorbachev of paywalls. Columbia Journalism Review. Retrieved from http://www.cjr.org/

Chyi, H. I. (2005). Willingness to pay for online news: An empirical study of the viability of the subscription model. Journal of Media Economics, 18(2), 131-142.

Chyi, H. I. \& Yang, M. J. (2009). Is online news an inferior good? Examining the economic nature of online news among users. Journalism \& Mass Communication Quarterly, 86(3), 594-612.

Chyi, H. I., Lewis, S. C., \& Zheng, N. (2011). A matter of life and death? Examining how newspapers covered the newspaper “crisis." Journalism Studies, 13(3), 305-324.

Chyi, H. I., \& Tennant, J. I. (2013, August). Less is better: The impact of reduced newspaper publication schedule on advertising revenue. Paper presented at the 
meeting of the Association for Education in Journalism and Mass

Communication, Washington, D.C.

Dean, J. P., \& Whyte, W. F. (1970). What kind of truth do you get? In L. A. Dexter (Ed.), Elite and specialized interviewing (pp. 119-138). Evanston, IL: Northwestern University.

Denscombe, M. (2009). Item non-response rates: a comparison of online and paper questionnaires. International Journal of Social Research Methodology, 12(4), 281-291.

Doctor, K. (2010). Newsonomics: Twelve new trends that will shape the news you get. New York, NY: St. Martin's Press.

Duke, S. S. (2011). The talk about and share experience/implementing experiences. In A. Peck, \& E. C. Malthouse (Eds.), Medill on media management (pp. 177-195). Creskill, NJ: Hampton Press.

Edge, M. (2012, August). Not dead yet: Newspaper company annual reports show chains still profitable. Paper presented at the meeting of the Association for Education in Journalism and Mass Communication, Chicago, IL.

Edmonds, R., Guskin, E., Mitchell, A., \& Jurkowitz, M. (2013, July 18). Newspapers: Stabilizing but still threatened. The state of the news media 2013. Retrieved from http://stateofthemedia.org/print-chapter/?print_id=12990

Edmonds, R., Guskin, E., Rosenstiel, T., \& Mitchell, A. (2012, April 11). Newspapers: Building digital revenues proves painfully slow. The state of the news media 
2012. Retrieved from http://stateofthemedia.org/2012/newspapers-buildingdigital-revenues-proves-painfully-slow/

Efrati, A. (2012, September 20). Google expected to surpass Facebook in display-ad sales. Wall Street Journal. Retrieved from http://online.wsj.com/

Emery, E. (1972). The press and America: An interpretive history of the mass media. Englewood Cliffs, NJ: Prentice-Hall.

Farhi, P. (2008, December/January). Online salvation? American Journalism Review. Retrieved from http://www.ajr.org/

Fink, C. C. (1996). Strategic newspaper management. Needham Heights, MA: Allyn \& Bacon.

Fitzgerald, M. (2009, June 4). Get out of the printing business, Moody's tells newspapers. Editor \& Publisher. Retrieved from http://www.editorandpublisher.com/

Fleming, J. (2009). Editor \& publisher international data book: Book 1: Dailies. Irvine, CA: Duncan McIntosh.

Fleming, J. (2012a). Editor \& publisher international data book: Book 1: Dailies. Irvine, CA: Duncan McIntosh.

Fleming, J. (2012b). Editor \& publisher international data book: Book 2: Weeklies. Irvine, CA: Duncan McIntosh.

Garden, M. (2010). Are predictions of newspapers' impending demise exaggerated? Asia Pacific Media Educator, 20(1), 37-52. 
Harvey, W. S. (2011). Strategies for conducting elite interviews. Qualitative Research, 11(4), 431-441.

Helman, C. (2013, January 2). Breaking: A local newspaper chain that's actually making good money. Forbes. Retrieved from http://www.forbes.com/

Hendriks, P. (1999). Newspapers: A lost cause? Dordrecht, The Netherlands: Kluwer Academic Publishers.

Herrick, C. (2008). To the west and east of Interstate-35: Obesity, philanthropic entrepreneurialism, and the delineation of risk in Austin, Texas. Environment and Planning, 40(11), 2715-2733.

Hoskins, C., McFayden, S., \& Finn, A. (2004). Media economics: Applying economics to new and traditional media. Thousand Oaks, CA: Sage.

Houston Chronicle. (n.d.). Hearst Corporation. Retrieved July 1, 2013, from http://www.hearst.com/newspapers/houston-chronicle.php

Houston newspapers and news media. (n.d.). ABYZ News Links. Retrieved October 1, 2013, from http://www.abyznewslinks.com/unitetxhs.htm

Ingram, M. (2012, October 10). No, giving away the news doesn't mean lower-quality journalism. GigaOm. Retrieved from http://gigaom.com/

Ingram, M. (2013a, April 11). Two charts that tell you everything you need to know about the future of newspapers. PaidContent. Retrieved from http:// paidcontent.org/ 
Ingram, M. (2013b, September 30). Another wall tumbles: The Dallas Morning News dismantles its paywall, tries to sell premium features instead. PaidContent. Retrieved from http://paidcontent.org/

Jacobson, M. (2005, November 6). The Voice from beyond the grave. New York. Retrieved from http://nymag.com/

Jenner, M. (2012, February 28). From failed strategy to fad to full-fledged movement. Paid content comes of age. Retrieved from http://www.rjionline.org/store/paidcontent-comes-age

Jonathan McElvy and McElvy Media, LLC, have purchased The Leader newspaper. (2012, July 24). Editor \& Publisher. Retrieved from http://www. editorandpublisher.com/

Jones, M. (2013, March 22). SXSW: A victim of its own success? The Independent. Retrieved from http://www.independent.co.uk/

Jose, V. (2000). The free paper in America: Struggle for survival. Richmond, IN: Graphic Press.

Kaye, J., \& Quinn, S. (2010). Funding journalism in the digital age: Business models, strategies, issues and trends. New York, NY: Peter Lang.

Kirchhoff, S. M. (2010, September 9). The U.S. newspaper industry in transition. Congressional Research Service. Retrieved from www.fas.org/sgp/crs/misc /R40700.pdf 
Kohut, A., Keeter, S., Doherty, C., Dimock, M, \& Christian, L. (2012, May 15). Assessing the representativeness of public opinion surveys. The Pew Research Center: For the People \& the Press.

Küng, L., Picard, R. G., \& Towse, R. (2008). Theoretical perspectives on the impact of the internet on the mass media industries. In L. Küng, R. G. Picard, \& R. Towse (Eds.), The internet and the mass media (pp. 17-44). Thousand Oaks, CA: Sage.

Küng, L. Picard, R. G., \& Towse, R. (2008a). Conclusions. In L. Küng, R. G. Picard, \& R. Towse (Eds.), The internet and the mass media (pp. 170-177). Thousand Oaks, CA: Sage.

Ladurantaye, S. (2012a, October 15). The Globe to roll out metered paywall as industry shifts to digital revenue. The Globe and Mail. Retrieved from http://www. theglobeandmail.com/

Ladurantaye, S. (2012b, October 25). Postmedia ramps up its paywall push. The Globe and Mail. Retrieved from http://www.theglobeandmail.com/

Malthouse, E. C, \& Peck, A. (2011). Medill on media management: An introduction. In A. Peck \& E. C. Malthouse (Eds.), Medill on media management (pp. 3-19). Creskill, NJ: Hampton.

Marshall, C., \& Rossman, G. B. (1989). Designing qualitative research. Newbury Park, CA: Sage. 
Metro Silicon Valley. (2013, September 10). Alt-Weeklies' four-letter festivals:

Movement grows as Silicon Valley launches C2SV. Association of alternative media. Retrieved from http://www.altweeklies.com/

Meyers, P. (2004). The vanishing newspaper: Saving journalism in the information age. Columbia, MO: University of Missouri.

Mindich, D. T. Z. (1998). Just the facts: How "objectivity” came to define American journalism. New York, NY: New York University.

Mitchell, A. \& Rosenstiel, T. (n.d.). Key findings. The state of the news media 2012. Retrieved April 5, 2012, from http://stateofthemedia.org/2012/overview-4/keyfindings/

Morrissey, C. (1970). On oral history interviewing. In L. A. Dexter (Ed.), Elite and specialized interviewing (pp. 109-118). Evanston, IL: Northwestern University.

Morton, J. (2001). Going local. American Journalism Review, 23(8), 88.

Morton, J. (2009, June/July). Not dead yet. American Journalism Review. Retrieved from http://www.ajr.org/

Napoli, P. M. (2011). Audience evolution: New technologies and the transformation of media audiences. New York, NY: Columbia University.

Nerone, J. C. (1987). The mythology of the penny press. Critical Studies in Mass Communication, 4(4), 376-404. 
Newsweeklies directory. (2013). Association of Alternative Newsmedia. Retrieved September 30, 2013, from http://www.altweeklies.com/aan/directories /Newsweeklies

North, S. N. D. (1884). History and present condition of the newspaper and periodical press of the United States with a catalogue of the publications of the census year. Washington, DC: Department of the Interior.

Picard, R. G. (2002). The economics and financing of media companies. New York: Fordham University.

Picard, R. G. (2008). Shifts in newspaper advertising expenditures and their implications for the future of newspapers. Journalism Studies, 9(5), 704-716.

Picard, R. G. \& Brody, J. H. (1997). The newspaper publishing industry. Needham Heights, MA: Allyn \& Bacon.

Poindexter, P. M., \& McCombs, M. E. (2000). Research in mass communication: A practical guide. Boston, MA: Bedford/St. Martin's.

Rosenstiel, T., \& Mitchell, A. (n.d.). Overview. The state of the news media. Retrieved April 20, 2011, from http://stateofthemedia.org/2011/overview-2/

Salkever, A. (2012, October 10). Prognosis positive for small-town newspapers? StreetFight. Retrieved from http://streetfightmag.com/

Schudson, M. (1978). Discovering the news: A social history of American newspapers. New York, NY: Basic. 
Shirky, C. (2012, September/October). Failing geometry. Columbia Journalism Review, 29-30.

Sloan, W. M. D. (2008). The media in America ( $2^{\text {nd }}$ ed.). Northport, AL: Vision Press.

Soloski, J. (2012, August). Collapse of the newspaper industry: Goodwill, leverage and bankruptcy. Paper presented at the meeting of the Association for Education in Journalism and Mass Communication, Chicago, IL.

Spencer, D. R. (2007). The yellow journalism: The press and America's emergence as a world power. Evanston, ILL: Northwestern University.

Stainburn, S. (2013, April 30). First ever web page reactivated on $20^{\text {th }}$ anniversary of World Wide Web. GlobalPost. Retrieved from http://www.globalpost.com/

Steffen, C. G. (2003). Newspapers for free: The economies of newspaper circulation in the early Republic. Journal of the Early Republic, 23(3), 381-419.

Stephenson, L. B., \& Crête, J. (2011). Studying political behavior: A comparison of Internet and telephone surveys. International Journal of Public Opinion Research, 23(1), 24-55.

Stovall, J. G. (1991). The penny press, 1833-1861: Product of great men or natural forces? In W. D. Sloan (Ed.), Perspectives on mass communication history (pp. 123-138). Hillsdale, NJ: Lawrence Erlbaum Associates.

Sue, V. M., \& Ritter, L. A. (2012). Conducting online surveys. Thousand Oaks, CA: Sage Publications Inc. 
Tebo, M. (2009). Editor \& publisher international year book: Part 2 weeklies. New York, NY: Editor \& Publisher.

Tennant, J. I. (2011, November 4). Dallas Morning News less reliant on ad revenue, offering hope for the future of newspapers, publisher tells academics. Knight Center for Journalism in the Americas. Retrieved from https://knightcenter. utexas.edu/

The American newspaper media industry revenue profile 2012. (n.d.). Newspapers of America. Retrieved 2013, April 8, 2013, from http://www.naa.org/

Thurman, N. \& Myllylahti, M. (2009). Taking the paper out of news: A case study of Taloussanomat, Europe's first online-only newspaper. Journalism Studies, (10)5, 691-708.

Van der Wurff, R. (2008a). The impact of the internet on media content. In L. Küng, R. G. Picard, \& R. Towse (Eds.), The internet and the mass media (pp. 65-85). Thousand Oaks, CA: Sage.

Van der Wurff, R., Bakker, P., \& Picard, R. G. (2008b). Economic growth and advertising expenditures in different media in different countries. Journal of Media Economics, 21, 28-52.

Washington Post media advertising. (2013, September 23). Express. Retrieved from http://www.washingtonpostads.com/products/products-express

Who killed the newspaper? (2006, August 26). Economist, 9. 
Wilkinson, E. J. (2011, December 15). Wind behind transformation: U.S. publishers' EBITDA at half of peak. INMA. Retrieved from http://www.inma.org/

Zachary, J. (2013, October 10). Newspapers are dead rumor needs to die. Henry Daily Herald. Retrieved from http://www.henryherald.com/

Zerba, A. (2013). Young adults expect more from free news tabloids. Newspaper Research Journal, (34)2, 6-21. 